\title{
LOCATIONS AND MONITORING WELL COMPLETION LOGS OF WELLS SURVEYED BY U.S. GEOLOGICAL SURVEY AT AIR FORCE PLANT 4 AND NAVAL AIR STATION, JOINT RESERVE BASE, CARSWELL FIELD, FORT WORTH AREA, TEXAS
}

By M.D. Williams and E.L. Kuniansky

U.S. GEOLOGICAL SURVEY

Open-File Report 96-650

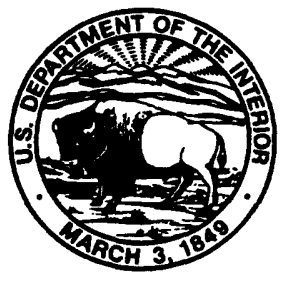

Prepared in cooperation with the U.S. AIR FORCE AERONAUTICAL SYSTEMS CENTER, ENVIRONMENTAL MANAGEMENT DIRECTORATE 


\section{U.S. DEPARTMENT OF THE INTERIOR \\ BRUCE BABBITT, Secretary \\ U.S. GEOLOGICAL SURVEY \\ Gordon P. Eaton, Director}

Any use of trade, product, or firm names is for descriptive purposes only and does not imply endorsement by the U.S. Government.

For additional information write to:

Copies of this report can be purchased from:

District Chief

U.S. Geological Survey

8011 Cameron Rd.

Austin, TX 78754-3898
U.S. Geological Survey

Branch of Information Services

Box 25286

Denver, CO 80225-0286 


\section{CONTENTS}

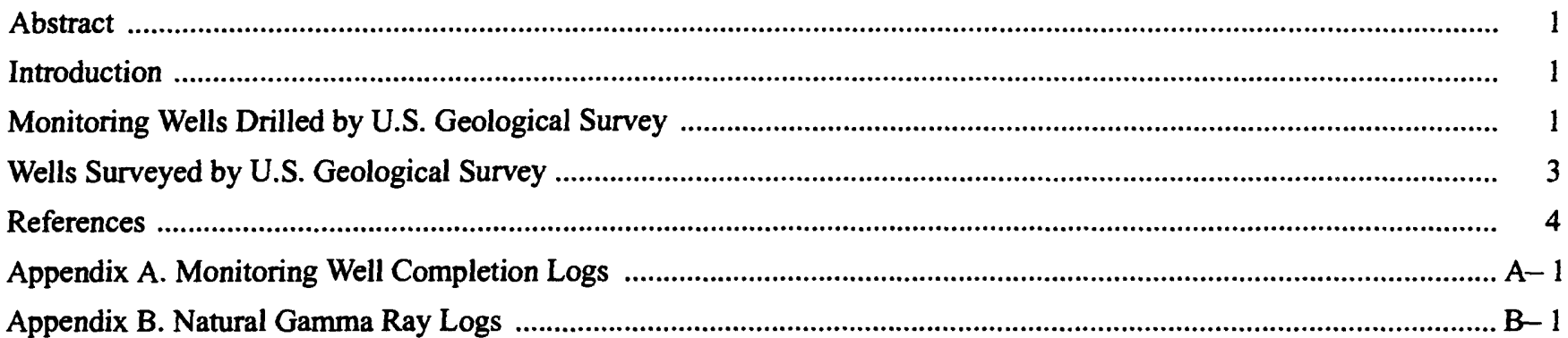

\section{FIGURES}

1. Map showing location of study area and wells installed or surveyed by U.S. Geological Survey

\section{TABLES}

1. Survey data for monitoring wells installed by U.S. Geological Survey ................................................................ 3

2. Survey data for wells installed by Geo-Marine, Inc. ....................................................................................... 4

\section{VERTICAL DATUM, ABBREVIATIONS, AND ACRONYMS}

Sea level: In this report "sea level" refers to the National Geodetic Vertical Datum of 1929 (NGVD of 1929) -a geodetic datum derived from a general adjustment of the first-order level nets of both the United States and Canada, formerly called Sea Level Datum of 1929.

\section{Abbreviations:}

$\mathrm{ft}$, feet

in., inches

$\mathrm{mR} / \mathrm{hr}$, millirems per hour

ppm, parts per million

\section{Acronyms:}

AFP4, Air Force Plant 4

ASC, U.S. Air Force Aeronautical Systems Center, Environmental Management Directorate

GOCO, Government-Owned Contractor-Operator

LEL, lower explosive limit

NAD, North American Datum

NAS, Naval Air Station, Joint Reserve Base, Carswell Field

OVA, organic vapor analyzer

$R A D$, radiation

USCS, Unified Soil Classification Symbol

USEPA, U.S. Environmental Protection Agency

USGS, U.S. Geological Survey 


\title{
Locations and Monitoring Well Completion Logs of Wells Surveyed by U.S. Geological Survey at Air Force Plant 4 and Naval Air Station, Joint Reserve Base, Carswell Field, Fort Worth Area, Texas
}

\author{
By M.D. Williams and E.L. Kuniansky
}

\section{Abstract}

Completion logs are presented for 16 monitoring wells installed by the U.S. Geological Survey at Air Force Plant 4 and Naval Air Station, Joint Reserve Base, Carswell Field, in the Fort Worth area, Texas. Natural gamma-ray logs are presented for selected monitoring wells. Also included are survey data for eight wells installed by Geo-Marine, Inc.

\section{INTRODUCTION}

Air Force Plant 4 (AFP4) in the Fort Worth area, Texas (fig. 1), is a Government-Owned ContractorOperator (GOCO) facility for building aircraft. AFP4 has been in operation since World War II. Ground-water contamination of the surficial terrace alluvial aquifer has occurred at AFP4 and adjacent Naval Air Station, Joint Reserve Base, Carswell Field (NAS) (GeoMarine, Inc., 1995; RUST Geotech, 1995). In August 1990, AFP4 was placed on the U.S. Environmental Protection Agency (USEPA) National Priorities List as a Superfund clean-up site. At the request of the U.S. Air Force Aeronautical Systems Center, Environmental Management Directorate (ASC), the U.S. Geological Survey (USGS) installed 16 monitoring wells at NAS and along Lake Worth adjacent to AFP4 (fig. 1). Additionally, the USGS completed surveying for eight wells installed at NAS (fig. 1) by Geo-Marine, Inc.

The purpose of this report is to document the locations of the 16 monitoring wells and to present well completion logs of all monitoring wells and natural gamma-ray logs of selected monitoring wells. Survey data for the wells installed by Geo-Marine, Inc., also are included. The data presented in this report were col- lected as part of the Remedial Investigations and the ground-water monitoring at AFP4 for the U.S. Air Force Installation Restoration Program.

\section{MONITORING WELLS DRILLED BY U.S. GEOLOGICAL SURVEY}

According to the Field Sampling, Analysis, and Testing Plan submitted by Bartolino (1993), several investigation sites were selected for drilling monitoring wells. For drilling purposes, these sites were identified with either a $\mathrm{P}$ (Paluxy aquifer) or T (terrace alluvial aquifer) followed by a sequence number. These numbers were used in the field for hole locations. Some holes subsequently were abandoned and plugged because they were unsuitable for well installation. The hole number should not be confused with the well number. The well numbers were assigned by J.R. Bartolino on the basis of the nomenclature of 1993, which ensured unique numbers for each well (drilling contractor, arbitrary sequence number, hydrologic unit). Ten wells were installed by the USGS at AFP4 and NAS. Additionally, one set of three nested wells (completed in the upper, middle, and lower zones of the Paluxy aquifer) was installed at the National Guard Armory, and a second set of three nested wells was installed along Lake Worth on public land (fig. 1). These nested wells were located to provide additional sampling points in the area of the domestic wells west of AFP4 (Kuniansky and others, 1996, fig. 2) as requested by the Remediation Program Manager for ASC, Fred Oelrich.

All shallow wells in the terrace alluvial aquifer were drilled using a hollow stem auger. The deeper wells in the middle and lower zones of the Paluxy aquifer were drilled using mud rotary. Wells drilled in the upper zone of the Paluxy were drilled using air rotary. 


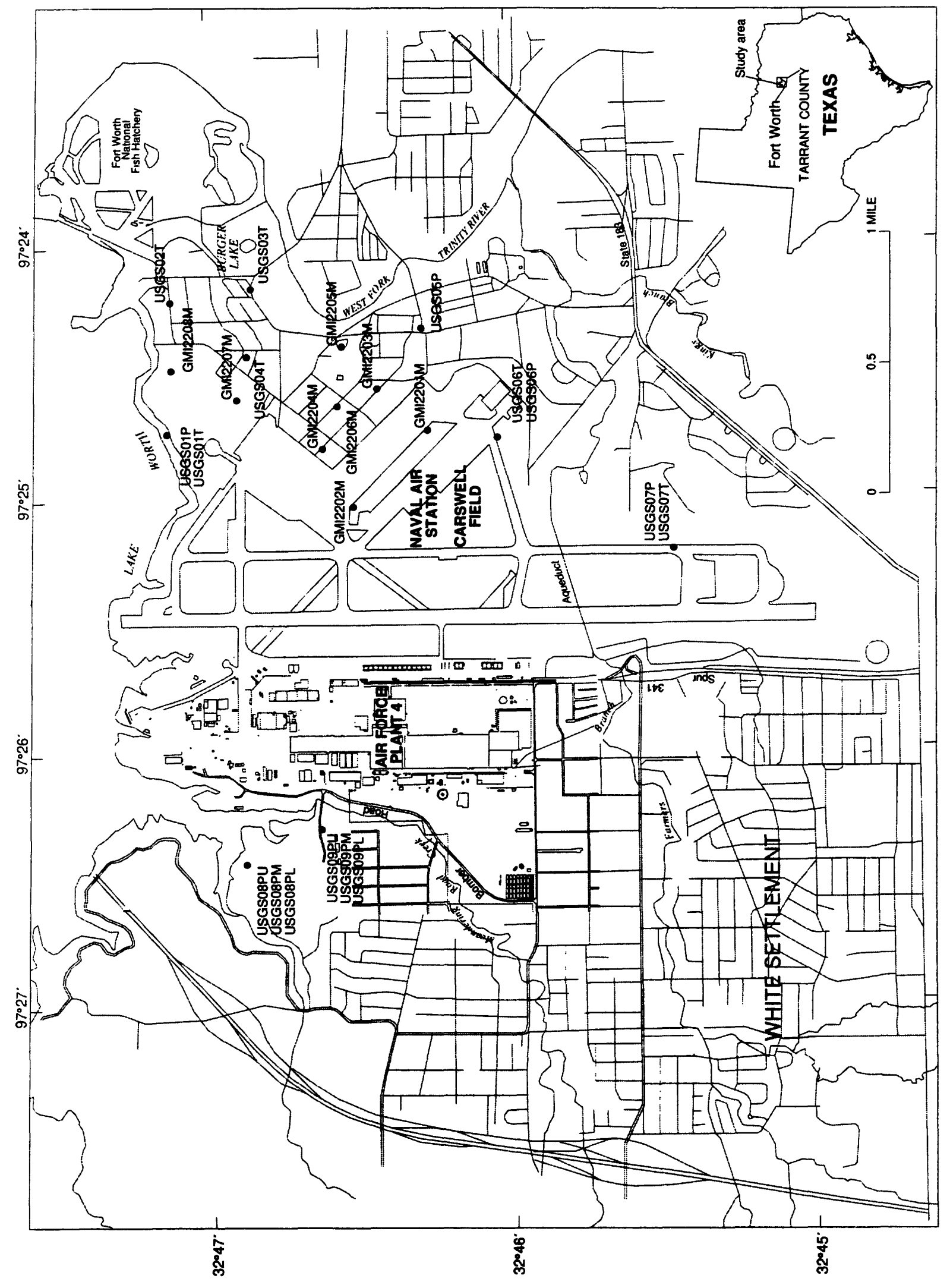

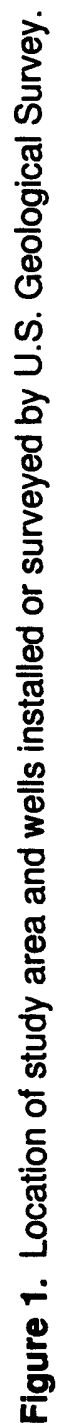


This information is provided on each well completion $\log$ (appendix A). Wells were logged by USGS geologists J.R. Bartolino, Eloise Kendy, and G.A. Rivers. Drilling began in November 1993 and was completed in January 1994.

Natural gamma-ray logs (appendix B) were collected in September 1995 at selected monitoring wells by E.L. Kuniansky (USGS) and Ruben Martinez (Parsons Engineering Sciences, Denver, Colo.)

\section{WELLS SURVEYED BY U.S. GEOLOGICAL SURVEY}

Surveying was done using a first order triangulation station for latitude and longitude according to horizontal datum-North American Datum (NAD) 1983 for the wells shown in figure 1. The first order station used is Carrico, latitude $32^{\circ} 52^{\prime} 46.47436^{\prime \prime} \mathrm{N}$, longitude $097^{\circ} 25^{\prime} 32.03501$ "W. Wells USGS07T and USGS01T were the control points on NAS that were brought in using two instruments. These locations approach first order quality with precision being estimated at 0.08 ppm (Trimble Navigation, 1991, chap. 4). The Northing and Easting are provided in state plane coordinates, Texas North Central zone 4202. Surveying was done by D.A. Brown and G.A. Rivers (USGS) during February 9-11, 1994 and March 30-April 6, 1994.

Vertical datums used were referenced to mean sea level (msl) with accuracy to $0.05 \mathrm{ft}$. The U.S. Department of Commerce, Coast and Geodetic Survey (1979) established six benchmarks at NAS for vertical control.

Survey data for wells installed by the USGS are listed in table 1. Well USGS08PL, one of a set of nested wells, shows an approximate location. The location shown for USGS08PL is the location for USGS08PM. Survey data for wells installed by Geo-Marine, Inc., are listed in table 2.

Table 1. Survey data for monitoring wells installed by U.S. Geological Survey

\begin{tabular}{|c|c|c|c|c|c|c|c|}
\hline Well no. & $\begin{array}{c}\text { Hole } \\
\text { no. }\end{array}$ & $\begin{array}{c}\text { Land } \\
\text { surface } \\
\text { (ft above } \\
\text { msl) }\end{array}$ & $\begin{array}{c}\text { Measuring } \\
\text { point } \\
\text { (ft above } \\
\text { msl) }\end{array}$ & Northing & Easting & $\begin{array}{c}\text { Latitude } \\
\text { (NAD 1983) }\end{array}$ & $\begin{array}{c}\text { Longitude } \\
\text { (NAD 1983) }\end{array}$ \\
\hline USGS01P & P3-C & 604.97 & 604.83 & 6970387.260 & 2297664.372 & $32^{\circ} 47^{\prime} 07.786^{\prime \prime} \mathrm{N}$ & $097^{\circ} 25^{\prime} 43.898^{\prime \prime} \mathrm{W}$ \\
\hline USGS01T & P3-A & 604.97 & 604.77 & 6970383.711 & 2297660.564 & $32^{\circ} 47^{\prime} 07.75127^{\prime \prime N} \mathrm{~N}$ & $097^{\circ} 25^{\prime} 43.94303^{\prime \prime} \mathrm{W}$ \\
\hline USGS02T & P4 & 604.57 & 604.23 & 6970326.565 & 2300333.854 & $32^{\circ} 47^{\prime} 06.915^{\prime \prime} \mathrm{N}$ & $097^{\circ} 25^{\prime} 12.635^{\prime \prime} \mathrm{W}$ \\
\hline USGS03T & T3 & 575.23 & 575.11 & 6968690.574 & 2300609.179 & $32^{\circ} 46^{\prime} 50.699 " \mathrm{~N}$ & $097^{\circ} 25^{\prime} 09.607^{\prime \prime} \mathrm{W}$ \\
\hline USGS04T & $\mathrm{T} 7$ & 605.12 & 604.88 & 6968758.854 & 2299177.893 & $32^{\circ} 46^{\prime} 51.520^{\prime \prime N} \mathrm{~N}$ & $097^{\circ} 25^{\prime} 26.364^{\prime \prime} \mathrm{W}$ \\
\hline USGS05P & P7 & 576.75 & 576.80 & 6965287.947 & 2299736.320 & $32^{\circ} 46^{\prime} 17.119^{\prime \prime} \mathrm{N}$ & $097^{\circ} 25^{\prime} 20.240^{\prime \prime} \mathrm{W}$ \\
\hline USGS06P & $\mathrm{T} 4-\mathrm{C}$ & 606.57 & 606.47 & 6963771.976 & 2297557.639 & $32^{\circ} 46^{\prime} 02.339^{\prime \prime} \mathrm{N}$ & $097^{\circ} 25^{\prime} 45.938^{\prime \prime} \mathrm{W}$ \\
\hline USGS06T & T4-A & 606.64 & 606.49 & 6963763.623 & 2297541.330 & $32^{\circ} 46^{\prime} 02.258^{\prime \prime} \mathrm{N}$ & $097^{\circ} 25^{\prime} 46.130^{\prime \prime} \mathrm{W}$ \\
\hline USGS07P & P6-C & 632.48 & 632.06 & 6960150.744 & 2295249.942 & $32^{\circ} 45^{\prime} 26.739^{\prime \prime} \mathrm{N}$ & $097^{\circ} 26^{\prime} 13.394^{\prime \prime} \mathrm{W}$ \\
\hline USGS07T & P6-A & 632.52 & 632.45 & 6960168.206 & 2295245.799 & $32^{\circ} 45^{\prime} 26.91220^{\prime \prime} \mathrm{N}$ & $097^{\circ} 26^{\prime} 13.44044^{\prime \prime} \mathrm{W}$ \\
\hline USGS08PL & P1-L & 636.71 & 638.71 & ${ }^{1} 6968817.36$ & ${ }^{1} 2288965.88$ & ${ }^{1} 32^{\circ} 46^{\prime} 53.120^{\prime \prime} \mathrm{N}$ & ${ }^{1} 097^{\circ} 27^{\prime} 26.221^{\prime \prime} \mathrm{W}$ \\
\hline USGS08PM & $\mathrm{P} 1-\mathrm{M}$ & 636.74 & 638.57 & 6968817.360 & 2288944.883 & $32^{\circ} 46^{\prime} 53.120^{\prime \prime} \mathrm{N}$ & $097^{\circ} 27^{\prime} 26.221^{\prime \prime W}$ \\
\hline USGS08PU & $\mathrm{Pl}-\mathrm{U}$ & 636.82 & 637.95 & 6968826.038 & 2288943.602 & $32^{\circ} 46^{\prime} 53.206^{\prime \prime N}$ & $097^{\circ} 27^{\prime} 26.235^{\prime \prime} \mathrm{W}$ \\
\hline USGS09PL & P2-L & 631.64 & 631.49 & 6967334.994 & 2289687.935 & $32^{\circ} 46^{\prime} 38.379^{\prime \prime} \mathrm{N}$ & $097^{\circ} 27^{\prime} 17.690^{\prime \prime} \mathrm{W}$ \\
\hline USGS09PM & $\mathrm{P} 2-\mathrm{M}$ & 631.82 & 631.75 & 6967336.210 & 2289678.015 & $32^{\circ} 46^{\prime} 38.392^{\prime \prime} \mathrm{N}$ & $097^{\circ} 27^{\prime} 17.805^{\prime \prime} \mathrm{W}$ \\
\hline USGS09PU & P2-U & 632.08 & 631.81 & 6967337.726 & 2289668.015 & $32^{\circ} 46^{\prime} 38.408^{\prime \prime} \mathrm{N}$ & $097^{\circ} 27^{\prime} 17.923^{\prime \prime} \mathrm{W}$ \\
\hline
\end{tabular}

${ }^{1}$ Approximate location. 
Tabie 2. Survey data for wells installed by Geo-Marine, Inc.

\begin{tabular}{|c|c|c|c|c|c|c|}
\hline Well no. & $\begin{array}{l}\text { Land surface } \\
\text { (ft above msl) }\end{array}$ & $\begin{array}{c}\text { Measuring } \\
\text { point } \\
\text { (ft above msl) }\end{array}$ & Northing & Easting & $\begin{array}{c}\text { Latitude } \\
\text { (NAD 1983) }\end{array}$ & $\begin{array}{c}\text { Longitude } \\
\text { (NAD 1983) }\end{array}$ \\
\hline GMI2201M & 606.86 & 606.62 & 6965108.032 & 2297688.404 & $32^{\circ} 46^{\prime} 15.546^{\prime \prime} \mathrm{N}$ & $097^{\circ} 25^{\prime} 44.247^{\prime \prime} \mathrm{W}$ \\
\hline GMI2202M & 619.12 & 619.19 & 6966618.789 & 2296186.659 & $32^{\circ} 46^{\prime} 30.646^{\prime \prime} \mathrm{N}$ & $097^{\circ} 26^{\prime} 01.656^{\prime \prime} \mathrm{W}$ \\
\hline GMI2203M & 604.91 & 607.99 & 6966205.754 & 2298538.600 & $32^{\circ} 46^{\prime} 26.322^{\prime \prime} \mathrm{N}$ & $097^{\circ} 25^{\prime} 34.158^{\prime \prime} \mathrm{W}$ \\
\hline GMI2204M & 608.08 & 610.71 & 6967236.378 & 2297339.713 & $32^{\circ} 46^{\prime} 36.641^{\prime \prime} \mathrm{N}$ & $097^{\circ} 25^{\prime} 48.077^{\prime \prime} \mathrm{W}$ \\
\hline GMI2205M & 581.45 & 584.36 & 6966926.165 & 2299431.281 & $32^{\circ} 46^{\prime} 33.360^{\prime \prime} \mathrm{N}$ & $097^{\circ} 25^{\prime} 23.616^{\prime \prime} \mathrm{W}$ \\
\hline GMI2206M & 604.19 & 606.77 & 6966990.331 & 2298185.828 & $32^{\circ} 46^{\prime} 34.121^{\prime \prime} \mathrm{N}$ & $097^{\circ} 25^{\prime} 38.196^{\prime \prime} \mathrm{W}$ \\
\hline GMI2207M & 602.86 & 605.63 & 6969004.570 & 2298321.745 & $32^{\circ} 46^{\prime} 54.038^{\prime \prime} \mathrm{N}$ & $097^{\circ} 25^{\prime} 36.363^{\prime \prime} \mathrm{W}$ \\
\hline GMI2208M & 604.12 & 606.92 & 6970309.448 & 2298970.700 & $32^{\circ} 47^{\prime} 06.884 " \mathrm{~N}$ & $097^{\circ} 25^{\prime} 28.605^{\prime \prime} \mathrm{W}$ \\
\hline
\end{tabular}

\section{REFERENCES}

Bartolino, J.R., 1993, Field sampling, analysis, and testing plan, ground-water monitoring program, Air Force Plant 4, Fort Worth, Texas: Prepared for U.S. Air Force, Aeronautical Systems Center, ASC/EMVR/OL-BA.

Geo-Marine, Inc., 1995, Groundwater survey and subsurface soil delineation, hydrant fueling system, Carswell Air Force Base, SE, Fort Worth, Texas_-Phase I and II: Prepared for U.S. Army Corps of Engineers, Fort Worth District, Contract No. DACA63-93-D-0014, Modification to Delivery Order No. 055, $93 \mathrm{p}$.

Kuniansky, E.L., Jones, S.A., Brock, R.D., and Williams, M.D., 1996, Hydrogeology at Air Force Plant 4 and vicinity and water quality of the Paluxy aquifer, Fort
Worth, Texas: U.S. Geological Survey Water-Resources Investigations Report, 41 p.

RUST Geotech, 1995, Air Force Plant 4, Remedial investigation and preliminary assessment/site inspection report, v. I: Prepared for U.S. Air Force, Headquarters Aeronautical Systems Center, Wright-Patterson Air Force Base, Ohio, Department of Energy Contract No. DE-AC04-861D12584, GJPO-WMP-75, 545 p.

Trimble Navigation, 1991, Trimvec Plus GPS survey software, revision E: Sunnyvale, Calif., Trimble Navigation, Ltd.

U.S. Department of Commerce, Coast and Geodetic Survey, 1979, Index map-control leveling, State of Texas, northeast section: U.S. Department of Commerce. 


\section{APPENDIX A. MONITORING WELL COMPLETION LOGS}


Drilier: U.S. Geological Survey

Method: Mud rotary

Well no. USGS01P

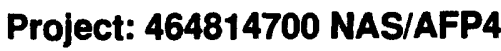

Hole no.: P3-C

Location: NW of Boy Scout Lodge

Northing:

Ground elevation ( $\mathrm{ft} \mathrm{msl}$ ):

Hole depth (ft):

MP height (ft):

Surface bit size (in.):

Below surface (in.):

Coring bit size (in.):

\begin{tabular}{|c|c|c|}
\hline 6970387.260 & Easting: & 2297664.372 \\
\hline 604.97 & Lat/Long: & 3247080972544 \\
\hline 114 & How determined: & Survey \\
\hline 604.83 & Well depth (ft): & 114 \\
\hline $97 / 8 \mathrm{OD}$ & MP description: & Top of 2-in. PVC riser \\
\hline $57 / 8 \mathrm{OD}$ & Slot size: & 0.020 \\
\hline N/A & Reaming bit size (in.): & \\
\hline
\end{tabular}

\begin{tabular}{|c|c|c|c|c|}
\hline TYPE & $\begin{array}{c}\text { DIA } \\
\text { (in. OD) }\end{array}$ & \multicolumn{3}{|c|}{$\begin{array}{l}\text { INTERVAL } \\
\text { (ft) }\end{array}$} \\
\hline Outer casing: PVC flush joint Tri-Lok & 6.0 & $\overline{0}$ & to & 22.5 \\
\hline Blank casing: PVC flush joint Tri-Lok & & -- & to & -- \\
\hline Blank casing: PVC flush joint Tri-Lok & 2.0 & 0 & to & 103.5 \\
\hline Screen: PVC slotted Tri-Lok, 0.020 & 2.0 & 103.5 & to & 113.5 \\
\hline End cap: PVC flush joint Tri-Lok & 2.0 & 113.5 & to & 114 \\
\hline Surface seal: concrete & 0.0 & 3 & to & 22.5 \\
\hline Upper seal: cement grout w/4 $8 \%$ bentonite & 0.0 & -- & to & -- \\
\hline Lower seal: bentonite grout & 0.0 & 3 & to & 85 \\
\hline Secondary sand pack: washed silica sand - 30-70 & 0.0 & 85 & to & 88 \\
\hline Primary sand pack: washed silica sand - 10-20 & 0.0 & 88 & to & 114 \\
\hline
\end{tabular}

Date drilled: $12 / 10$ to $12 / 12 / 93$

Logged by: G.A. Rivers 


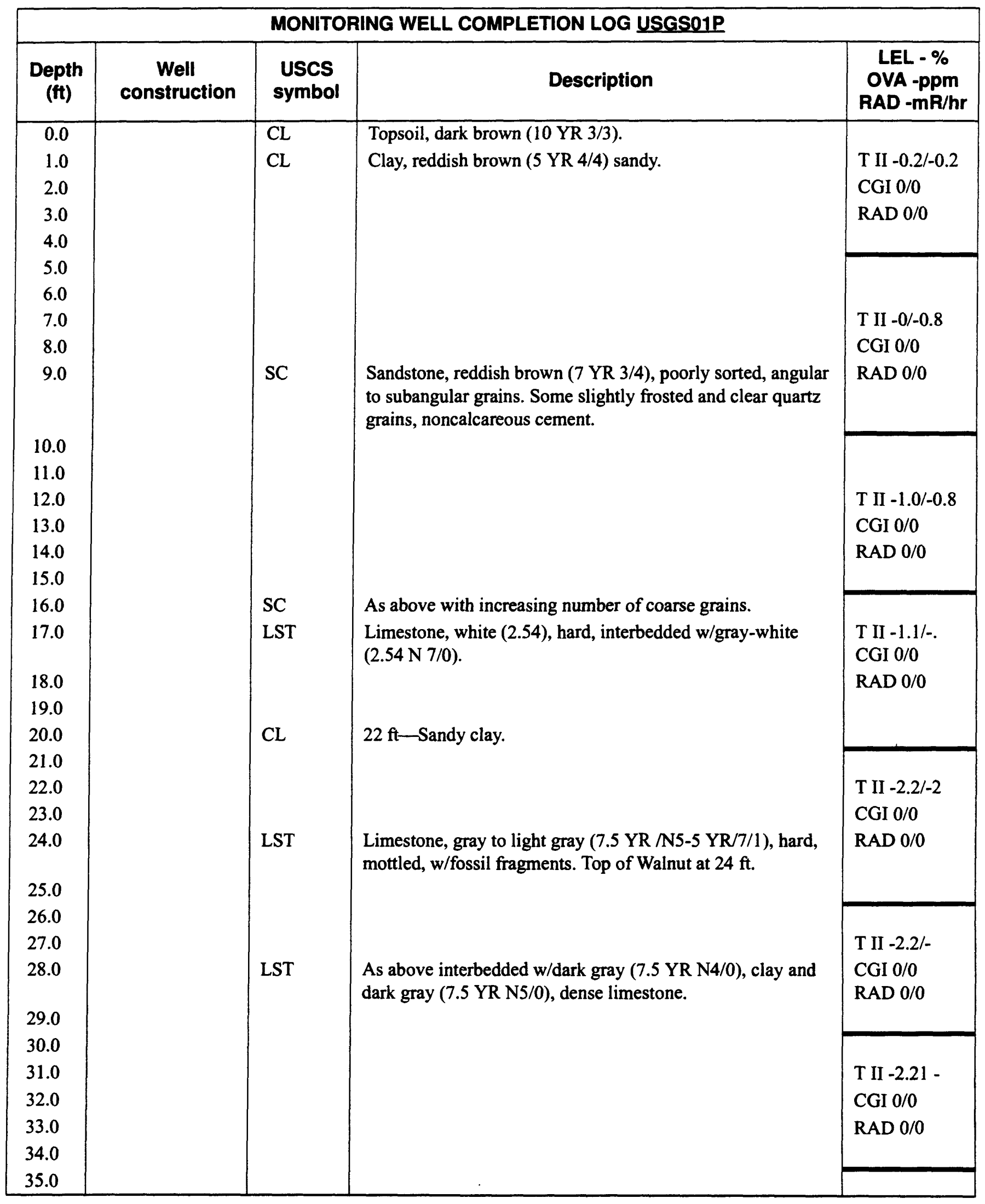




\begin{tabular}{|c|c|c|c|c|}
\hline \multicolumn{5}{|c|}{ MONITORING WELL COMPLETION LOG USGSO1P } \\
\hline $\begin{array}{l}\text { Depth } \\
\text { (ft) }\end{array}$ & $\begin{array}{l}\text { Well } \\
\text { construction }\end{array}$ & $\begin{array}{l}\text { USCS } \\
\text { symbol }\end{array}$ & Description & $\begin{array}{l}\text { LEL - \% } \\
\text { OVA -ppm } \\
\text { RAD - mR/hr }\end{array}$ \\
\hline $\begin{array}{l}36.0 \\
37.0 \\
38.0 \\
39.0\end{array}$ & & \multirow{6}{*}{$\mathrm{CL}$} & \multirow{6}{*}{$\begin{array}{l}\text { Clay, light gray ( } 5 \text { YR } 7 / 1) \text {, calcareous, w/very fine quartz } \\
\text { sand grains. Top of Paluxy at } 47 \mathrm{ft} \text {. }\end{array}$} & $\begin{array}{l}\text { T II }-2.3 /-2 \\
\text { CGI } 0 / 0 \\
\text { RAD } 0 / 0\end{array}$ \\
\hline $\begin{array}{l}40.0 \\
41.0 \\
42.0 \\
43.0 \\
44.0\end{array}$ & & & & $\begin{array}{l}\text { T II }-2.2 /-2 \\
\text { CGI } 0 / 0 \\
\text { RAD 0/0 }\end{array}$ \\
\hline $\begin{array}{r}45.0 \\
46.0 \\
47.0 \\
48.0 \\
49.0 \\
50.0\end{array}$ & & & & $\begin{array}{l}\text { T II }-2.3 /-2 \\
\text { CGI } 0 / 0 \\
\text { RAD 0/0 }\end{array}$ \\
\hline $\begin{array}{l}51.0 \\
52.0 \\
53.0 \\
54.0 \\
55.0\end{array}$ & & & & $\begin{array}{l}\text { T II }-2.3 /-2 \\
\text { CGI } 0 / 0 \\
\text { RAD 0/0 }\end{array}$ \\
\hline $\begin{array}{l}56.0 \\
57.0 \\
58.0 \\
59.0\end{array}$ & & & & $\begin{array}{l}\text { T II }-2.3 /-1 \\
\text { CGI } 0 / 0 \\
\text { RAD 0/0 }\end{array}$ \\
\hline $\begin{array}{l}60.0 \\
61.0 \\
62.0 \\
63.0 \\
64.0\end{array}$ & & & & $\begin{array}{l}\text { T II }-2.3 / 0 \\
\text { CGI } 0 / 0 \\
\text { RAD 0/0 }\end{array}$ \\
\hline $\begin{array}{l}65.0 \\
66.0 \\
67.0 \\
68.0 \\
69.0 \\
70.0\end{array}$ & & \multirow[t]{2}{*}{ CL } & \multirow[t]{2}{*}{ Clay, greenish gray ( $5 \mathrm{G} 6 / 1$ ), w/very fine sand grains. } & $\begin{array}{l}\text { T II }-2.0 / 1 \\
\text { CGI } 0 / 0 \\
\text { RAD } 0 / 0\end{array}$ \\
\hline $\begin{array}{l}71.0 \\
72.0 \\
73.0 \\
74.0\end{array}$ & & & & $\begin{array}{l}\text { T II }-1.9 / 1 \\
\text { CGI } 0 / 0 \\
\text { RAD 0/0 }\end{array}$ \\
\hline
\end{tabular}




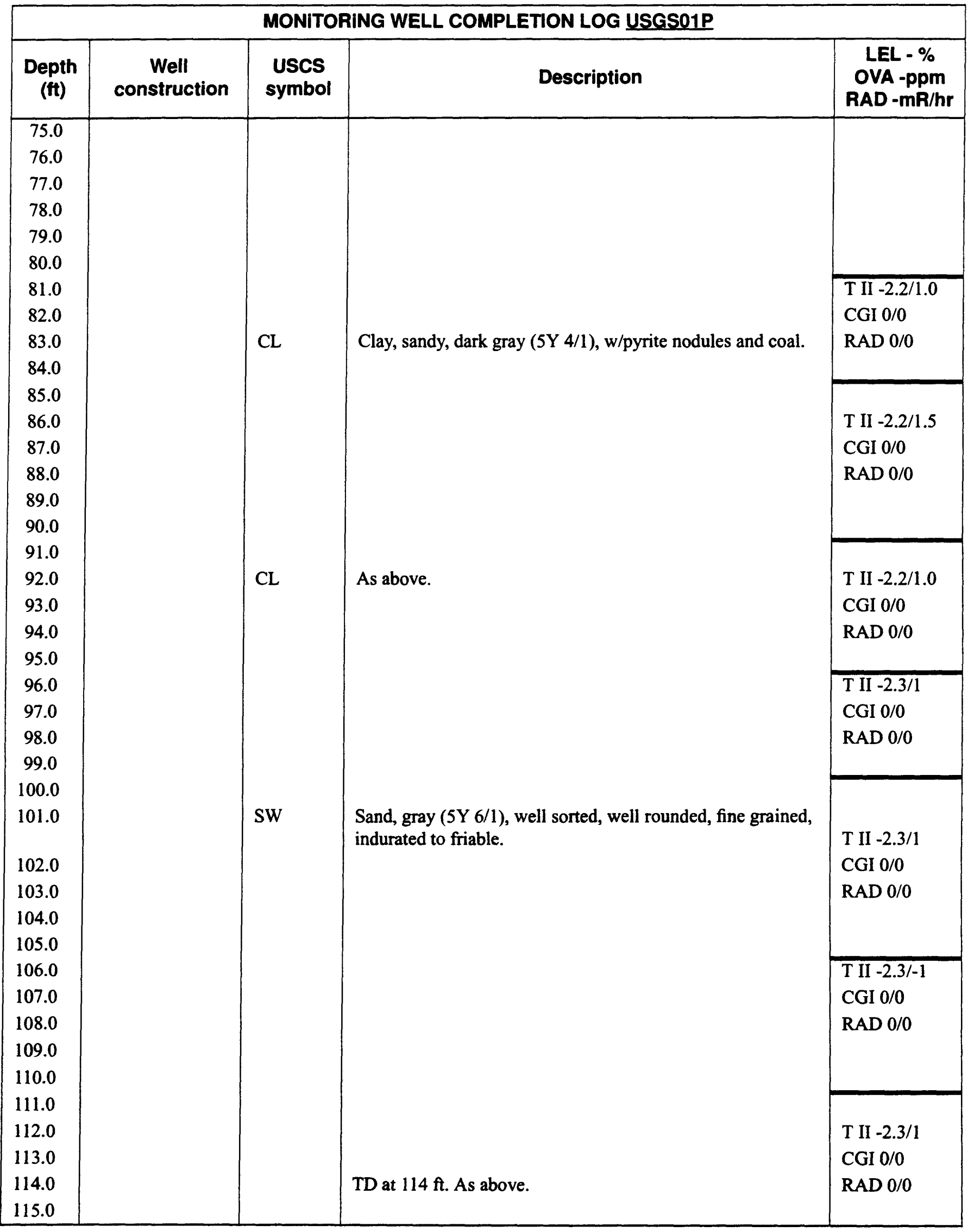




\section{MONITORING WELL COMPLETION LOG}

Driller: U.S. Geological Survey

Method: Hollow Stem Auger

Well no. USGS01T

Project: 464814700 NAS/AFP4

Hole no.: P3-A (Terrace)

\begin{tabular}{|c|c|c|c|}
\hline \multicolumn{4}{|c|}{ Location: NW of Boy Scout Lodge } \\
\hline Northing: & 6970383.711 & Easting: & 2297660.564 \\
\hline Ground elevation ( $\mathrm{ft} \mathrm{msl}$ ): & 604.97 & Lat/Long: & 3247080972544 \\
\hline Hole depth $(\mathrm{ft})$ : & 20.5 & How determined: & Survey \\
\hline MP height (ft): & 604.77 & Well depth (ft): & 20.5 \\
\hline Hollow-stem auger size (in.): & $85 / 8 \mathrm{ID} \times 41 / 4 \mathrm{OD}$ & MP description: & Inside edge of 2 -in. casing \\
\hline Auger head size (in.): & $85 / 8 / 41 / 4 \quad$ ID/OD & Slot size: & 0.020 \\
\hline Coring bit size (in.): & & Reaming bit size (in.): & $85 / 8$ \\
\hline
\end{tabular}

\begin{tabular}{|c|c|c|c|c|}
\hline TYPE & $\begin{array}{c}\text { DIA } \\
\text { (in. OD) }\end{array}$ & \multicolumn{3}{|c|}{$\begin{array}{l}\text { INTERVAL } \\
\text { (ft) }\end{array}$} \\
\hline Outer casing: PVC flush joint Tri-Lok & & $\overline{--}$ & to & - \\
\hline Blank casing: PVC flush joint Tri-Lok & 10.0 & $\overline{--}$ & to & - \\
\hline Blank casing: PVC flush joint Tri-Lok & 2.0 & 0 & to & 10 \\
\hline Screen: PVC slotted Tri-Lok, 0.020 & 2.0 & 10 & to & 20 \\
\hline End cap: PVC flush joint Tri-Lok & 2.0 & 20 & to & 20.5 \\
\hline Surface seal: concrete & 0.0 & 0 & to & 2.5 \\
\hline Upper seal: cement grout $w / 4-8 \%$ bentonite & 0.0 & - & to & -- \\
\hline Lower seal: bentonite grout & 0.0 & 2.5 & to & 6 \\
\hline Secondary sand pack: washed silica sand - 30-70 & 0.0 & 6 & to & 9 \\
\hline Primary sand pack: washed silica sand - 10-20 & 0.0 & 9 & to & 20.5 \\
\hline Date drilled: $11 / 10 / 93$ at 0900 & Logged by & 5 & lino & \\
\hline
\end{tabular}




\begin{tabular}{|c|c|c|c|c|}
\hline \multicolumn{5}{|c|}{ MONITORING WELL COMPLETION LOG USGS01T } \\
\hline $\begin{array}{l}\text { Depth } \\
\text { (ft) }\end{array}$ & $\begin{array}{c}\text { Well } \\
\text { construction }\end{array}$ & $\begin{array}{l}\text { USCS } \\
\text { symbol }\end{array}$ & Description & $\begin{array}{l}\text { LEL }-\% \\
\text { OVA -ppm } \\
\text { RAD - } \mathbf{m R} / \mathrm{hr}\end{array}$ \\
\hline 0.0 & & $\mathrm{CL}$ & $\begin{array}{l}\text { Silty clay - topsoil - poorly sorted, plastic dark yellowish } \\
\text { brown (10 YR 3/4). }\end{array}$ & $\begin{array}{l}\text { T II }-1.0 /-1.0 \\
\text { CGI } 0 / 0 \\
\text { RAD 0/0 }\end{array}$ \\
\hline $\begin{array}{l}1.0 \\
2.0\end{array}$ & & & & \\
\hline 2.5 & & SC & $\begin{array}{l}\text { Silty clay w/increasing amount clay } w /<1 \% \text { white, med-sand } \\
\text { sized grains of caliche/limestone, plastic reddish brown ( } 5 \\
\text { YR } 4 / 4) \text {. }\end{array}$ & $\begin{array}{l}\text { T II }-0.7 /-0.7 \\
\text { CGI } 0 / 0 \\
\text { RAD } 0 / 0\end{array}$ \\
\hline 3.0 & & & & \\
\hline 4.0 & & $\mathrm{SC}$ & $\begin{array}{l}\text { Same, sand size increasing to coarse sand, yellowish red ( } 5 \\
\text { YR 4/6). }\end{array}$ & \\
\hline 5.0 & & & & T II $-0.7 /-0.6$ \\
\hline 6.0 & & & & CGI $0 / 0$ \\
\hline 7.0 & & & & RAD 0/0 \\
\hline 8.0 & & & & \\
\hline 9.0 & & & & \\
\hline 10.0 & & & & T Il 2.5/2.0 \\
\hline 11.0 & & SC & $\begin{array}{l}\text { Silty to clayey fine grained sand, poorly sorted, slightly } \\
\text { plastic, saturated, <1\% white med-sand sized grains, reddish } \\
\text { brown ( } 5 \text { YR } 5 / 4) \text {. }\end{array}$ & $\begin{array}{l}\text { CGI 0/0 } \\
\text { RAD 0/0 }\end{array}$ \\
\hline 12.0 & & & & \\
\hline 13.0 & & & Water? & \\
\hline 14.0 & & SC & $\begin{array}{l}\text { Silty to clayey med sand, better sorted than above, more } \\
\text { coarse sand - } 1-2 \% \text {, strong brown ( } 7.5 \text { YR } 5 / 6) \text {. }\end{array}$ & \\
\hline 15.0 & & & & \\
\hline 16.0 & & & & T II $1.0 / 2.1$ \\
\hline 17.0 & & & & CGI $0 / 0$ \\
\hline 18.0 & & & & RAD $0 / 0$ \\
\hline 18.5 & & GM & $\begin{array}{l}\text { Weathered limestone gravel, dry white }(2.5 \mathrm{Y} 8 / 2) \text { angular to } \\
\text { subrounded clasts of limestone and some shale-clasts to } 2.0 \\
\text { in. Limestone, fine grained, gray }(2.5 \mathrm{Y} \text { N } 5) \text {; shale, mottled, } \\
\text { dry, light yellowish brown }(2.5 \text { Y } 6 / 4) \text {, Walnut } 20.5 \text { ? }\end{array}$ & \\
\hline 19.0 & & & & T II $-0.4 / 3.0$ \\
\hline 20.0 & & & & CGI 0/0 \\
\hline 20.5 & & TD & & RAD 0/0 \\
\hline
\end{tabular}


Driller: U.S. Geological Survey

Method: Hollow Stem Auger

Well no. USGSO2T

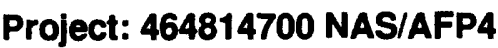

Hole no.: P4

Location: End of visiting officers' quarters (VOQ)

Northing:

Ground elevation ( $\mathrm{ft} \mathrm{msl):}$

Hole depth (ft):

MP height (ft):

Hollow-stem auger size (in.):

Auger head size (in.):

Coring bit size (in.):

\begin{tabular}{l}
6970326.565 \\
\hline 604.57 \\
\hline 48 \\
\hline 604.23 \\
\hline $41 / 4$ ID $\times 85 / 8$ OD \\
\hline $85 / 8 \quad$ OD \\
\hline N/A
\end{tabular}

Easting:

Lat/Long:

How determined:

Well depth (ft):

MP description:

Slot size:

Reaming bit size (in.):

\begin{tabular}{l}
\hline 2300333.854 \\
\hline 3247070972513 \\
\hline Survey \\
\hline 30.5 \\
\hline Inside edge of casing \\
\hline 0.020 \\
\hline $85 / 8$
\end{tabular}

\begin{tabular}{|c|c|c|c|c|}
\hline TYPE & $\begin{array}{c}\text { DIA } \\
\text { (In. OD) }\end{array}$ & \multicolumn{3}{|c|}{$\begin{array}{l}\text { INTERVAL } \\
(\mathbf{f t})\end{array}$} \\
\hline Outer casing: PVC flush joint Tri-Lok & & - & to & -- \\
\hline Blank casing: PVC flush joint Tri-Lok & 10.0 & - & to & -- \\
\hline Blank casing: PVC flush joint Tri-Lok & 2.0 & 0 & to & 15 \\
\hline Screen: PVC slotted Tri-Lok, 0.020 & 2.0 & 15 & to & 30 \\
\hline End cap: PVC flush joint Tri-Lok & 2.0 & 30 & to & 30.5 \\
\hline Surface seal: concrete & 0.0 & 0 & to & 2 \\
\hline $\begin{array}{l}\text { Upper seal: Portland cement grout w/3-6\% } \\
\text { volclay bentonite }\end{array}$ & 0.0 & 2 & to & 9 \\
\hline Lower seal: volclay bentonite grout & 0.0 & 9 & to & 13 \\
\hline Secondary sand pack: washed silica sand - 30-70 & 0.0 & 13 & to & 4 \\
\hline Primary sand pack: washed silica sand - 10-20 & 0.0 & 14 & to & 31 \\
\hline Native sand backfill (cave-in) & & 31 & to & 48 \\
\hline Date drilled: $11 / 17$ to $11 / 18 / 93$ & Logged by & Uise & ndy & \\
\hline
\end{tabular}




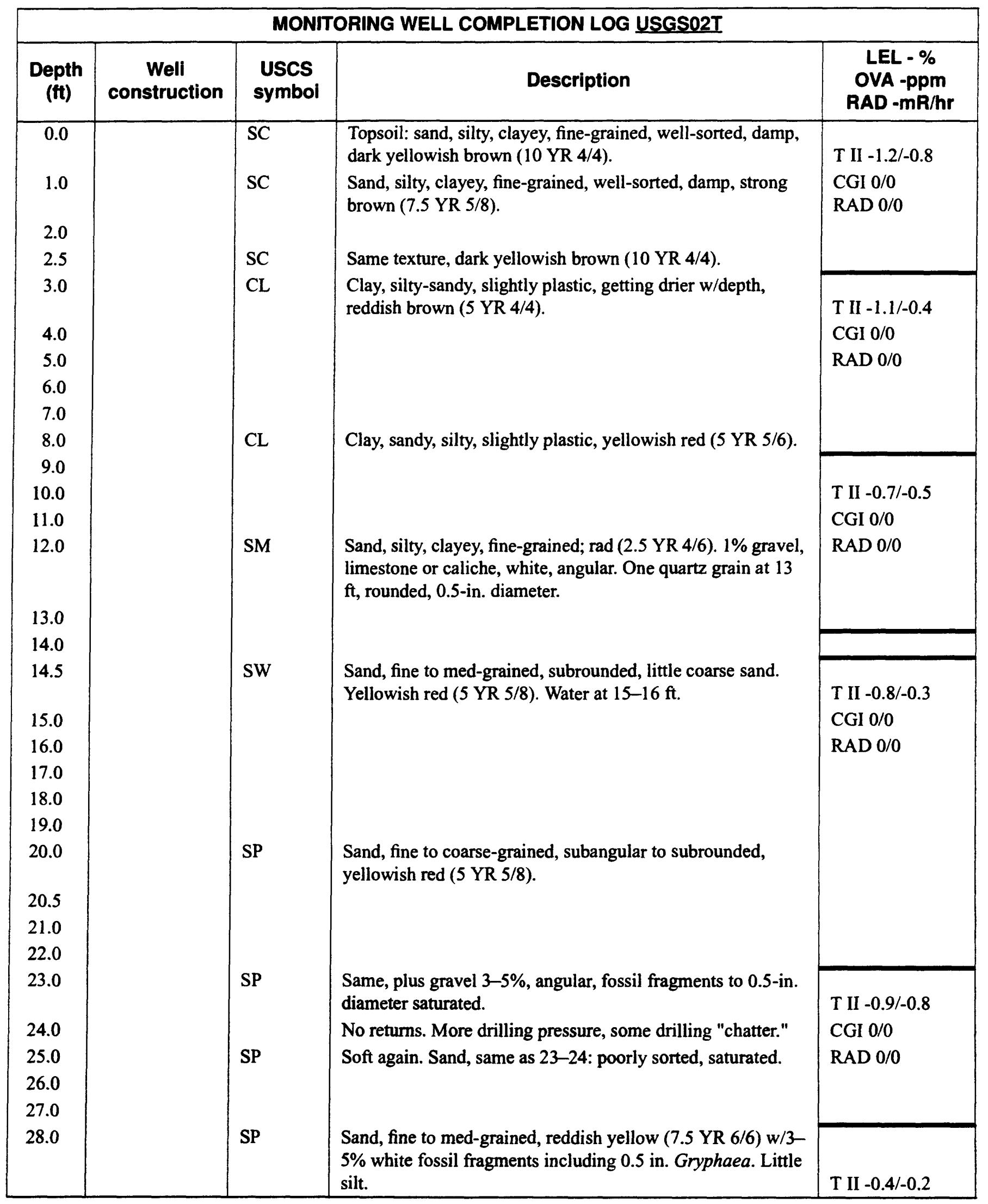




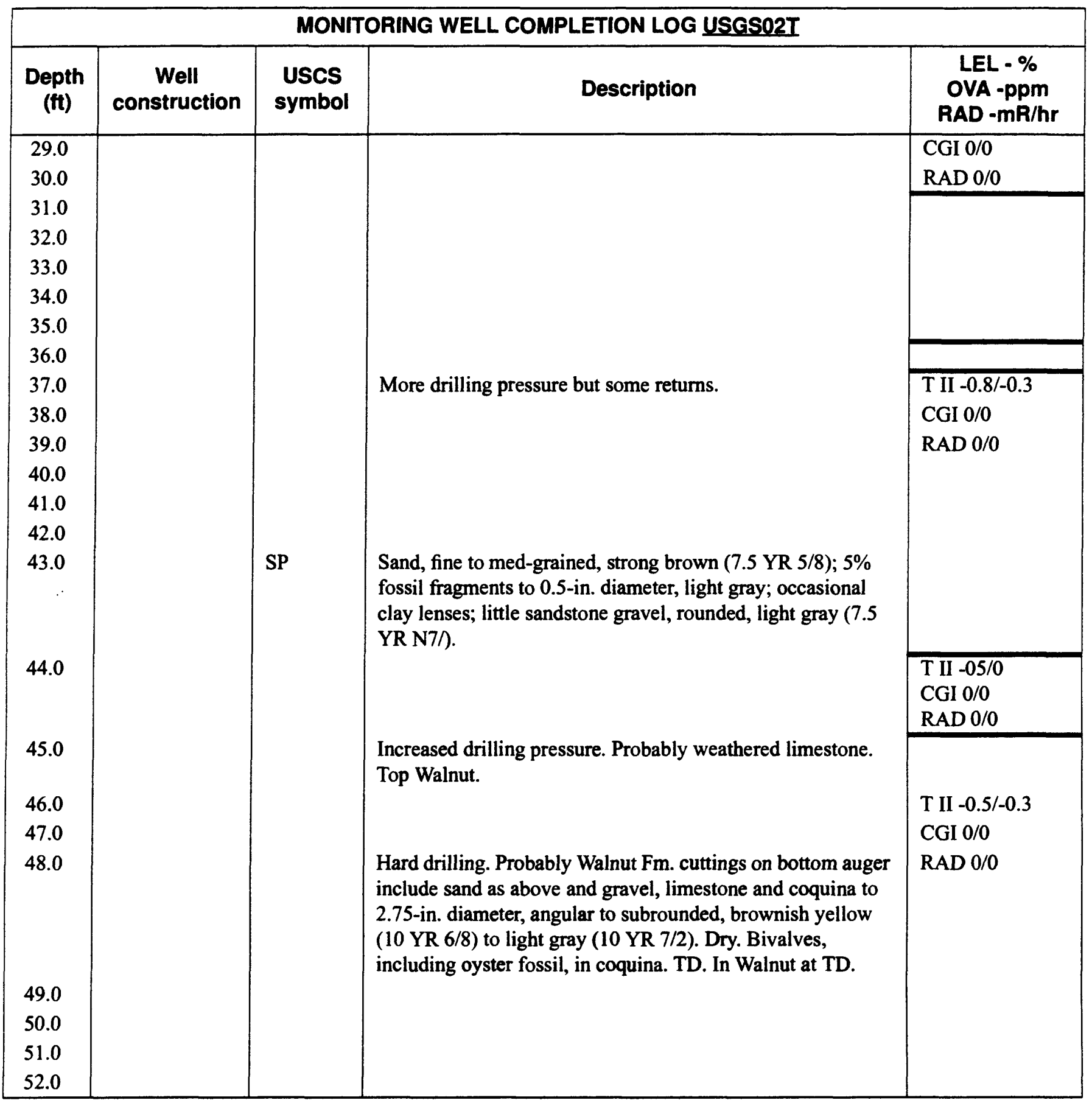




\section{MONITORING WELL COMPLETION LOG}

Driller: U.S. Geological Survey

Method: Hollow Stem Auger

Well no. USGS03T

Project: 464814700 NAS/AFP4

Hole no.: T3

Location: On Stratofortress Ct., across from Berger Ln.

Northing:

Ground elevation (ft msl):

Hole depth (ft):

MP height ( $\mathrm{ft}$ ):

Hollow-stem auger size (in.):

Auger head size (in.):

Coring bit size (in.):

\begin{tabular}{l}
6968690.574 \\
\hline 575.23 \\
\hline 48 \\
\hline 575.11 \\
\hline $41 / 4$ ID $\times 85 / 8$ OD \\
\hline $85 / 8 / 41 / 4$ ID/OD \\
\hline N/A \\
\hline
\end{tabular}

Easting:

Lat/Long:

How determined:

Well depth (ft):

MP description:

Slot size:

Reaming bit size (in.):

\begin{tabular}{l}
2300609.179 \\
\hline 3246510972510 \\
\hline Survey \\
\hline 8.5 \\
\hline Inside edge of casing \\
\hline 0.020 \\
\hline $85 / 8$ \\
\hline
\end{tabular}

\begin{tabular}{|c|c|c|c|c|}
\hline TYPE & $\begin{array}{c}\text { DIA } \\
\text { (in. OD) }\end{array}$ & \multicolumn{3}{|c|}{$\begin{array}{c}\text { INTERVAL } \\
\text { (ft) }\end{array}$} \\
\hline Outer casing: PVC flush joint Tri-Lok & & -- & to & -- \\
\hline Blank casing: PVC flush joint Tri-Lok & 10.0 & - & to & - \\
\hline Blank casing: PVC flush joint Tri-Lok & 2.0 & 0 & to & 5.5 \\
\hline Screen: PVC slotted Tri-Lok, 0.020 & 2.0 & $\overline{5.5}$ & to & $\overline{8.0}$ \\
\hline End cap: PVC flush joint Tri-Lok & 2.0 & 8.0 & to & $\overline{8.5}$ \\
\hline Surface seal: concrete & 0.0 & 0 & to & 2 \\
\hline Upper seal: cement grout $w / 4-8 \%$ bentonite & 0.0 & 2 & to & 3 \\
\hline Lower seal: volclay bentonite grout & 0.0 & 3 & to & $\overline{3.5}$ \\
\hline Secondary sand pack: washed silica sand - 30-70 & 0.0 & 3.5 & to & $\overline{4.5}$ \\
\hline Primary sand pack: washed silica sand - 10-20 & 0.0 & 4.5 & to & $\overline{8.5}$ \\
\hline Date drilled: $11 / 09 / 93$ at 1100 & Logged by & D. & lino & \\
\hline
\end{tabular}




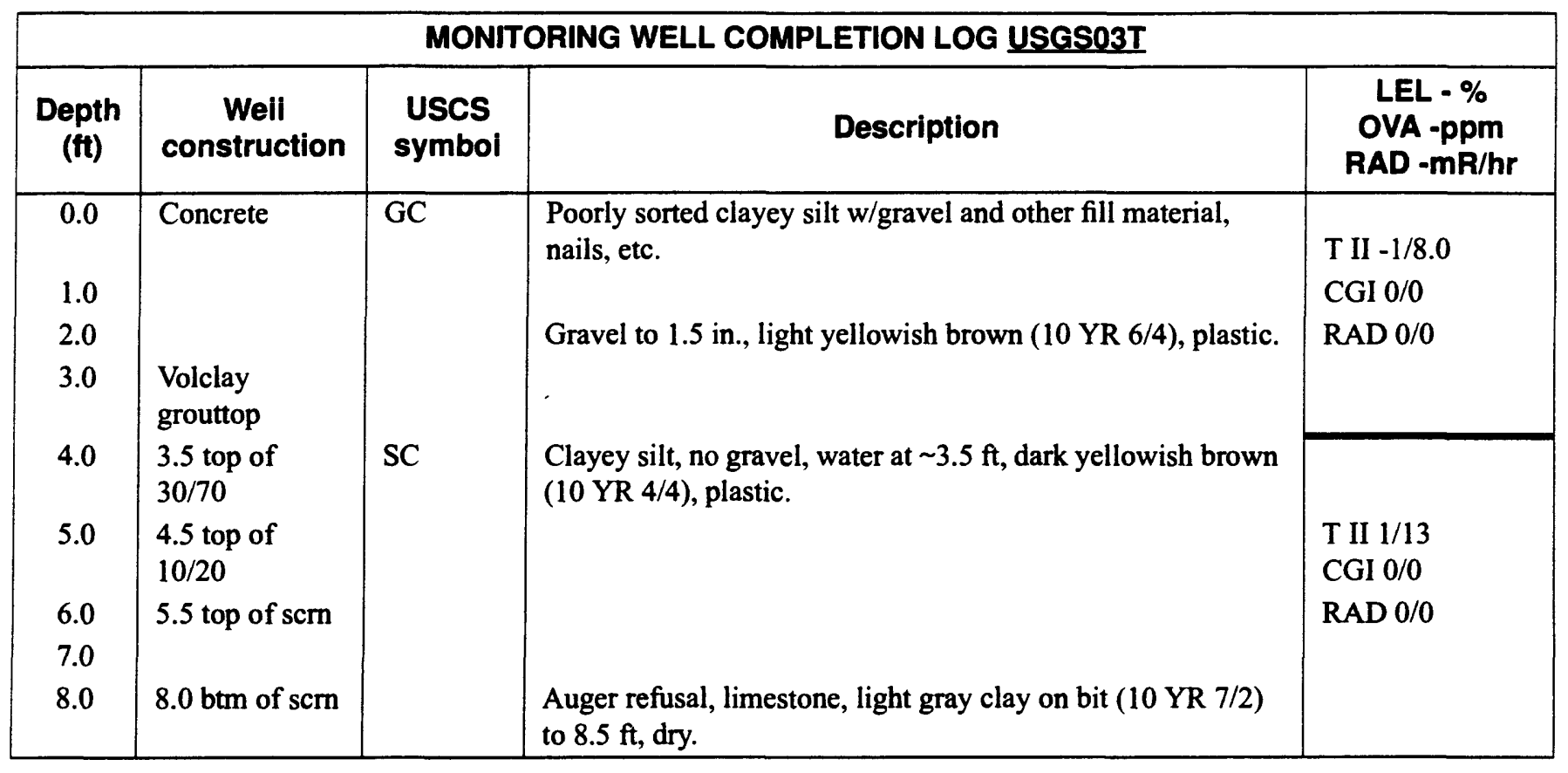


MONITORING WELL COMPLETION LOG

Driller: U.S. Geological Survey

Method: Hollow Stem Auger

Well no. USGSO4T

Project: $\mathbf{4 6 4 8 1 4 7 0 0}$ NAS/AFP4

Hole no.: $T 7$

\begin{tabular}{|c|c|}
\hline Location: NW comer of Seco & \\
\hline Northing: & 6968758.854 \\
\hline Ground elevation ( $\mathrm{ft} \mathrm{msl}$ ): & 605.12 \\
\hline Hole depth $(\mathrm{ft}):$ & 26.5 \\
\hline MP height (ft): & 604.88 \\
\hline Hollow-stem auger size (in.): & $41 / 4 \mathrm{ID} \times 85 / 8 \mathrm{OD}$ \\
\hline Auger head size (in.): & $85 / 8 / 41 / 4 \mathrm{ID} / \mathrm{OD}$ \\
\hline Coring bit size (in.): & N/A \\
\hline
\end{tabular}

\section{Easting:}

Lat/Long:

How determined:

Well depth (ft):

MP description:

Slot size:

Reaming bit size (in.):
2299177.893

3246520972526

Survey

26

Inside edge of casing

0.020

$85 / 8$

\section{TYPE}

DIA

(in. OD)

Outer casing: PVC flush joint Tri-Lok

Blank casing: PVC flush joint Tri-Lok

Blank casing: PVC flush joint Tri-Lok

Screen: PVC slotted Tri-Lok, 0.020

End cap: PVC flush joint Tri-Lok

Surface seal: concrete

Upper seal: cement grout $w / 4-8 \%$ bentonite

Lower seal: volclay bentonite grout

Secondary sand pack: washed silica sand - 30-70

Primary sand pack: washed silica sand - 10-20

\begin{tabular}{|c|c|c|c|}
\hline & -- & to & - \\
\hline 10.0 & N/A & to & N/A \\
\hline 2.0 & 0 & to & 15.5 \\
\hline 2.0 & 15.5 & to & 25.5 \\
\hline 2.0 & 25.5 & to & 26 \\
\hline 0.0 & 0 & to & 1 \\
\hline 0.0 & 1 & to & 8 \\
\hline 0.0 & 8 & to & 11.5 \\
\hline 0.0 & 11.5 & to & 13 \\
\hline 0.0 & 13 & to & 26.5 \\
\hline
\end{tabular}

Logged by: J.R. Bartolino

INTERVAL

(ft) 


\begin{tabular}{|c|c|c|c|c|}
\hline \multicolumn{5}{|c|}{ MONITORING WELL COMPLETION LOG USGSO4T } \\
\hline $\begin{array}{l}\text { Depth } \\
\text { (ft) }\end{array}$ & $\begin{array}{c}\text { Well } \\
\text { construction }\end{array}$ & $\begin{array}{l}\text { USCS } \\
\text { symbol }\end{array}$ & Description & $\begin{array}{c}\text { LEL - \% } \\
\text { OVA -ppm } \\
\text { RAD - mR/hr }\end{array}$ \\
\hline $\begin{array}{l}3.0 \\
3.5\end{array}$ & $\begin{array}{l}\text { Top of concrete } \\
\text { Top of cement } \\
\text { Bentonite } \\
\text { grout }\end{array}$ & $\mathrm{SC}$ & $\begin{array}{l}\text { Clayey to sandy silt, poorly sorted, <1\% sand sized grains, } \\
\text { reddish brown (5 YR 5/4), plastic. } \\
\text { Clayey to sandy silt, poorly sorted, white med-sand sized } \\
\text { grains (caliche, limestone?) and coarse sand to fine gravel } \\
<1 \% \text {, yellowish red (5 YR 4/6), plastic. }\end{array}$ & $\begin{array}{l}\text { T II } 2 / 1.7 \\
\text { CGI } 0 / 0 \\
\text { RAD } 0 / 0\end{array}$ \\
\hline $\begin{array}{l}4.0 \\
5.0 \\
6.0 \\
7.0 \\
8.0\end{array}$ & Top of volclay & & Limestone, light gray clay on bit ( 10 YR $7 / 2)$ to $8.5 \mathrm{ft}$. & $\begin{array}{l}\text { T II } 3 / 6.6 \\
\text { CGI } 0 / 0 \\
\text { RAD } 0 / 0\end{array}$ \\
\hline $\begin{array}{r}9.0 \\
10.0 \\
11.0 \\
11.5 \\
\\
\\
12.0 \\
13.0\end{array}$ & $\begin{array}{l}\text { Top of } 30 / 70 \\
\text { sand } \\
\text { Top of 10/20 } \\
\text { sand }\end{array}$ & & $\cdot$ & $\begin{array}{l}\text { T II } 0 / 25.3 \\
\text { CGI } 0 / 0 \\
\text { RAD } 0 / 0\end{array}$ \\
\hline $\begin{array}{l}14.0 \\
15.0 \\
16.0 \\
\\
17.0 \\
18.0\end{array}$ & $\begin{array}{l}\text { Top of scm } \\
15.5\end{array}$ & $\mathrm{SC}$ & $\begin{array}{l}\text { Clayey silt w/2\% sand and gravel. } \\
\text { As above, yellowish brown (10 YR 5/6), plastic. }\end{array}$ & $\begin{array}{l}\text { T II } 0 / 9.3 \\
\text { CGI } 0 / 0 \\
\text { RAD } 0 / 0\end{array}$ \\
\hline $\begin{array}{l}19.0 \\
20.0\end{array}$ & & & & \\
\hline $\begin{array}{l}21.0 \\
22.0 \\
23.0\end{array}$ & & GC & $\begin{array}{l}\text { Gravel layer, poorly sorted subrounded gravel to } 11 / 4 \text { in., } \\
\text { calcareous. }\end{array}$ & $\begin{array}{l}\text { T II } .9 / 0 / 8 \\
\text { CGI } 0 / 0 \\
\text { RAD } 0 / 0\end{array}$ \\
\hline $\begin{array}{l}24.0 \\
25.0 \\
26\end{array}$ & $\begin{array}{l}\text { Bottom of } \\
\text { screen } 25.5\end{array}$ & & & $\begin{array}{l}\text { T II } 1.4 / 1.0 \\
\text { CGI } 0 / 0 \\
\text { RAD } 0 / 0\end{array}$ \\
\hline 26.5 & $\begin{array}{l}\text { End cap, 10/20 } \\
\text { sand }\end{array}$ & LST & Auger refusal, dry, marly limestone, light gray (10 YR 6/1). & \\
\hline
\end{tabular}


Driller: U.S. Geological Survey

Method: Mud rotary

Well no. USGS05P

Project: 464814700 NAS/AFP4

Hole no.: P7

\begin{tabular}{|c|c|c|c|}
\hline \multicolumn{4}{|c|}{ Location: Near Shoppette at Carswell AFB, Texas } \\
\hline Northing: & 6965287.947 & \multirow{7}{*}{$\begin{array}{l}\text { Easting: } \\
\text { Lat/Long: } \\
\text { How determined: } \\
\text { Well depth (ft): } \\
\text { MP description: } \\
\text { Slot size: } \\
\text { Reaming bit size (in.): }\end{array}$} & 2299736.320 \\
\hline Ground elevation ( $\mathrm{ft} \mathrm{msl}$ ): & 576.75 & & 3246170972520 \\
\hline Hole depth $(\mathrm{ft})$ : & 90 & & Survey \\
\hline MP height (ft): & 576.80 & & 90 \\
\hline Surface bit size (in.): & $97 / 8 \mathrm{OD}$ & & Top of 2-in. riser \\
\hline Below surface (in.): & $57 / 8 \mathrm{OD}$ & & 0.020 \\
\hline Coring bit size (in.): & N/A & & \\
\hline
\end{tabular}

\begin{tabular}{|c|c|c|c|c|}
\hline TYPE & $\begin{array}{c}\text { DIA } \\
\text { (in. OD) }\end{array}$ & \multicolumn{3}{|c|}{$\begin{array}{l}\text { INTERVAL } \\
\text { (ft) }\end{array}$} \\
\hline Outer casing: PVC flush joint Tri-Lok & & & to & \\
\hline Blank casing: PVC flush joint Tri-Lok & 6.0 & 0.5 & to & 22 \\
\hline Blank casing: PVC flush joint Tri-Lok & 2.0 & 0 & to & $\overline{79.5}$ \\
\hline Screen: PVC slotted Tri-Lok, 0.020 & 2.0 & $\overline{79.5}$ & to & 89.5 \\
\hline End cap: PVC flush joint Tri-Lok & 2.0 & 89.5 & to & 90 \\
\hline Surface seal: Pakmix concrete & 0.0 & 0 & to & 3 \\
\hline $\begin{array}{l}\text { Upper seal: Portland cement grout } w / 4-8 \% \\
\text { bentonite }\end{array}$ & 0.0 & .5 & to & 22 \\
\hline Lower seal: Volclay grout & 0.0 & .5 & to & 65 \\
\hline Secondary sand pack: washed silica sand - 30-70 & 0.0 & 65 & to & 71 \\
\hline Primary sand pack: washed silica sand - 10-20 & 0.0 & 71 & to & 90 \\
\hline Date drilled: $01 / 05$ to $01 / 06 / 94$ & & ho & Ri & \\
\hline
\end{tabular}




\begin{tabular}{|c|c|c|c|c|}
\hline \multicolumn{5}{|c|}{ MONITORING WELL COMPLETION LOG USGS05P } \\
\hline $\begin{array}{l}\text { Depth } \\
\text { (ft) }\end{array}$ & $\begin{array}{l}\text { Well } \\
\text { construction }\end{array}$ & $\begin{array}{l}\text { USCS } \\
\text { symbol }\end{array}$ & Description & $\begin{array}{l}\text { LEL - \% } \\
\text { OVA -ppm } \\
\text { RAD - mR/hr }\end{array}$ \\
\hline 0.0 & & \multirow{3}{*}{$\mathrm{CL}$} & \multirow{3}{*}{ Topsoil, dark brown (7 YR 3/3), clayey. } & \\
\hline 1.0 & & & & T II $-0.6 /-0.3$ \\
\hline 2.0 & & & & CGI $0 / 0$ \\
\hline 3.0 & & \multirow[t]{2}{*}{$\mathrm{CL}$} & \multirow[t]{2}{*}{ Clay, dark brown (7 YR 3/3), sandy. } & RAD 0/0 \\
\hline 4.0 & & & & \\
\hline 5.0 & & \multirow[t]{5}{*}{ LST } & \multirow[t]{5}{*}{$\begin{array}{l}\text { Limestone, light brown (7 YR 6/3), mottled, indurated, } 1 \% \\
\text { vuggy porosity, contains microgastropods. (Possibly } \\
\text { Goodland remnant? E.L. Kuniansky 3-2-95) }\end{array}$} & \\
\hline 6.0 & & & & T II $-0.6 /-0.3$ \\
\hline 7.0 & & & & CGI $0 / 0$ \\
\hline 8.0 & & & & RAD 0/0 \\
\hline 9.0 & & & & \\
\hline 10.0 & & \multirow[t]{3}{*}{$\mathrm{CL}$} & \multirow[t]{3}{*}{$\begin{array}{l}\text { Clay, pinkish gray ( } 7 \text { YR } 7 / 2) \text {, calcareous w/very fine quartz } \\
\text { grains. }\end{array}$} & \\
\hline 11.0 & & & & \\
\hline 12.0 & & & & T II $-0.7 /-0.5$ \\
\hline 13.0 & & \multirow[t]{8}{*}{ SM } & \multirow[t]{8}{*}{$\begin{array}{l}\text { Sand, clear quartz, med-fine grain, subangular to angular } \\
\text { w/15\% rose quartz and chert ( } 5 \text { YR } 3 / 6 \text { ) grains. }\end{array}$} & $\begin{array}{l}\text { CGI 0/0 } \\
\text { RAD 0/0 }\end{array}$ \\
\hline 14.0 & & & & \\
\hline 15.0 & & & & \\
\hline 16.0 & & & & \\
\hline 17.0 & & & & T II $-0.9 /-0.8$ \\
\hline 18.0 & & & & CGI 0/0 \\
\hline 19.0 & & & & RAD $0 / 0$ \\
\hline 20.0 & & & & \\
\hline 21.0 & & \multirow[t]{4}{*}{ LST } & \multirow{4}{*}{$\begin{array}{l}\text { Limestone, gray ( } 2.5 \text { YR N6/0) to dark gray ( } 2.5 \text { YR N4/0), } \\
\text { hard w/fossil fragments. } \\
\text { - TOP OF WALNUT at } 20 \mathrm{ft} 9 \text { in. - }\end{array}$} & \\
\hline 22.0 & & & & T II $-1.0 /-0.7$ \\
\hline 23.0 & & & & CGI $0 / 0$ \\
\hline 24.0 & & & & $\mathrm{RAD} 0 / 0$ \\
\hline 25.0 & & \multirow[t]{6}{*}{ LST } & \multirow[t]{6}{*}{$\begin{array}{l}\text { Limestone, light gray to gray ( } 2.5 \text { YR N } 7 / 0 \text { to } 2.54 \mathrm{~N} 5 / 0 \text { ), } \\
\text { lithographic, w/1\% euhedral and subeuhedral calcite crystals. } \\
\text { Interbedded w/clay lenses, } 3-5 \text { in. thick, gray ( } 10 \text { YR } 5 / 1) \text {, } \\
\text { sandy, calcareous. }\end{array}$} & \\
\hline 26.0 & & & & \\
\hline 27.0 & & & & T II $-1.1 /-0.9$ \\
\hline 28.0 & & & & CGI $0 / 0$ \\
\hline 29.0 & & & & RAD 0/0 \\
\hline 30.0 & & & & \\
\hline & & & & \\
\hline
\end{tabular}




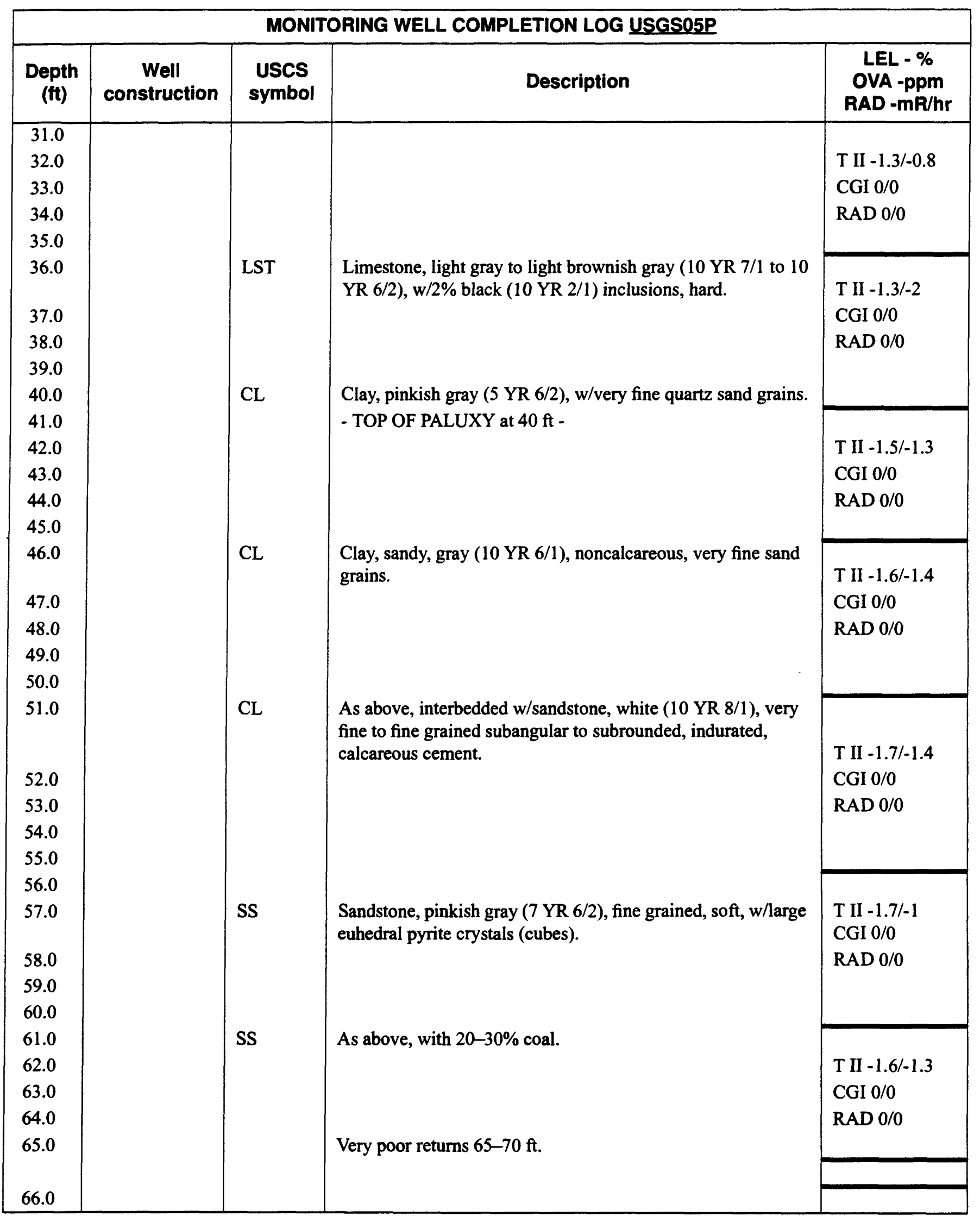




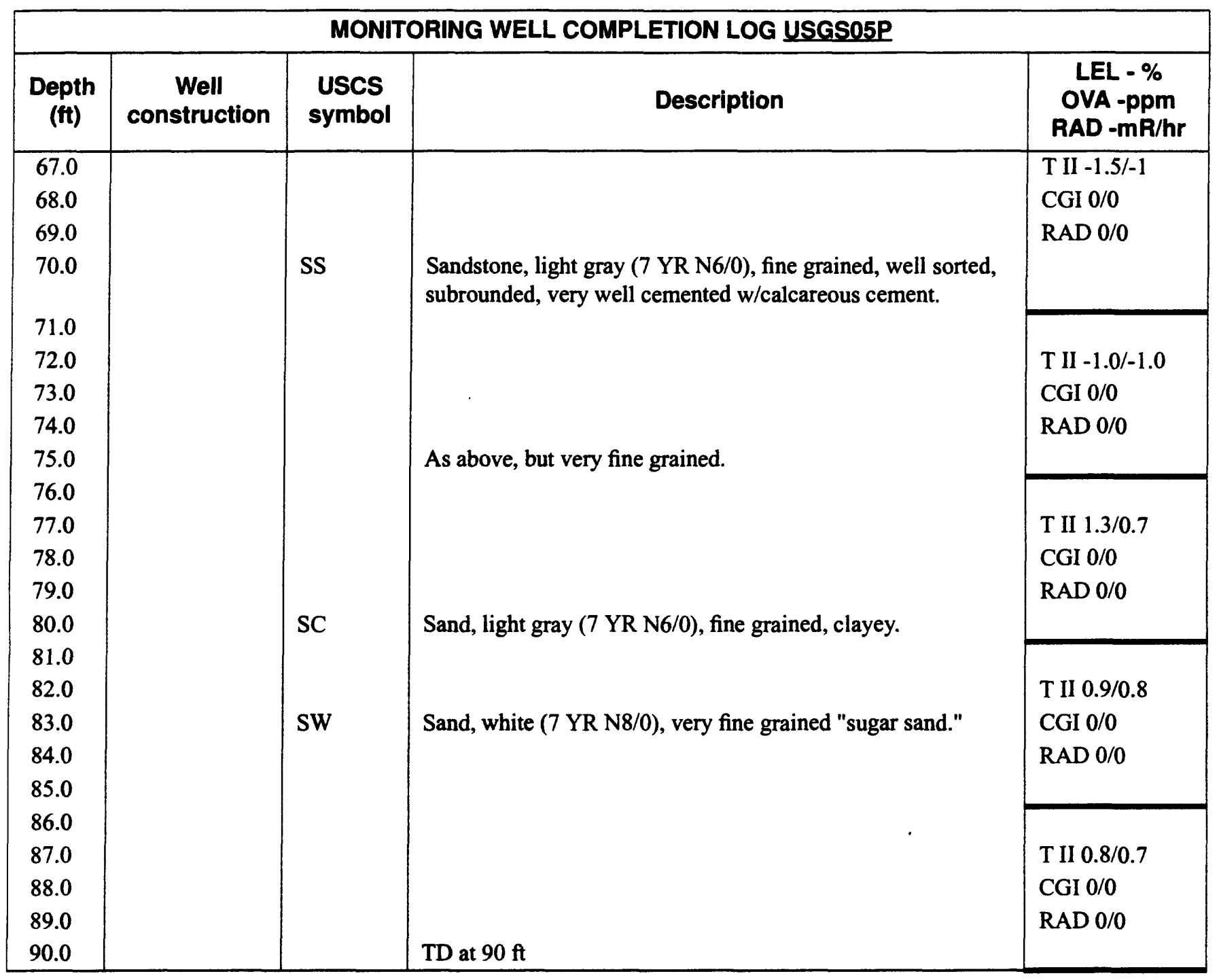


MONITORING WELL COMPLETION LOG

Driller: U.S. Geological Survey

Method: Mud rotary

Well no. USGS06P

Project: 464814700 NAS/AFP4

Hole no.: T4-C

\begin{tabular}{|c|c|c|c|}
\hline \multicolumn{4}{|c|}{ Location: NW of Bldg. 1024 , near the taxiway at Carswell AFB } \\
\hline Northing: & 6963771.976 & Easting: & 2297557.639 \\
\hline Ground elevation ( $\mathrm{ft} \mathrm{msl}$ ): & 606.57 & Lat/Long: & 3246020972546 \\
\hline Hole depth $(\mathrm{ft})$ : & 73.3 & How determined: & Survey \\
\hline MP height (ft): & 606.47 & Well depth (ft): & 73.3 \\
\hline Surface bit size (in.): & $97 / 8 \mathrm{OD}$ & MP description: & Inside edge of casing \\
\hline Below surface (in.): & $57 / 8 \mathrm{OD}$ & Slot size: & 0.020 \\
\hline Coring bit size (in.): & N/A & Reaming bit size (in.): & \\
\hline
\end{tabular}

\section{TYPE}

DIA

(in. OD)

Outer casing: PVC flush joint Tri-Lok

Blank casing: PVC flush joint Tri-Lok

Blank casing: PVC flush joint Tri-Lok

Screen: PVC slotted Tri-Lok, 0.020

End cap: PVC flush joint Tri-Lok

Surface seal: Pakmix concrete

Upper seal: Portland cement grout $w / 4-8 \%$

bentonite

Lower seal: volclay grout

Secondary sand pack: washed silica sand - 30-70

Primary sand pack: washed silica sand - 10-20

Date drilled: $12 / 13$ to $12 / 16 / 93$

$\begin{array}{llll}6.0 & 0 & \text { to } & 24.3 \\ 6.0 & -- & \text { to } & -- \\ 2.0 & 0 & \text { to } & 62.8 \\ 2.0 & \frac{62.8}{2} & \text { to } & 72.8 \\ 2.0 & \frac{72.8}{20} & \text { to } & 73.3 \\ 0.0 & 0 & \text { to } & 3 \\ & & & \end{array}$

\begin{tabular}{|c|c|c|c|}
\hline 0.0 & -- & to & -- \\
\hline 0.0 & 3 & to & 50 \\
\hline 0.0 & 50 & to & 54 \\
\hline 0.0 & 54 & to & 73.3 \\
\hline
\end{tabular}

Logged by: G.A. Rivers 


\begin{tabular}{|c|c|c|c|c|}
\hline \multicolumn{5}{|c|}{ MONITORING WELL COMPLETION LOG USGS05P } \\
\hline $\begin{array}{l}\text { Depth } \\
\text { (ft) }\end{array}$ & $\begin{array}{c}\text { Well } \\
\text { construction }\end{array}$ & $\begin{array}{l}\text { USCS } \\
\text { symbol }\end{array}$ & Description & $\begin{array}{l}\text { LEL - \% } \\
\text { OVA -ppm } \\
\text { RAD - } \mathbf{m R / h r}\end{array}$ \\
\hline $\begin{array}{l}0.0 \\
1.0 \\
2.0 \\
3.0 \\
4.0 \\
5.0\end{array}$ & & $\mathrm{OL}$ & $\begin{array}{l}\text { Topsoil, very dark brown (10 YR } 2 / 2) \text {, clayey and sandy. } \\
\text { Clay, strong brown ( } 7.5 \text { YR 5/8), w/very fine quartz grains, } \\
\text { calcareous. }\end{array}$ & $\begin{array}{l}\text { T II }-0.4 /-0.1 \\
\text { CGI } 0 / 0 \\
\text { RAD } 0 / 0\end{array}$ \\
\hline $\begin{array}{r}6.0 \\
7.0 \\
8.0 \\
9.0 \\
10.0\end{array}$ & & & As above, $w / 2 \%$ fine quartz sand grains. & $\begin{array}{l}\text { T II }-0.3 / 0 \\
\text { CGI } 0 / 0 \\
\text { RAD } 0 / 0\end{array}$ \\
\hline $\begin{array}{l}13.0 \\
14.0 \\
15.0\end{array}$ & & $\mathrm{CL}$ & $\begin{array}{l}\text { Clay, strong brown ( } 7.5 \text { YR } 5 / 8) \text {, w/50\% quartz sand grains } \\
\text { (fine) and red (10 YR } 4 / 8) \text { sand grains; grains are subangular to } \\
\text { rounded, some frosted. }\end{array}$ & $\begin{array}{l}\text { T II }-0.8 /-0.1 \\
\text { CGI } 0 / 0 \\
\text { RAD } 0 / 0\end{array}$ \\
\hline $\begin{array}{l}16.0 \\
17.0 \\
18.0 \\
19.0 \\
20.0\end{array}$ & & SP & $\begin{array}{l}\text { Sandstone, coarse, poorly sorted, subangular to subrounded } \\
\text { grains, contains grains of agate, chert, clear and rose quartz. }\end{array}$ & $\begin{array}{l}\text { T II }-0.7 /-0.5 \\
\text { CGI } 0 / 0 \\
\text { RAD } 0 / 0\end{array}$ \\
\hline $\begin{array}{l}21.0 \\
22.0 \\
23.0 \\
24.0\end{array}$ & & & $\begin{array}{l}\text { As above, w/few fine gravel grains. } \\
\text { Top of Walnut at } 24.3 \mathrm{ft} \text {-Limestone, mottled light gray ( } 7.5 \mathrm{YR} \\
7 . / 0 \text { ) to dark gray ( } 7.5 \mathrm{YR} \mathrm{N} 4 / 0 \text { ), dense, fossils. }\end{array}$ & $\begin{array}{l}\text { TI }-0.7 /-0.3 \\
\text { CGI } 0 / 0 \\
\text { RAD 0/0 }\end{array}$ \\
\hline 25.0 & & & & \\
\hline $\begin{array}{l}26.0 \\
27.0 \\
28.0 \\
29.0 \\
30.0\end{array}$ & & & As above, well indurated, w/crystalline calcite inclusions. & $\begin{array}{l}\text { T II } 1.4 / 1.7 \\
\text { CGI } 0 / 0 \\
\text { RAD } 0 / 0\end{array}$ \\
\hline $\begin{array}{l}31.0 \\
32.0 \\
33.0 \\
34.0 \\
35.0\end{array}$ & & & & \\
\hline
\end{tabular}




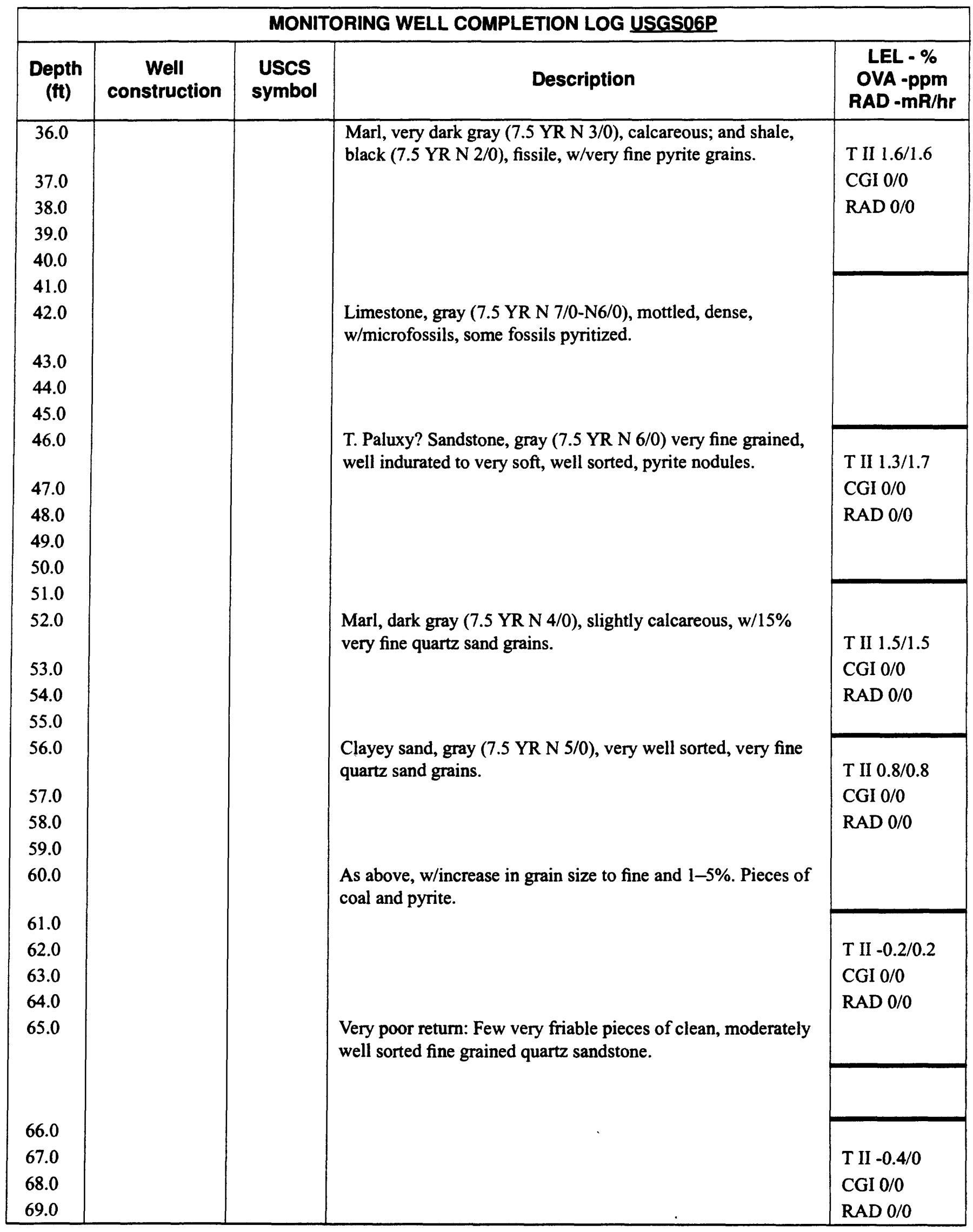




\begin{tabular}{|c|c|c|c|c|}
\hline \multicolumn{5}{|c|}{ MONITORING WELL COMPLETION LOG USGS06P } \\
\hline $\begin{array}{l}\text { Depth } \\
\text { (ft) }\end{array}$ & $\begin{array}{c}\text { Well } \\
\text { construction }\end{array}$ & $\begin{array}{c}\text { USCS } \\
\text { symbol }\end{array}$ & Description & $\begin{array}{c}\text { LEL - \% } \\
\text { OVA -ppm } \\
\text { RAD -mR/hr }\end{array}$ \\
\hline 70.0 & & & As above, w/coal and pyrite. & \\
\hline 71.0 & & & & \\
\hline 72.0 & & & & \\
\hline 73.0 & & & TD $73.3 \mathrm{ft}$. & \\
\hline 74.0 & & & & \\
\hline 75.0 & & & & \\
\hline
\end{tabular}


Driller: U.S. Geological Survey

Method: Hollow Stem Auger

Well no. USGS06T

\section{Project: 464814700 NAS/AFP4}

Location: East side of taxiway

Northing:

Ground elevation ( $\mathrm{ft} \mathrm{msl):}$

Hole depth (ft):

MP height (ft):

Hollow-stem auger size (in.):

Auger head size (in.):

Coring bit size (in.):
Hole no.: T4-A

\begin{tabular}{|c|c|c|}
\hline 6963763.623 & Easting: & 2297541.330 \\
\hline 606.64 & Lat/Long: & 3246020972546 \\
\hline$\overline{21.5}$ & How determined: & Survey \\
\hline 606.49 & Well depth (ft): & 22.5 \\
\hline $85 / 8 \mathrm{ID} \times 4 \mathrm{l} / 4 \mathrm{OD}$ & MP description: & Inside edge of casing \\
\hline $85 / 8 / 41 / 4 \mathrm{ID} / \mathrm{OD}$ & Slot size: & 0.020 \\
\hline N/A & Reaming bit size (in.): & $85 / 8$ \\
\hline
\end{tabular}

\begin{tabular}{|c|c|c|c|c|}
\hline TYPE & $\begin{array}{c}\text { DIA } \\
\text { (in. OD) }\end{array}$ & \multicolumn{3}{|c|}{$\begin{array}{l}\text { INTERVAL } \\
\text { (ft) }\end{array}$} \\
\hline Outer casing: PVC flush joint Tri-Lok & & N/A & to & N/A \\
\hline Blank casing: PVC flush joint Tri-Lok & 10.0 & -- & to & -- \\
\hline Blank casing: PVC flush joint Tri-Lok & 2.0 & 0 & to & 12 \\
\hline Screen: PVC slotted Tri-Lok, 0.020 & 2.0 & 12 & to & 22 \\
\hline End cap: PVC flush joint Tri-Lok & 2.0 & 22 & to & 22.5 \\
\hline Surface seal: concrete & 0.0 & 0 & to & 2.5 \\
\hline Upper seal: cement grout $w / 4-8 \%$ bentonite & 0.0 & N/A & to & N/A \\
\hline Lower seal: bentonite grout & 0.0 & 2.5 & to & 8 \\
\hline Secondary sand pack: washed silica sand $-30-70$ & 0.0 & 8 & to & 11 \\
\hline Primary sand pack: washed silica sand - 10-20 & 0.0 & 11 & to & 22.5 \\
\hline Date drilled: $11 / 13 / 93$ at 1215 & \multicolumn{4}{|c|}{ Logged by: J.R. Bartolino } \\
\hline
\end{tabular}




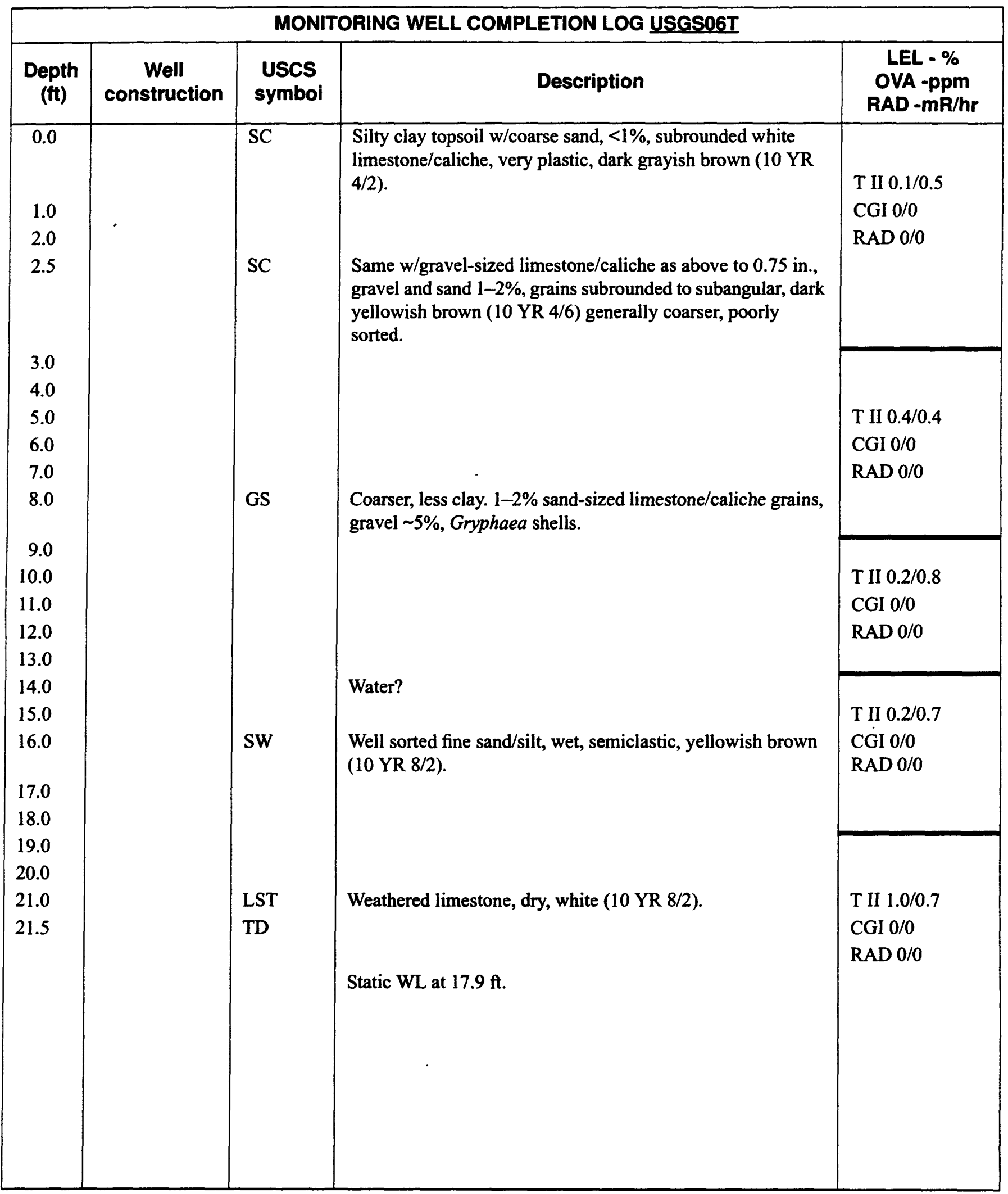


Driller: U.S. Geoiogicai Survey

Method: Mud rotary

Well no. USGSO7P

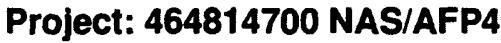

Hole no.: P6-C

Location: East edge of taxiway east of main runway

Northing:

\begin{tabular}{l}
6960150.744 \\
\hline 632.48 \\
\hline 140 \\
\hline 632.06 \\
\hline $97 / 8$ OD \\
\hline $57 / 8$ OD \\
\hline N/A
\end{tabular}

Easting:

2295249.942

Ground elevation ( $\mathrm{ft} \mathrm{msl):}$

Lat/Long:

3245270972613

Hole depth (ft):

MP height ( $\mathrm{ft}$ ):

Surface bit size (in.):

Below surface (in.):

Coring bit size (in.):

How determined:

Well depth (ft):

Survey

MP description:

140

Slot size:

Top of 2-in PVC riser

0.020

Reaming bit size (in.):

\section{TYPE}

Outer casing: PVC flush joint Tri-Lok

Blank casing: PVC flush joint Tri-Lok (surface)

Blank casing: PVC flush joint Tri-Lok

Screen: PVC slotted Tri-Lok, 0.020

End cap: PVC flush joint Tri-Lok

Surface seal: Pakmix concrete

Upper seal: cement grout $\mathrm{w} / 4-8 \%$ bentonite

Lower seal: volclay grout

Secondary sand pack: washed silica sand - 30-70

Primary sand pack: washed silica sand - 10-20

Date drilled: $12 / 16$ to $12 / 18 / 93$

\section{DIA INTERVAL}

(in. OD)

(ft)

\begin{tabular}{|c|c|c|c|}
\hline & & \multicolumn{2}{|l|}{ to } \\
\hline & 0 & to & 17.5 \\
\hline 2.0 & 0 & to & 117 \\
\hline 2.0 & 117 & to & 139.5 \\
\hline 2.0 & 139.5 & to & 140 \\
\hline 0.0 & 0 & to & 3 \\
\hline 0.0 & & to & N/A \\
\hline 0.0 & 3 & to & 102 \\
\hline 0.0 & 102 & to & 108 \\
\hline 0.0 & 108 & to & 140 \\
\hline
\end{tabular}

Logged by: G.A. Rivers 


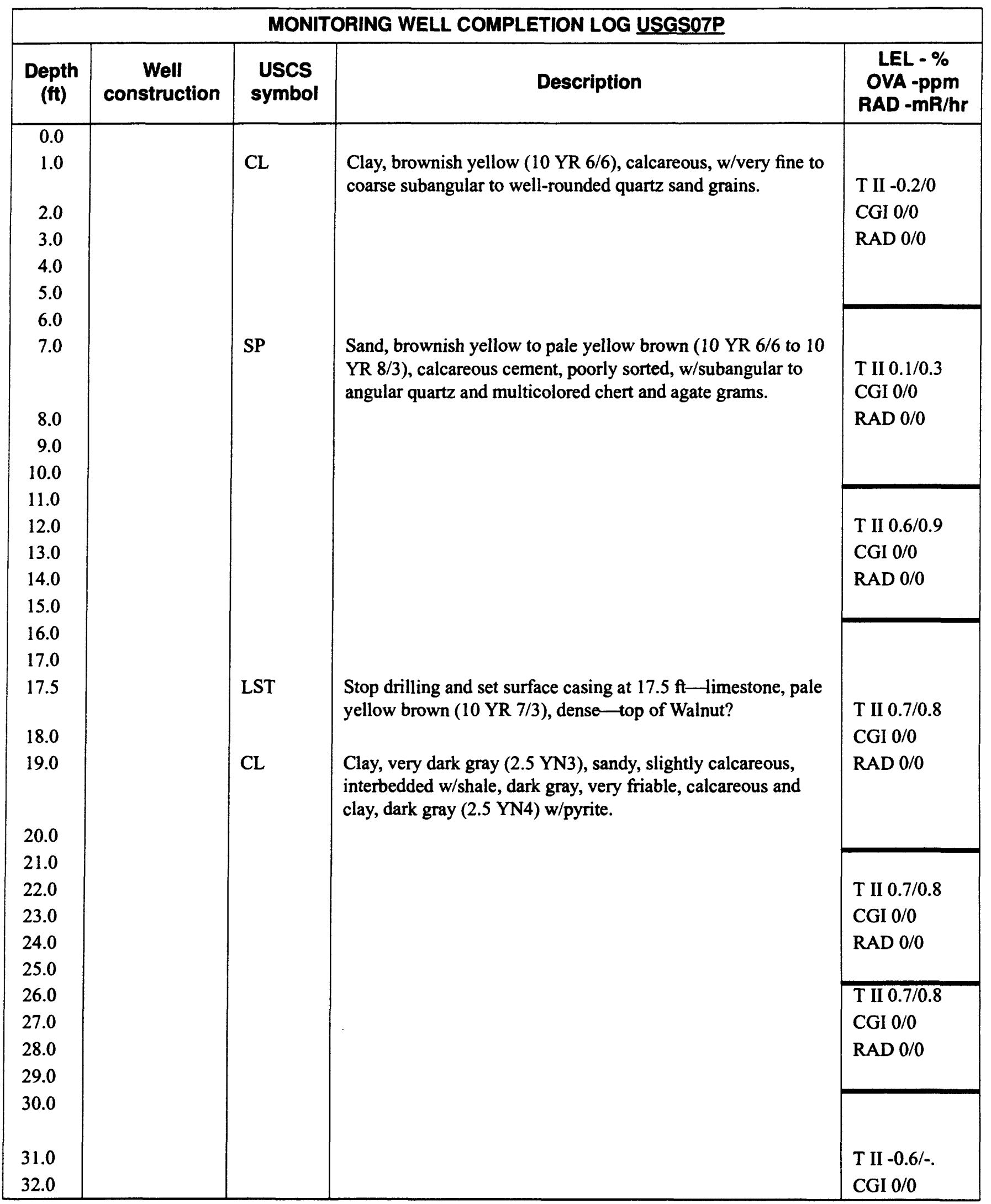




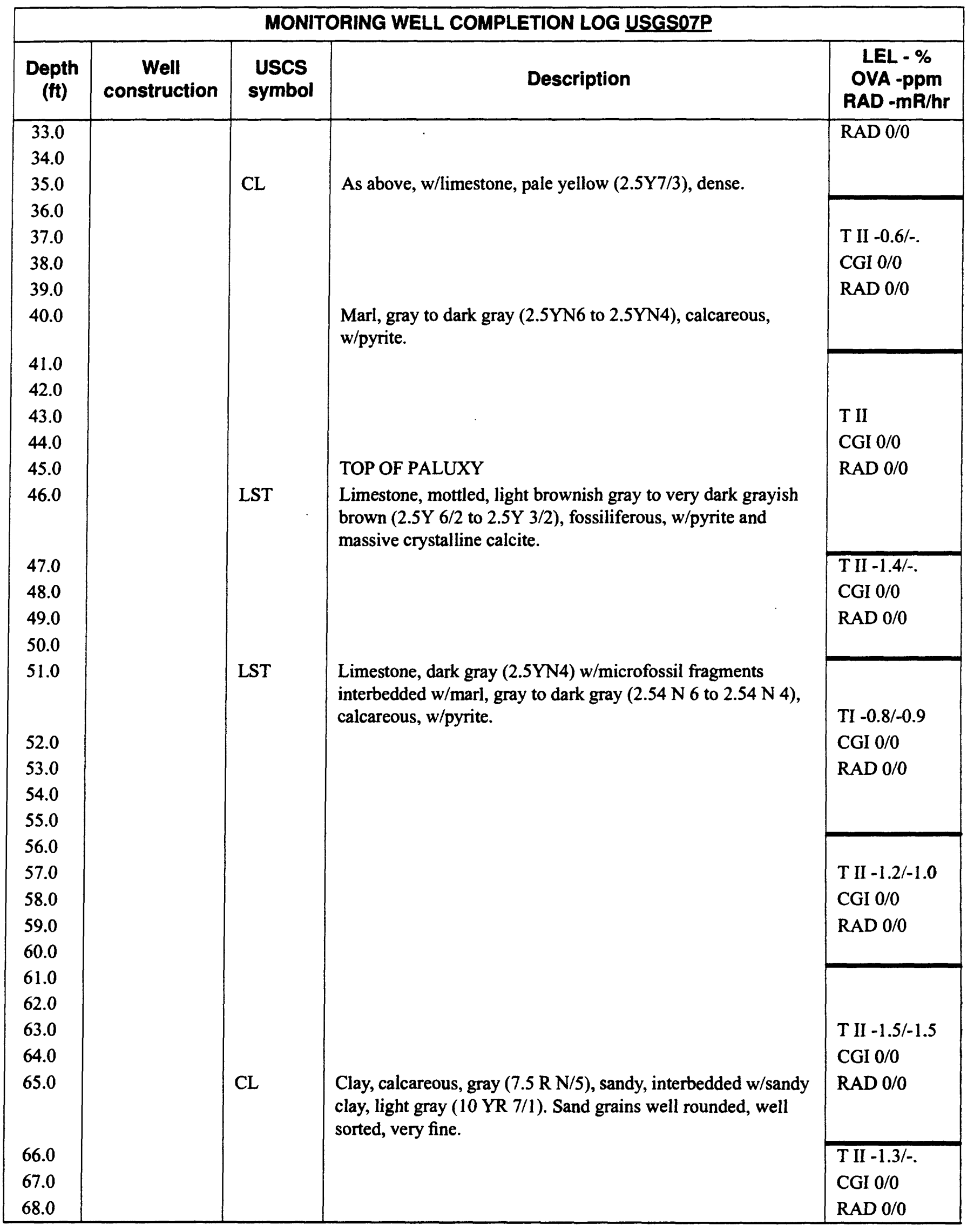




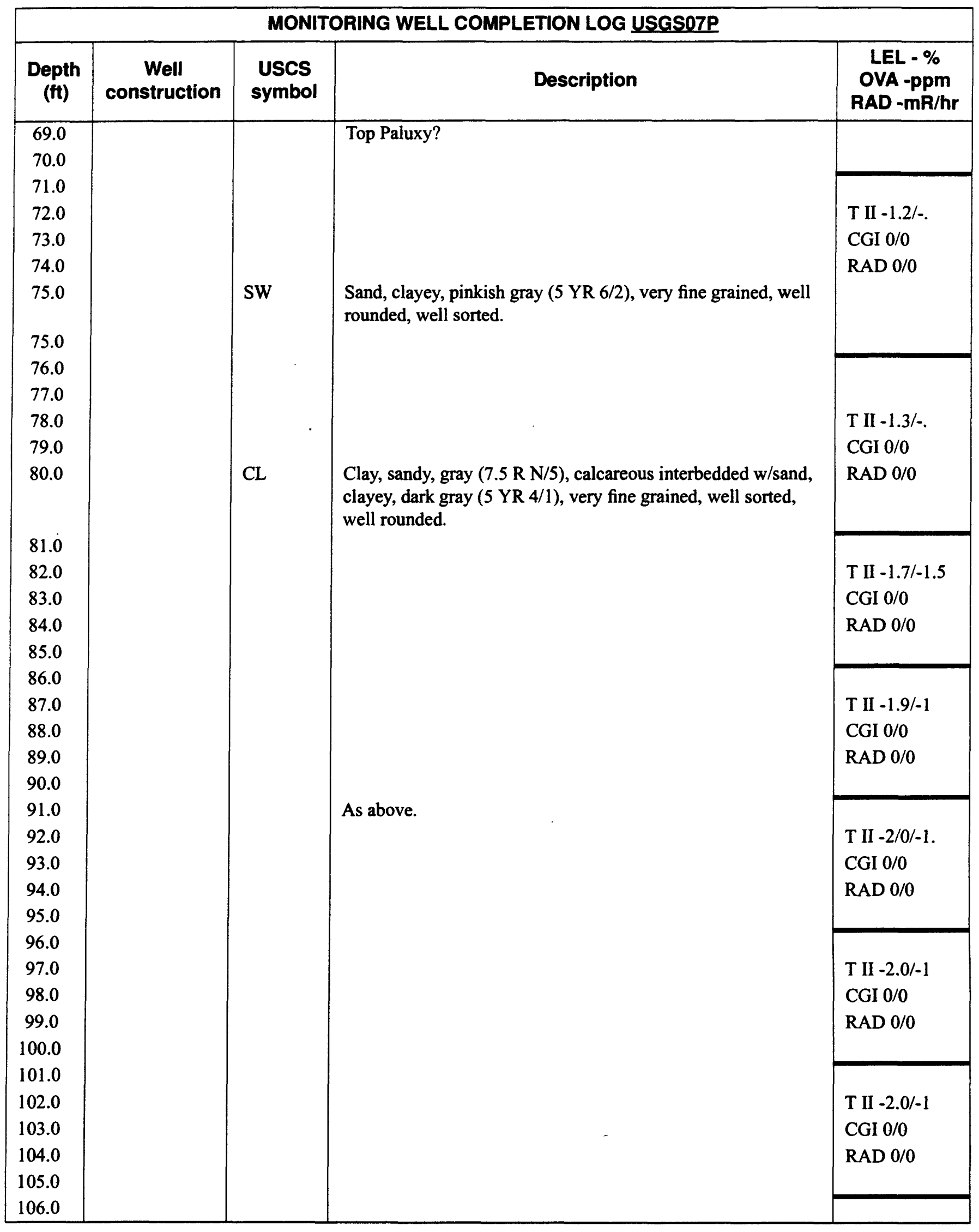




\begin{tabular}{|c|c|c|c|c|}
\hline \multicolumn{5}{|c|}{ MONITORING WELL COMPLETION LOG USGSO7P } \\
\hline $\begin{array}{l}\text { Depth } \\
\text { (ft) }\end{array}$ & $\begin{array}{c}\text { Well } \\
\text { construction }\end{array}$ & $\begin{array}{l}\text { USCS } \\
\text { symbol }\end{array}$ & Description & $\begin{array}{c}\text { LEL - \% } \\
\text { OVA -ppm } \\
\text { RAD - mR/hr }\end{array}$ \\
\hline $\begin{array}{l}107.0 \\
108.0 \\
109.0 \\
110.0\end{array}$ & & & 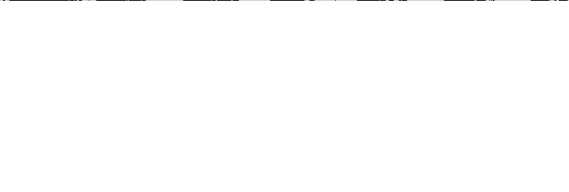 & $\begin{array}{l}\text { T II }-2.0 /-1 \\
\text { CGI } 0 / 0 \\
\text { RAD 0/0 }\end{array}$ \\
\hline $\begin{array}{l}111.0 \\
112.0 \\
113.0 \\
114.0 \\
115.0\end{array}$ & & & & $\begin{array}{l}\text { T II }-2.0 /-1.8 \\
\text { CGI } 0 / 0 \\
\text { RAD } 0 / 0\end{array}$ \\
\hline $\begin{array}{l}116.0 \\
117.0 \\
118.0 \\
119.0 \\
120.0\end{array}$ & & & & $\begin{array}{l}\text { T II }-2.0 /-1 \\
\text { CGI } 0 / 0 \\
\text { RAD 0/0 }\end{array}$ \\
\hline $\begin{array}{l}121.0 \\
122.0 \\
123.0 \\
124.0 \\
125.0\end{array}$ & & & & $\begin{array}{l}\text { T II }-1.8 /-1 \\
\text { RAD 0/0 } \\
\text { CGI } 0 / 0\end{array}$ \\
\hline $\begin{array}{l}126.0 \\
127.0 \\
128.0 \\
129.0 \\
130.0\end{array}$ & & & & $\begin{array}{l}\text { T II }-1.8 /-1 \\
\text { CGI } 0 / 0 \\
\text { RAD 0/0 }\end{array}$ \\
\hline $\begin{array}{l}131.0 \\
132.0 \\
133.0 \\
134.0 \\
135.0\end{array}$ & & & As above. & $\begin{array}{l}\text { T II }-1.7 /-1 \\
\text { CGI 0/0 } \\
\text { RAD 0/0 }\end{array}$ \\
\hline $\begin{array}{l}136.0 \\
137.0 \\
138.0 \\
139.0 \\
140.0\end{array}$ & & & TD at $140 \mathrm{ft}$. & $\begin{array}{l}\text { T II }-1.8 /-1 \\
\text { CGI } 0 / 0 \\
\text { RAD 0/0 }\end{array}$ \\
\hline
\end{tabular}




\section{MONITORING WELL COMPLETION LOG}

Driller: U.S. Geological Survey

Method: Hollow Stem Auger

Well no. USGSOTT

Project: 464814700 NAS/AFP4

Hole no.: P6-A (Terrace)

Location: East side of taxiway, near old radar range

Northing:

Ground elevation ( $\mathrm{ft} \mathrm{msl}$ ):

Hole depth (ft):

MP height ( $\mathrm{ft}$ ):

Hollow-stem auger size (in.):

Auger head size (in.):

Coring bit size (in.):

\begin{tabular}{l}
6960168.206 \\
\hline 632.52 \\
\hline 16.5 \\
\hline 632.45 \\
\hline $85 / 8$ ID $\times 4$ I/4 OD \\
\hline $85 / 8 / 41 / 4$ ID/OD \\
\hline N/A
\end{tabular}

\section{Easting:}

Lat/Long:

How determined:

Well depth (ft):

MP description:

Slot size:

Reaming bit size (in.):

\begin{tabular}{l}
\hline 2295245.799 \\
\hline 3245270972613 \\
\hline Survey \\
\hline 16.5 \\
\hline Inside edge of 2-in. casing \\
\hline 0.020 \\
\hline $85 / 8$
\end{tabular}

\begin{tabular}{|c|c|c|c|c|}
\hline TYPE & $\begin{array}{c}\text { DIA } \\
\text { (In. OD) }\end{array}$ & \multicolumn{3}{|c|}{$\begin{array}{l}\text { INTERVAL } \\
\text { (ft) }\end{array}$} \\
\hline Outer casing: PVC flush joint Tri-Lok & & N/A & to & N/A \\
\hline Blank casing: PVC flush joint Tri-Lok & 10.0 & $\overline{\mathrm{N} / \mathrm{A}}$ & to & N/A \\
\hline Blank casing: PVC flush joint Tri-Lok & 2.0 & 0 & to & 11 \\
\hline Screen: PVC slotted Tri-Lok, 0.020 & 2.0 & 11 & to & 16 \\
\hline End cap: PVC flush joint Tri-Lok & 2.0 & 16 & to & 16.5 \\
\hline Surface seal: concrete & 0.0 & 0 & to & 3 \\
\hline Upper seal: cement grout $w / 4-8 \%$ bentonite & 0.0 & - & to & -- \\
\hline Lower seal: bentonite grout & 0.0 & 3 & to & 6.5 \\
\hline Secondary sand pack: washed silica sand - 30-70 & 0.0 & 6.5 & to & 9.5 \\
\hline Primary sand pack: washed silica sand - 10-20 & 0.0 & 9.5 & to & 16.5 \\
\hline Date drilled: $11 / 12 / 93$ at 1010 & \multicolumn{4}{|c|}{ Logged by: J.R. Bartolino } \\
\hline
\end{tabular}




\begin{tabular}{|c|c|c|c|c|}
\hline \multicolumn{5}{|c|}{ MONITORING WELL COMPLETION LOG USGSOTT } \\
\hline $\begin{array}{l}\text { Depth } \\
\text { (ft) }\end{array}$ & $\begin{array}{c}\text { Well } \\
\text { construction }\end{array}$ & $\begin{array}{l}\text { USCS } \\
\text { symbol }\end{array}$ & Description & $\begin{array}{c}\text { LEL - \% } \\
\text { OVA -ppm } \\
\text { RAD - mR/hr }\end{array}$ \\
\hline $\begin{array}{l}1.0 \\
2.0 \\
2.5 \\
3.0\end{array}$ & & SC & $\begin{array}{l}\text { Sandy to silty clay, poorly sorted, }<1 \% \text { white subangular } \\
\text { caliche/limestone, grains to coarse sand size, damp, very } \\
\text { plastic, reddish yellow ( } 7.5 \text { YR } 6 / 6) \text {. }\end{array}$ & $\begin{array}{l}\text { T II } 0 / 0.1 \\
\text { CGI } 0 / 0 \\
\text { RAD } 0 / 0\end{array}$ \\
\hline 4.0 & & & & \\
\hline 5.0 & & & & T II $0 / 0.2$ \\
\hline 6.0 & & & & CGI $0 / 0$ \\
\hline 7.0 & & & & RAD 0/0 \\
\hline 8.0 & & & & \\
\hline 9.0 & & & & \\
\hline 10.0 & & & & T II $0 / 0$ \\
\hline 11.0 & & & & CGI $0 / 0$ \\
\hline 12.0 & & & & $\mathrm{RAD} 0 / 0$ \\
\hline 13.0 & & & & \\
\hline 14.0 & & & & \\
\hline 14.5 & & & Water? & \\
\hline 15.0 & & GC & $\begin{array}{l}\text { Weathered limestone gravel, subangular to angular, gravel to } \\
11 / 4 \text { in. white }(2.5 \text { YR } 2 / 2) \text {. }\end{array}$ & $\begin{array}{l}\text { T II }-0.1 / 0.1 \\
\text { CGI } 0 / 0\end{array}$ \\
\hline 16.0 & & LST & Competent limestone white (2.5 YR 2/2), dry. & RAD 0/0 \\
\hline 16.5 & & & & \\
\hline
\end{tabular}




\section{MONITORING WELL COMPLETION LOG}

Driller: U.S. Geological Survey

Method: Mud rotary

Well no. USGS08PL

Project: 464814700 NAS/AFP4

Hole no.: P1-L

\begin{tabular}{|c|c|c|c|}
\hline \multicolumn{4}{|c|}{ Location: On Shoreview Dr. across intersection with Killdeer } \\
\hline Northing: & 6968817.36 & Easting: & 2288965.88 \\
\hline Ground elevation ( $\mathrm{ft} \mathrm{msl}$ ): & 636.71 & Lat/Long: & 3246530972726 \\
\hline Hole depth (ft): & 203 & How determined: & Survey and P1-4 \\
\hline MP height (ft): & 638.71 & Well depth (ft): & 203 \\
\hline Surface bit size (in.): & $97 / 8 \mathrm{OD}$ & MP description: & Top of 2-in. PVC riser \\
\hline Below surface (in.): & $57 / 8 \mathrm{OD}$ & Slot size: & 0.020 \\
\hline Coring bit size (in.): & & Reaming bit size (in.): & \\
\hline
\end{tabular}

\begin{tabular}{|c|c|c|c|c|}
\hline TYPE & $\begin{array}{c}\text { DIA } \\
\text { (in. OD) }\end{array}$ & \multicolumn{3}{|c|}{$\begin{array}{l}\text { INTERVAL } \\
\text { (ft) }\end{array}$} \\
\hline Outer casing: PVC flush joint Tri-Lok & & & to & \\
\hline Blank casing: PVC flush joint Tri-Lok & 2.0 & 0 & to & 152.5 \\
\hline Blank casing: PVC flush joint Tri-Lok & 2.0 & 182.5 & to & 202.5 \\
\hline Screen: PVC slotted Tri-Lok, 0.020 & 2.0 & 152.5 & to & 182.5 \\
\hline End cap: PVC flush joint Tri-Lok & 2.0 & 202.5 & to & 203 \\
\hline Surface seal: concrete & 0.0 & 0 & to & 3 \\
\hline Upper seal: cement grout $w / 4-8 \%$ bentonite & 0.0 & & to & N/A \\
\hline Lower seal: bentonite grout & 0.0 & 3 & to & 138 \\
\hline Secondary sand pack: washed silica sand - 30-70 & 0.0 & 138 & to & 144 \\
\hline Primary sand pack: washed silica sand - 10-20 & 0.0 & 144 & to & 203 \\
\hline Date drilled: $1 / 8 / 94$ to $1 / 10 / 94$ & Log & 1 oy: & A. Ri & \\
\hline
\end{tabular}

Depth to water $53.641 / 10 / 94$ 


\begin{tabular}{|c|c|c|c|c|}
\hline \multicolumn{5}{|c|}{ MONITORING WELL COMPLETION LOG USGSO8PL } \\
\hline $\begin{array}{l}\text { Depth } \\
\text { (ft) }\end{array}$ & $\begin{array}{c}\text { Well } \\
\text { construction }\end{array}$ & $\begin{array}{l}\text { USCS } \\
\text { symbol }\end{array}$ & Description & $\begin{array}{c}\text { LEL - \% } \\
\text { OVA -ppm } \\
\text { RAD - mR/hr }\end{array}$ \\
\hline 0.0 & & LST & Limestone, gray (5 YR 6/1), fossiliferous. & \\
\hline 1.0 & & & Dense. & \\
\hline 2.0 & & & Clay, reddish brown (2.5 YR 6/4) moist. & \\
\hline 2.5 & & & & \\
\hline 3.0 & & & & \\
\hline 4.0 & & LST & $\begin{array}{l}\text { Limestone, pinkish white to reddish yellow ( } 5 \text { YR } 8 / 2 \text { to } 5 \\
\text { YR 6/8) dense. }\end{array}$ & \\
\hline 5.0 & & & & \\
\hline 6.0 & & & & \\
\hline 7.0 & & LST & $\begin{array}{l}\text { Limestone, gray to very dark gray ( } 2.5 \mathrm{YR} \text { N6/0 to } 2.5 \mathrm{YR} \\
\mathrm{N} 3 / 0 \text { ), dense, fossiliferous. }\end{array}$ & \\
\hline 8.0 & & & & \\
\hline 9.0 & & & & \\
\hline 10.0 & & & $\begin{array}{l}\text { Limestone, gray ( } 2.5 \text { YR N6/0), very dense with microscopic } \\
\text { black ( } 2.5 \text { YR N2.5/0), inclusions. }\end{array}$ & \\
\hline 11.0 & & & & \\
\hline 12.0 & & & & \\
\hline 13.0 & & & & \\
\hline 14.0 & & & & \\
\hline 15.0 & & & & \\
\hline 16.0 & & LST & $\begin{array}{l}\text { Limestone, white ( } 10 \text { YR } 8 / 1) \text { with } 50 \% \text { black ( } 2.5 \mathrm{YR} \\
\mathrm{N} 2.5 / 0 \text { ) inclusions and a few euhedral pyrite crystals. }\end{array}$ & \\
\hline 17.0 & & & & \\
\hline 18.0 & & & & \\
\hline 19.0 & & & & \\
\hline 20.0 & & & & \\
\hline 21.0 & & & & \\
\hline 22.0 & & & & \\
\hline 23.0 & & & & \\
\hline 24.0 & & & & \\
\hline 25.0 & & & & \\
\hline 26.0 & & & & \\
\hline 27.0 & & & & \\
\hline 28.0 & & & & \\
\hline 29.0 & & SS & $\begin{array}{l}\text { Top of Paluxy, sandstone, light reddish brown ( } 2.5 \text { YR } 6 / 4) \\
\text { with red inclusions ( } 2.5 \text { YR } 5 / 8) \text {, very fine grained, well } \\
\text { rounded, well sorted also lots of pyrite and dark reddish } \\
\text { brown ( } 2.5 \text { YR } 3 / 3 \text { ) iron nodules. }\end{array}$ & \\
\hline 30.0 & & SW & $\begin{array}{l}\text { Sand, light reddish brown ( } 2.5 \text { YR } 6 / 4 \text { ) very fine grained, } \\
\text { well sorted, subrounded clear quartz grains. }\end{array}$ & \\
\hline
\end{tabular}




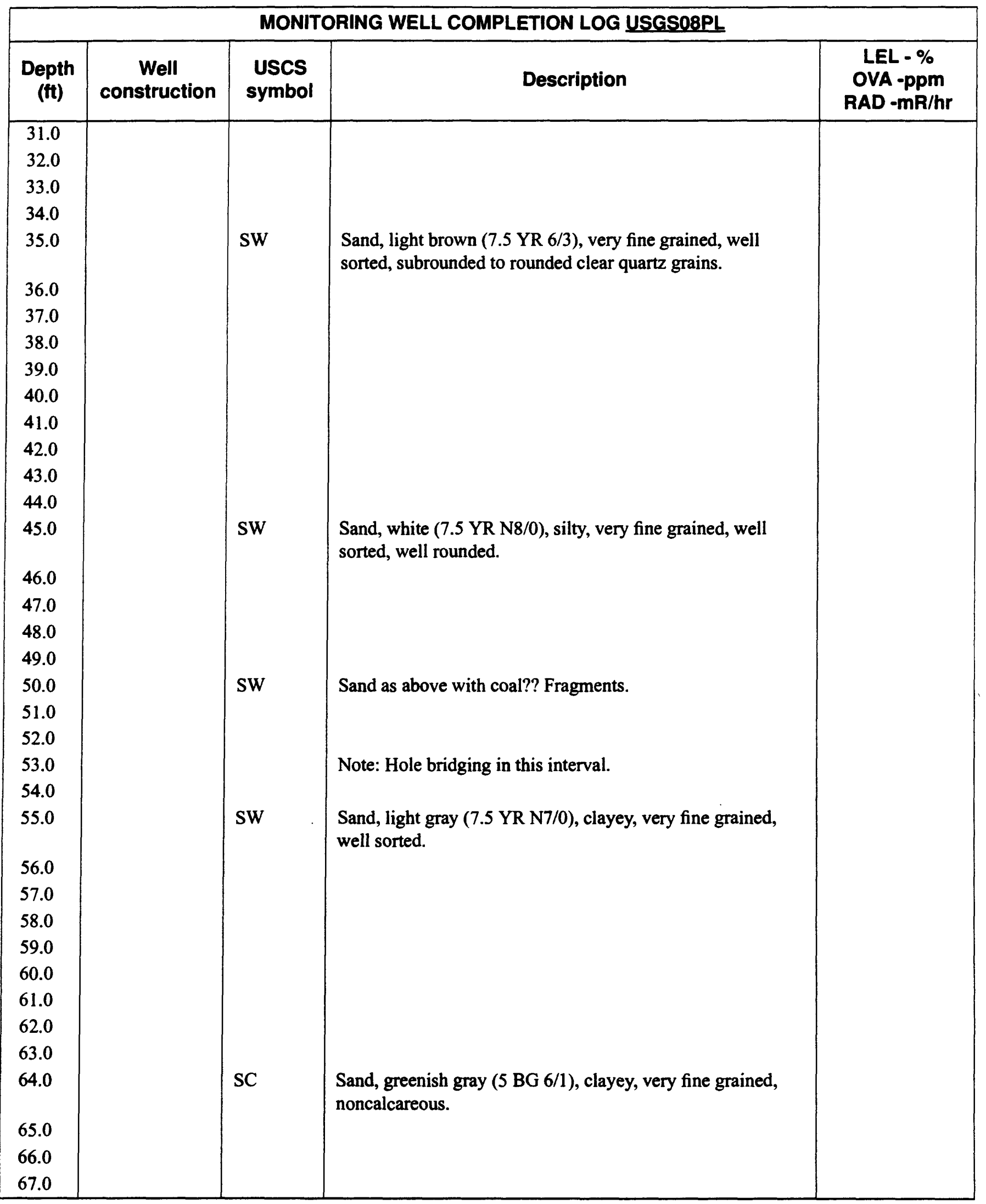




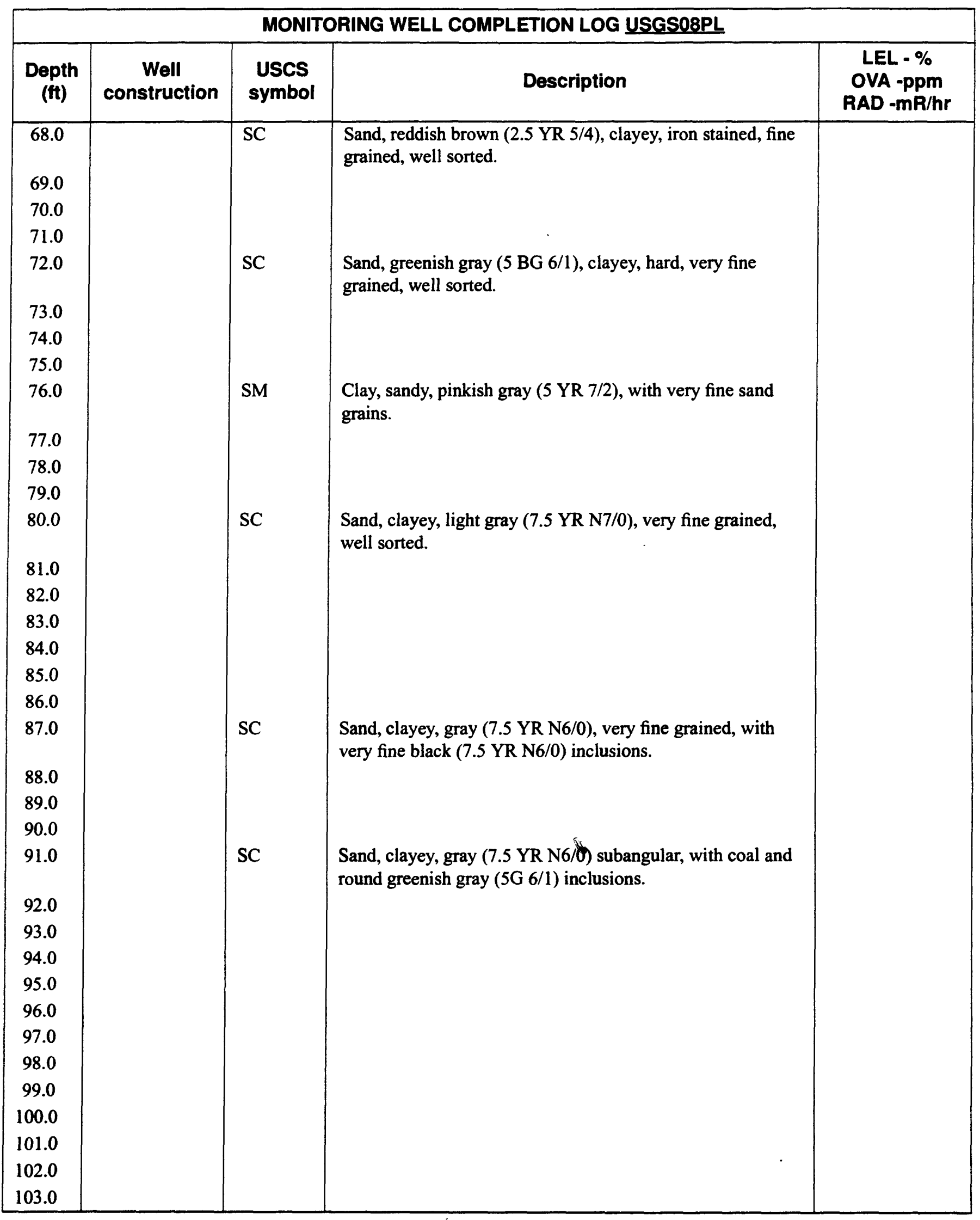




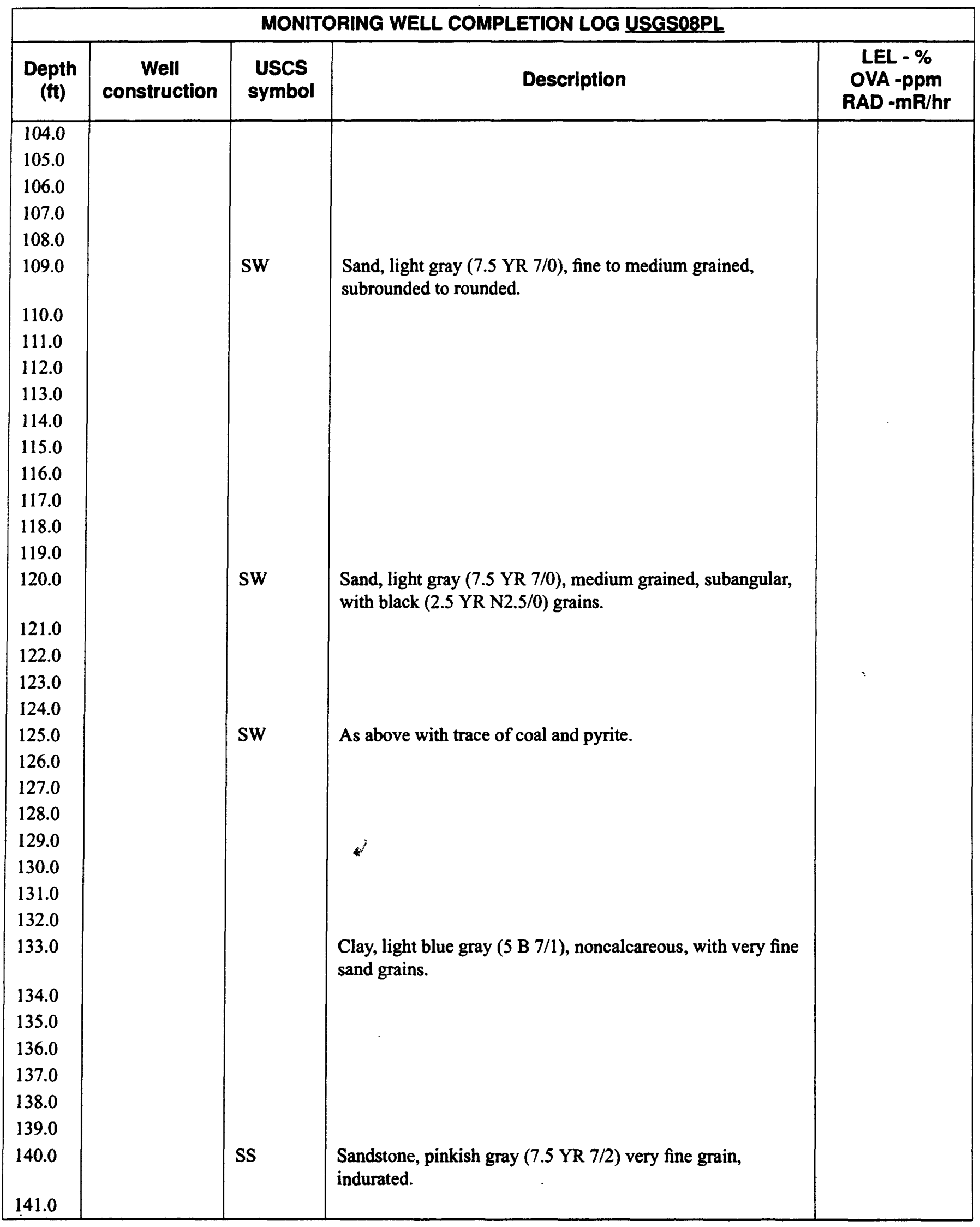




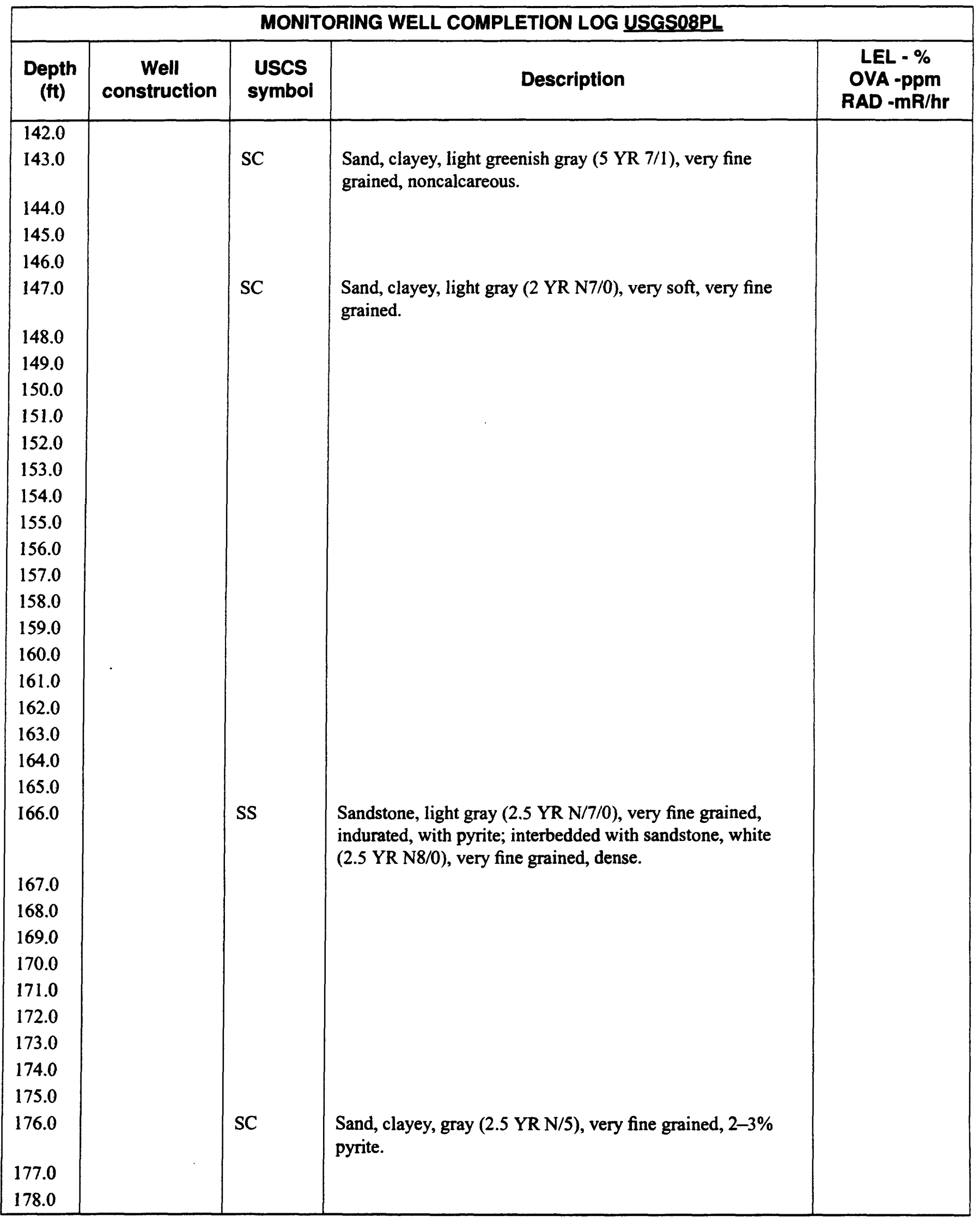




\begin{tabular}{|c|c|c|c|c|}
\hline \multicolumn{5}{|c|}{ MONITORING WELL COMPLETION LOG USGS08PL } \\
\hline $\begin{array}{l}\text { Depth } \\
\text { (ft) }\end{array}$ & $\begin{array}{c}\text { Well } \\
\text { construction }\end{array}$ & $\begin{array}{l}\text { USCS } \\
\text { symbol }\end{array}$ & Description & $\begin{array}{c}\text { LEL - \% } \\
\text { OVA -ppm } \\
\text { RAD - mR/hr }\end{array}$ \\
\hline $\begin{array}{l}179.0 \\
180.0 \\
181.0 \\
182.0 \\
183.0 \\
184.0 \\
185.0 \\
186.0 \\
187.0 \\
188.0 \\
189.0 \\
190.0 \\
191.0 \\
192.0 \\
193.0 \\
194.0 \\
195.0 \\
196.0 \\
197.0 \\
198.0 \\
199.0 \\
200.0 \\
201.0 \\
202.0 \\
203.0 \\
204.0 \\
205.0\end{array}$ & & $\begin{array}{l}\text { SH } \\
\text { LST }\end{array}$ & (1) & $\cdot$ \\
\hline
\end{tabular}




\section{MONITORING WELL COMPLETION LOG}

Drilier: U.S. Geological Survey

Method: Mud rotary

Well no. USGS08PM

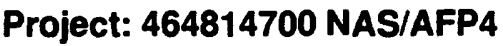

Hole no.: P1-M

Location: On Shoreview Dr. across intersection with Killdeer

Northing:

6968817.360

Ground elevation ( $\mathrm{ft} \mathrm{msl}$ ):

636.74

Easting:

2288944.883

Hole depth (ft):

MP height ( $\mathrm{ft}$ ):

Surface bit size (in.):

Below surface (in.):

Coring bit size (in.):

127 How determined

3246530972726

638.57 Well depth (ft):

97/8 OD MP description:

$57 / 8$ OD Slot size:

Reaming bit size (in.):

\begin{tabular}{l}
\hline Survey \\
\hline 127 \\
\hline Top of 2-in. PVC riser \\
\hline 0.020 \\
\hline
\end{tabular}

\begin{tabular}{|c|c|c|c|c|}
\hline TYPE & $\begin{array}{c}\text { DIA } \\
\text { (in. OD) }\end{array}$ & \multicolumn{3}{|c|}{$\begin{array}{l}\text { INTERVAL } \\
\text { (ft) }\end{array}$} \\
\hline Outer casing: PVC flush joint Tri-Lok & & & to & \\
\hline Blank casing: PVC flush joint Tri-Lok & 6.0 & & to & N/A \\
\hline Blank casing: PVC flush joint Tri-Lok & 2.0 & 0 & to & 106.5 \\
\hline Screen: PVC slotted Tri-Lok, 0.020 & 2.0 & 106.5 & to & 126.5 \\
\hline End cap: PVC flush joint Tri-Lok & 2.0 & 126.5 & to & 127 \\
\hline Surface seal: Pakmix concrete & 0.0 & 0 & to & 3 \\
\hline Upper seal: cement grout $w / 4-8 \%$ bentonite & 0.0 & & to & N/A \\
\hline Lower seal: volclay bentonite grout & 0.0 & 3 & to & 91 \\
\hline Secondary sand pack: washed silica sand $-30-70$ & 0.0 & 91 & to & 97 \\
\hline Primary sand pack: washed silica sand - 10-20 & 0.0 & 97 & to & 127 \\
\hline
\end{tabular}

Depth to water 44.10 1/12/94 


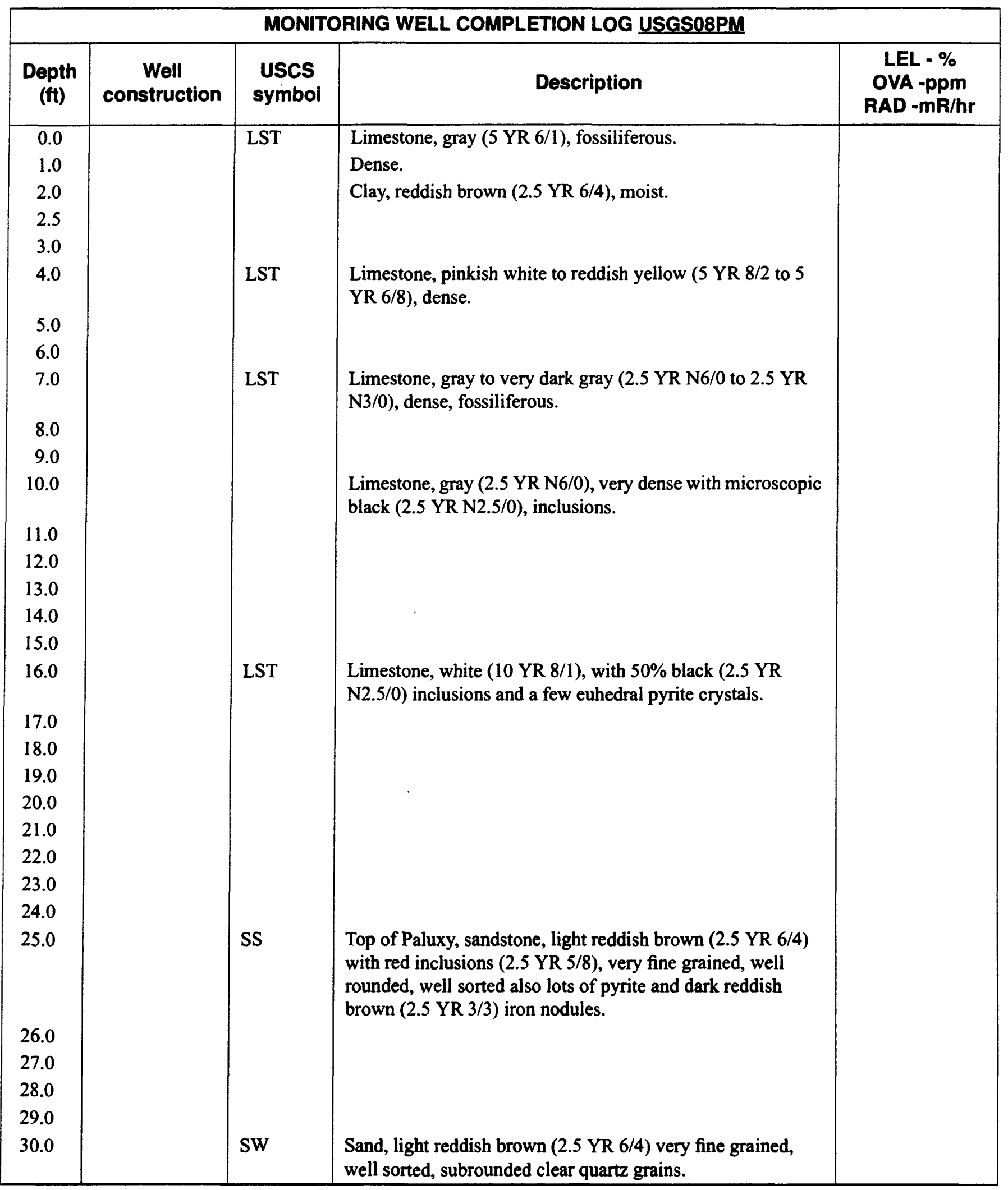




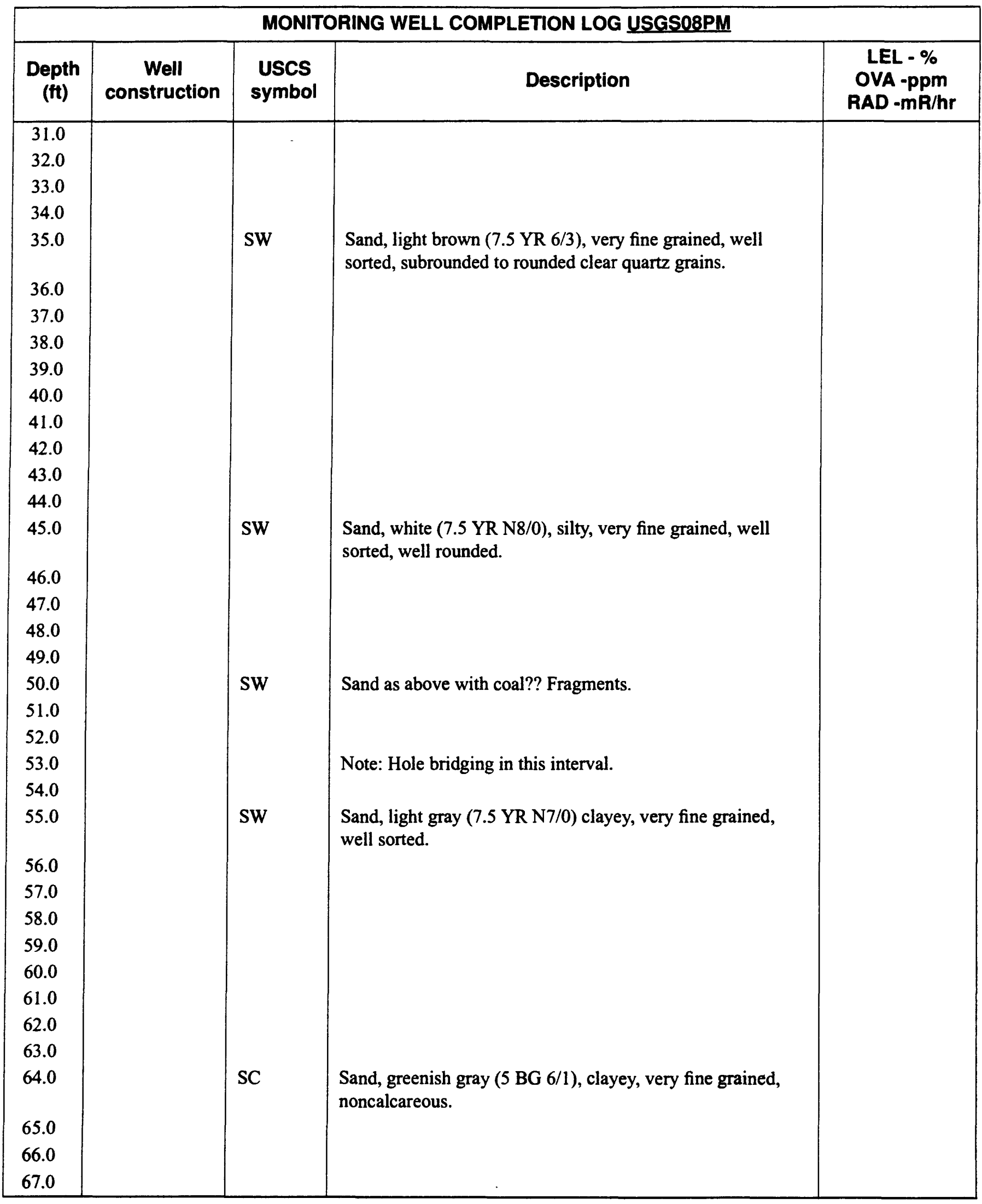




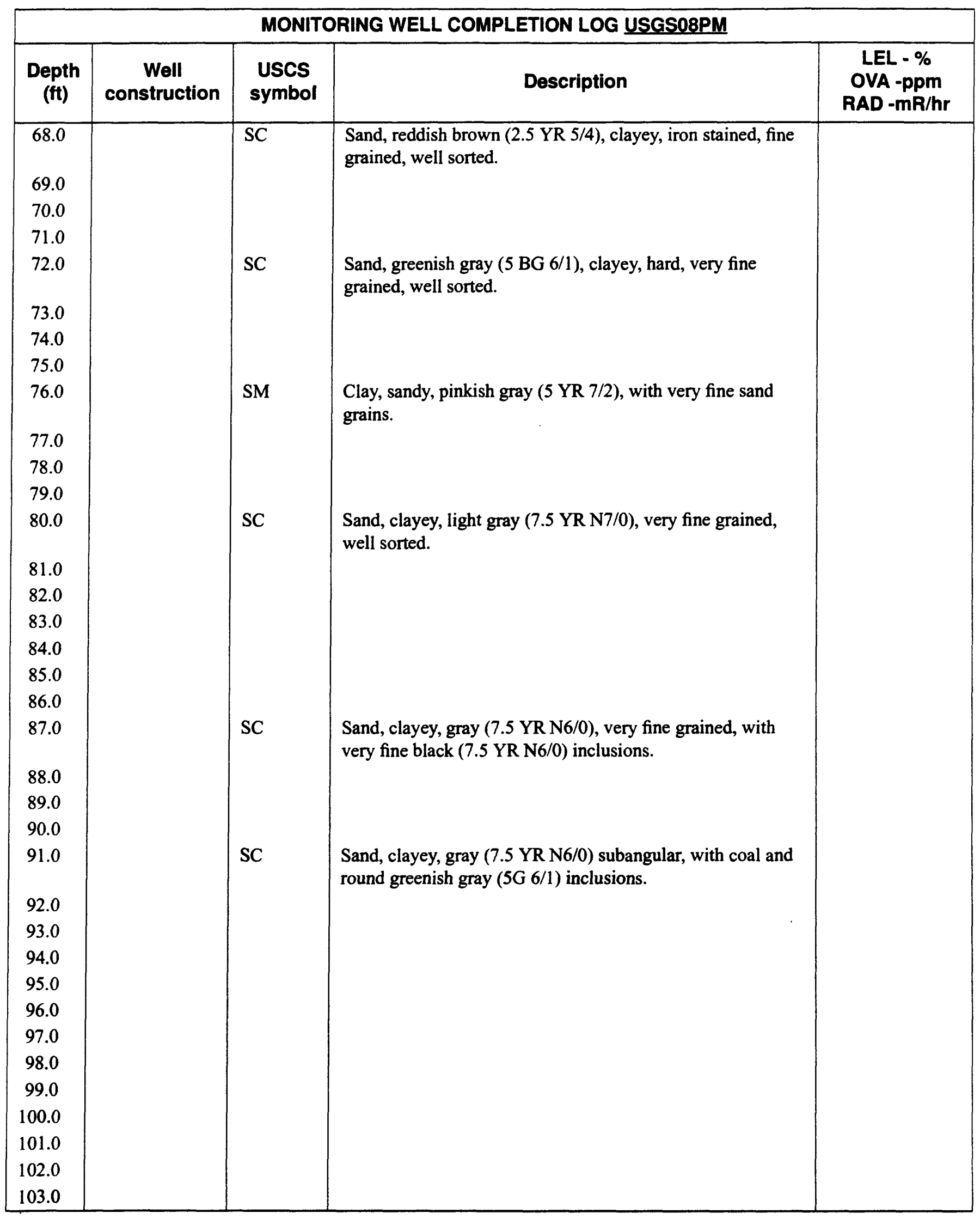




\begin{tabular}{|c|c|c|c|c|}
\hline \multicolumn{5}{|c|}{ MONITORING WELL COMPLETION LOG USGS08PM } \\
\hline $\begin{array}{l}\text { Depth } \\
\text { (ft) }\end{array}$ & $\begin{array}{c}\text { Well } \\
\text { construction }\end{array}$ & $\begin{array}{l}\text { USCS } \\
\text { symbol }\end{array}$ & Description & $\begin{array}{c}\text { LEL - \% } \\
\text { OVA -ppm } \\
\text { RAD -mR/hr }\end{array}$ \\
\hline $\begin{array}{l}104.0 \\
105.0 \\
106.0 \\
107.0 \\
108.0 \\
109.0 \\
110.0 \\
111.0 \\
112.0 \\
113.0 \\
114.0 \\
115.0 \\
116.0 \\
117.0 \\
118.0 \\
119.0 \\
120.0 \\
121.0 \\
122.0 \\
123.0 \\
124.0 \\
125.0 \\
126.0 \\
127.0 \\
128.0 \\
129.0 \\
130.0\end{array}$ & & SW & $\begin{array}{l}\text { Sand, light gray ( } 7.5 \text { YR } 7 / 0) \text {, fine to medium grained, } \\
\text { subrounded to rounded. } \\
\text { Sand, light gray }(7.5 \mathrm{YR} 7 / 0) \text {, medium grained, subangular, } \\
\text { with black ( } 2.5 \mathrm{YR} N 2.5 / 0) \text { grains. } \\
\text { As above, with trace of coal and pyrite. } \\
\text { TD at } 127 \mathrm{ft} \text {. }\end{array}$ & \\
\hline
\end{tabular}




\section{MONITORING WELL COMPLETION LOG}

Drilier: U.S. Geologlcal Survey

Method: Air rotary

Well no. USGS08PU

Project: 464814700 NAS/AFP4

Hole no.: P1-U

Location: On Shoreview Dr. across intersection with Killdeer

Northing:

Ground elevation ( $\mathrm{ft} \mathrm{msl}$ ):

Hole depth (ft):

MP height ( $\mathrm{ft}$ ):

Surface bit size (in.):

Below surface (in.):

Coring bit size (in.):

\begin{tabular}{ll}
$\frac{6968826.038}{636.82}$ & Easting: \\
\cline { 1 - 1 } & Lat/Long: \\
How determined: & Well depth (ft): \\
\cline { 1 - 1 } 637.95 & MP description: \\
\hline $97 / 8$ OD & Slot size: \\
\cline { 1 - 1 } $57 / 8$ OD & Reaming bit size (in.):
\end{tabular}

\begin{tabular}{l}
\hline 2288943.602 \\
\hline 3246530972726 \\
\hline Survey \\
\hline 70 \\
\hline Top of 2-in. PVC riser \\
\hline 0.020 \\
\hline
\end{tabular}

\begin{tabular}{|c|c|c|c|c|}
\hline TYPE & $\begin{array}{c}\text { DIA } \\
\text { (in. OD) }\end{array}$ & \multicolumn{3}{|c|}{$\begin{array}{l}\text { INTERVAL } \\
\text { (ft) }\end{array}$} \\
\hline Outer casing: PVC flush joint Tri-Lok & & & to & \\
\hline Blank casing: PVC flush joint Tri-Lok & 6.0 & & to & N/A \\
\hline Blank casing: PVC flush joint Tri-Lok & 2.0 & 0 & to & 49.5 \\
\hline Screen: PVC slotted Tri-Lok, 0.020 & 2.0 & 49.5 & to & $\overline{69.5}$ \\
\hline End cap: PVC flush joint Tri-Lok & 2.0 & 69.5 & to & $\overline{70.0}$ \\
\hline Surface seal: Pakmix concrete & 0.0 & 0 & to & 3 \\
\hline Upper seal: cement grout w/ $4-8 \%$ bentonite & 0.0 & & to & N/A \\
\hline Lower seal: volclay bentonite grout & 0.0 & 3 & to & 27 \\
\hline Secondary sand pack: washed silica sand - 30-70 & 0.0 & 27 & to & 39 \\
\hline Primary sand pack: washed silica sand - 10-20 & 0.0 & 39 & to & 70 \\
\hline
\end{tabular}

Depth to water $42.741 / 11 / 94$ 


\begin{tabular}{|c|c|c|c|c|}
\hline \multicolumn{5}{|c|}{ MONITORING WELL COMPLETION LOG USGS08PU } \\
\hline $\begin{array}{l}\text { Depth } \\
\text { (ft) }\end{array}$ & $\begin{array}{c}\text { Well } \\
\text { construction }\end{array}$ & $\begin{array}{l}\text { USCS } \\
\text { symbol }\end{array}$ & Description & $\begin{array}{l}\text { LEL - \% } \\
\text { OVA -ppm } \\
\text { RAD - mR/hr }\end{array}$ \\
\hline 0.0 & & LST & Limestone, gray (5 YR 6/1), fossiliferous. & \\
\hline 1.0 & & & Dense. & \\
\hline 2.0 & & & Clay, reddish brown (2.5 YR 6/4), moist. & \\
\hline 2.5 & & & & \\
\hline 3.0 & & & & \\
\hline 4.0 & & LST & $\begin{array}{l}\text { Limestone, pinkish white to reddish yellow ( } 5 \text { YR } 8 / 2 \text { to } 5 \\
\text { YR 6/8), dense. }\end{array}$ & \\
\hline 5.0 & & & & \\
\hline 6.0 & & & & \\
\hline 7.0 & & LST & $\begin{array}{l}\text { Limestone, gray to very dark gray ( } 2.5 \text { YR N6/0 to } 2.5 \mathrm{YR} \\
\mathrm{N} 3 / 0 \text { ), dense, fossiliferous. }\end{array}$ & \\
\hline 8.0 & & & & \\
\hline 9.0 & & & & \\
\hline 10.0 & & & $\begin{array}{l}\text { Limestone, gray ( } 2.5 \text { YR N6/0), very dense with microscopic } \\
\text { black ( } 2.5 \text { YR N2.5/0) inclusions. }\end{array}$ & \\
\hline 11.0 & & & & \\
\hline 12.0 & & & & \\
\hline 13.0 & & & & \\
\hline 14.0 & & & & \\
\hline 15.0 & & & & \\
\hline 16.0 & & LST & $\begin{array}{l}\text { Limestone, white ( } 10 \text { YR } 8 / 1) \text { with } 50 \% \text { black ( } 2.5 \mathrm{YR} \\
\mathrm{N} 2.5 / 0) \text { inclusions and a few euhedral pyrite crystals. }\end{array}$ & \\
\hline 17.0 & & & & \\
\hline 18.0 & & & & \\
\hline 19.0 & & & & \\
\hline 20.0 & & & & \\
\hline 21.0 & & & & \\
\hline 22.0 & & & & \\
\hline 23.0 & & & & \\
\hline 24.0 & & & & \\
\hline 25.0 & & SS & $\begin{array}{l}\text { Top of Paluxy, sandstone, light reddish brown ( } 2.5 \text { YR } 6 / 4) \\
\text { with red inclusions ( } 2.5 \text { YR } 5 / 8) \text {, very fine grained, well } \\
\text { rounded, well sorted also lots of pyrite and dark reddish } \\
\text { brown ( } 2.5 \text { YR } 3 / 3 \text { ) iron nodules. }\end{array}$ & \\
\hline 26.0 & & & & \\
\hline 27.0 & & & & \\
\hline 28.0 & & & & \\
\hline 29.0 & & & & \\
\hline 30.0 & & SW & $\begin{array}{l}\text { Sand, light reddish brown ( } 2.5 \text { YR } 6 / 4 \text { ), very fine grained, } \\
\text { well sorted, subrounded clear quartz grains. }\end{array}$ & \\
\hline
\end{tabular}




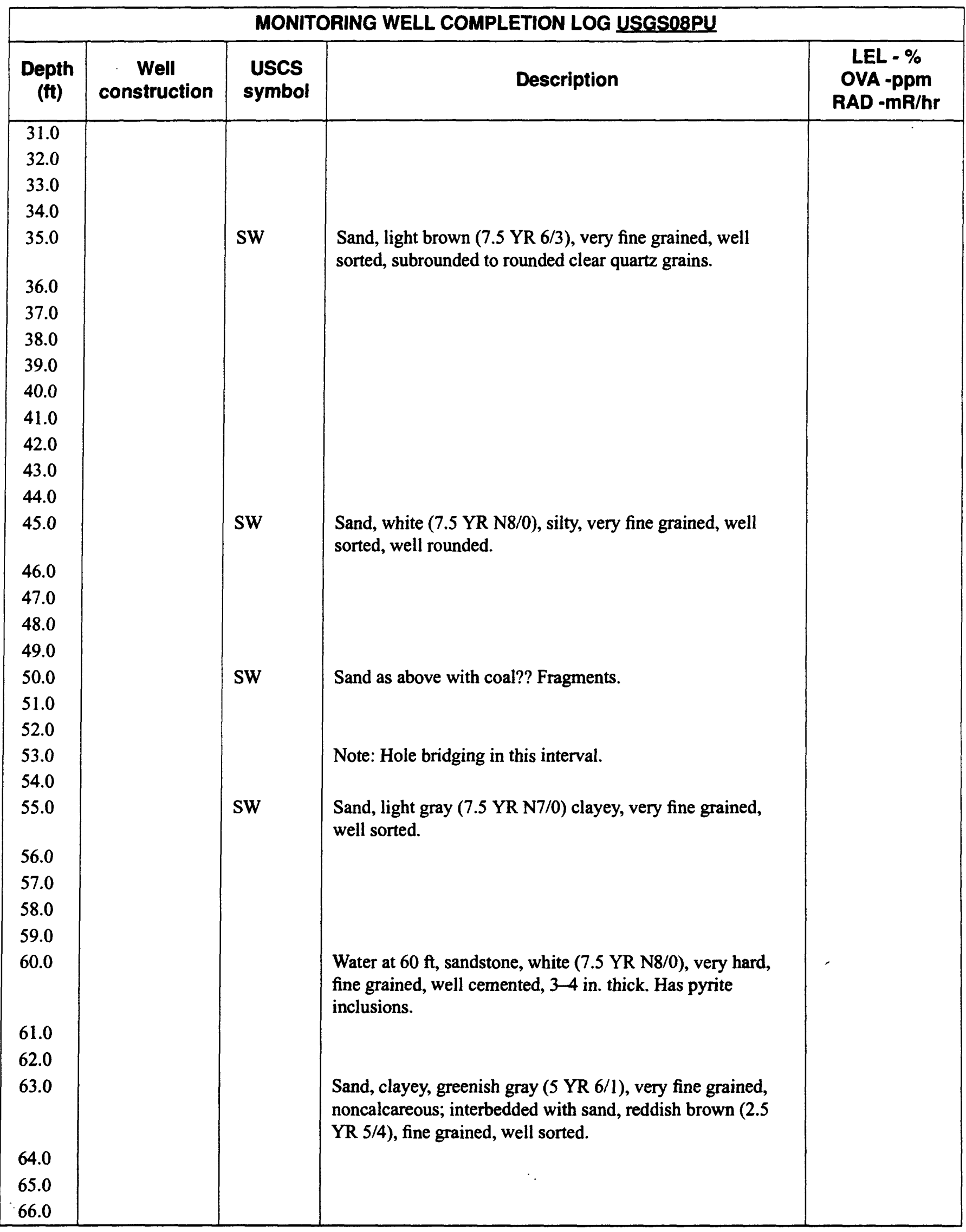




\begin{tabular}{|c|c|c|c|c|}
\hline \multicolumn{3}{|c|}{ MONITORING WELL COMPLETION LOG USGS08PU } \\
\hline $\begin{array}{c}\text { Depth } \\
(\mathrm{ft})\end{array}$ & $\begin{array}{c}\text { Well } \\
\text { construction }\end{array}$ & $\begin{array}{c}\text { USCS } \\
\text { symbol }\end{array}$ & Description & $\begin{array}{c}\text { LEL - \% } \\
\text { OVA -ppm } \\
\text { RAD -mR/hr }\end{array}$ \\
\hline 67.0 & & & & \\
68.0 & & & TD & \\
69.0 & & & & \\
70.0 & & & & \\
\hline
\end{tabular}




\section{MONITORING WELL COMPLETION LOG}

Driller: U.S. Geological Survey

Method: Mud rotary

Well no. USGS09PL

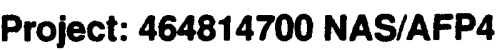

Hole no.: P2-L

Location: East of Texas Army National Guard Armory

Northing:

Ground elevation ( $\mathrm{ft} \mathrm{msl):}$

Hole depth ( $\mathrm{ft}$ ):

MP height ( $f t)$ :

Surface bit size (in.):

Below surface (in.):

Coring bit size (in.):

\begin{tabular}{|c|c|c|}
\hline 6967334.994 & Easting: & 2289687.935 \\
\hline 631.64 & \multirow{6}{*}{$\begin{array}{l}\text { Lat/Long: } \\
\text { How determined: } \\
\text { Well depth (ft): } \\
\text { MP description: } \\
\text { Slot size: } \\
\text { Reaming bit size (in.): }\end{array}$} & 3246380972718 \\
\hline 207 & & Survey \\
\hline 631.49 & & 207 ; Depth to water 56.5 \\
\hline $97 / 8$ OD & & Inside edge of 2 -in. riser \\
\hline $57 / 8 \mathrm{OD}$ & & 0.020 \\
\hline & & \\
\hline
\end{tabular}

\begin{tabular}{|c|c|c|c|c|}
\hline TYPE & $\begin{array}{c}\text { DIA } \\
\text { (in. OD) }\end{array}$ & \multicolumn{3}{|c|}{$\begin{array}{l}\text { INTERVAL } \\
\text { (ft) }\end{array}$} \\
\hline Outer casing: PVC flush joint Tri-Lok & 6.0 & 0 & to & $\overline{7.0}$ \\
\hline Blank casing: PVC flush joint Tri-Lok & 2.0 & .5 & to & 166.5 \\
\hline Blank casing: PVC flush joint Tri-Lok & 2.0 & 186.5 & to & 206.5 \\
\hline Screen: PVC slotted Tri-Lok, 0.020 & 2.0 & 166.5 & to & 186.5 \\
\hline End cap: PVC flush joint Tri-Lok & 2.0 & 206.5 & to & 207 \\
\hline Surface seal: Pakmix concrete & 0.0 & 0 & to & 3 \\
\hline Upper seal: cement grout $w / 4-8 \%$ bentonite & 0.0 & & to & N/A \\
\hline Lower seal: volclay grout & 0.0 & 3 & to & 150 \\
\hline Secondary sand pack: washed silica sand - 30-70 & 0.0 & 150 & to & 156 \\
\hline Primary sand pack: washed silica sand - 10-20 & 0.0 & 156 & to & 207 \\
\hline Date drilled: $1 / 25 / 94$ to $1 / 26 / 94$ & Log & a oy & I. $R$ & \\
\hline
\end{tabular}




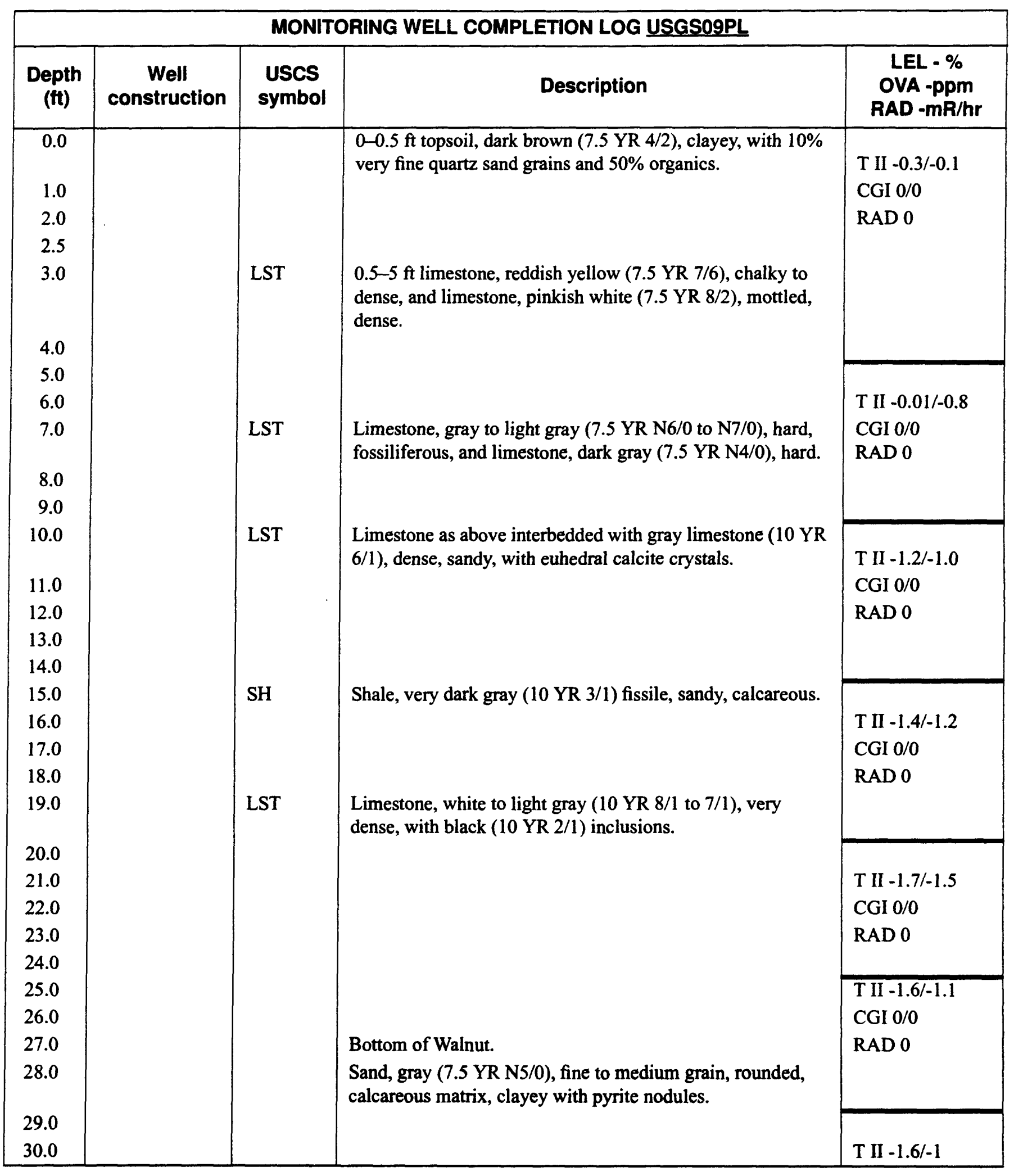




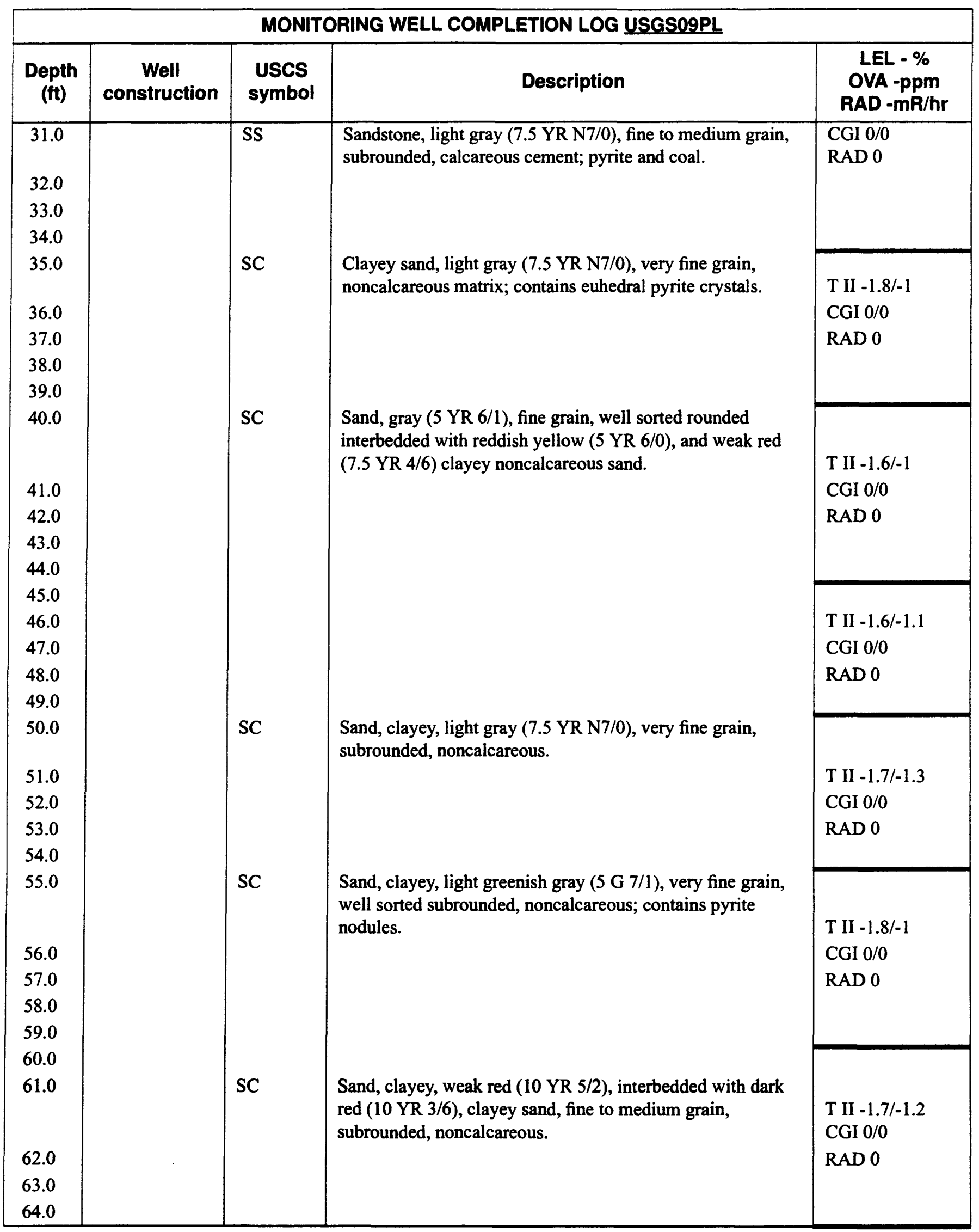




\begin{tabular}{|c|c|c|c|c|}
\hline \multicolumn{5}{|c|}{ MONITORING WELL COMPLETION LOG USGSO9PL } \\
\hline $\begin{array}{l}\text { Depth } \\
\text { (ft) }\end{array}$ & $\begin{array}{c}\text { Well } \\
\text { construction }\end{array}$ & $\begin{array}{l}\text { USCS } \\
\text { symbol }\end{array}$ & Description & $\begin{array}{l}\text { LEL }-\% \\
\text { OVA -ppm } \\
\text { RAD -mR/hr }\end{array}$ \\
\hline 65.0 & & \multirow{6}{*}{$\mathrm{CL}$} & \multirow{6}{*}{$\begin{array}{l}\text { Clay, sandy, greenish gray ( } 5 \text { BG } 6 / 1 \text { ), noncalcareous; } \\
\text { contains pyrite nodules. }\end{array}$} & \\
\hline 66.0 & & & & $\begin{array}{l}\text { T II }-1.8 /-1.5 \\
\text { CGI } 0 / 0\end{array}$ \\
\hline 67.0 & & & & RAD 0 \\
\hline 68.0 & & & & \\
\hline 69.0 & & & & \\
\hline 70.0 & & & & \\
\hline 71.0 & & \multirow[t]{9}{*}{$\mathrm{CL}$} & \multirow[t]{9}{*}{$\begin{array}{l}\text { As above interbedded with sand, clayey, light gray ( } 7.5 \text { YR } \\
\text { N7/0), noncalcareous, fine grain, well sorted, rounded; } 50 \% \\
\text { pyrite. }\end{array}$} & $\begin{array}{l}\text { T II }-1.8 /-1 \\
\text { CGI } 0 / 0\end{array}$ \\
\hline 72.0 & & & & RAD 0 \\
\hline 73.0 & & & & \\
\hline 74.0 & & & & \\
\hline 75.0 & & & & \\
\hline 76.0 & & & & T II $-1.8 /-1$ \\
\hline 77.0 & & & & CGI $0 / 0$ \\
\hline 78.0 & & & & RAD 0 \\
\hline 79.0 & & & & \\
\hline 80.0 & & \multirow[t]{11}{*}{ SC } & \multirow[t]{10}{*}{$\begin{array}{l}\text { Sand, quartz, fine to medium grain, poorly sorted, subangular } \\
\text { to subrounded, friable, } 1-2 \% \text { clay matrix. }\end{array}$} & T II $-1.9 /-1.5$ \\
\hline 81.0 & & & & CGI $0 / 0$ \\
\hline 82.0 & & & & RAD 0 \\
\hline 83.0 & & & & \\
\hline 84.0 & & & & \\
\hline 85.0 & & & & \\
\hline 86.0 & & & & T II $-1.9 /-1.4$ \\
\hline 87.0 & & & & CGI $0 / 0$ \\
\hline 88.0 & & & & RAD 0 \\
\hline 89.0 & & & & \\
\hline 90.0 & & & & \\
\hline 91.0 & & \multirow[t]{10}{*}{ SW } & \multirow[t]{10}{*}{$\begin{array}{l}\text { Sand, white ( } 10 \text { YR } 8 / 1) \text {, medium grain subangular, well } \\
\text { sorted, interbedded with nodular pyrite. }\end{array}$} & $\begin{array}{l}\text { T II }-1.8 /-1 \\
\text { CGI } 0 / 0\end{array}$ \\
\hline 92.0 & & & & RAD 0 \\
\hline 93.0 & & & & \\
\hline 94.0 & & & & \\
\hline $\begin{array}{l}95.0 \\
960\end{array}$ & & & & T II $-18 /-1$ \\
\hline 97.0 & & & & CGI $0 / 0$ \\
\hline 98.0 & & & & RAD 0 \\
\hline 99.0 & & & & \\
\hline 100.0 & & & & T II $-1.9 /-1$ \\
\hline 101.0 & & & & CGI $0 / 0$ \\
\hline
\end{tabular}




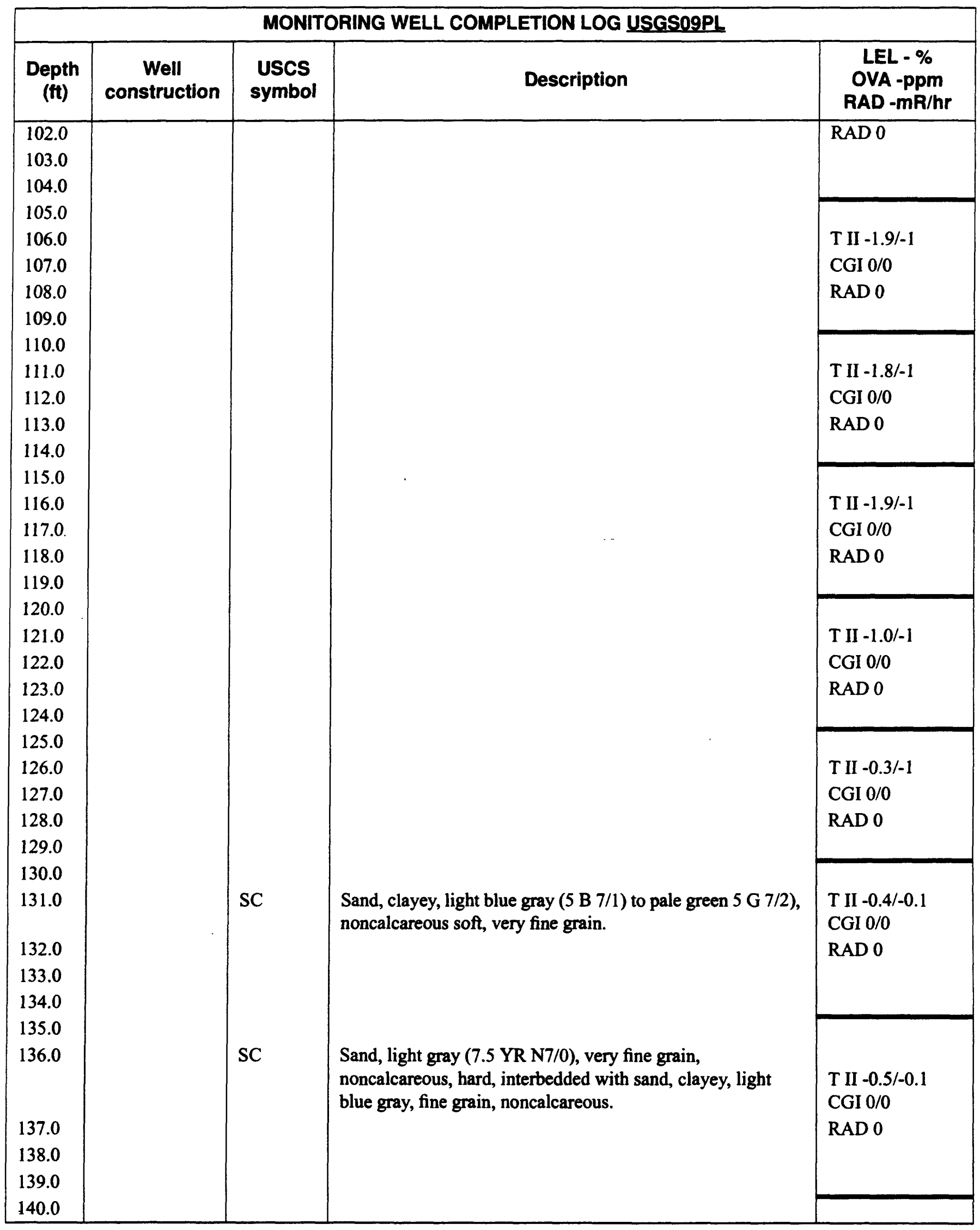




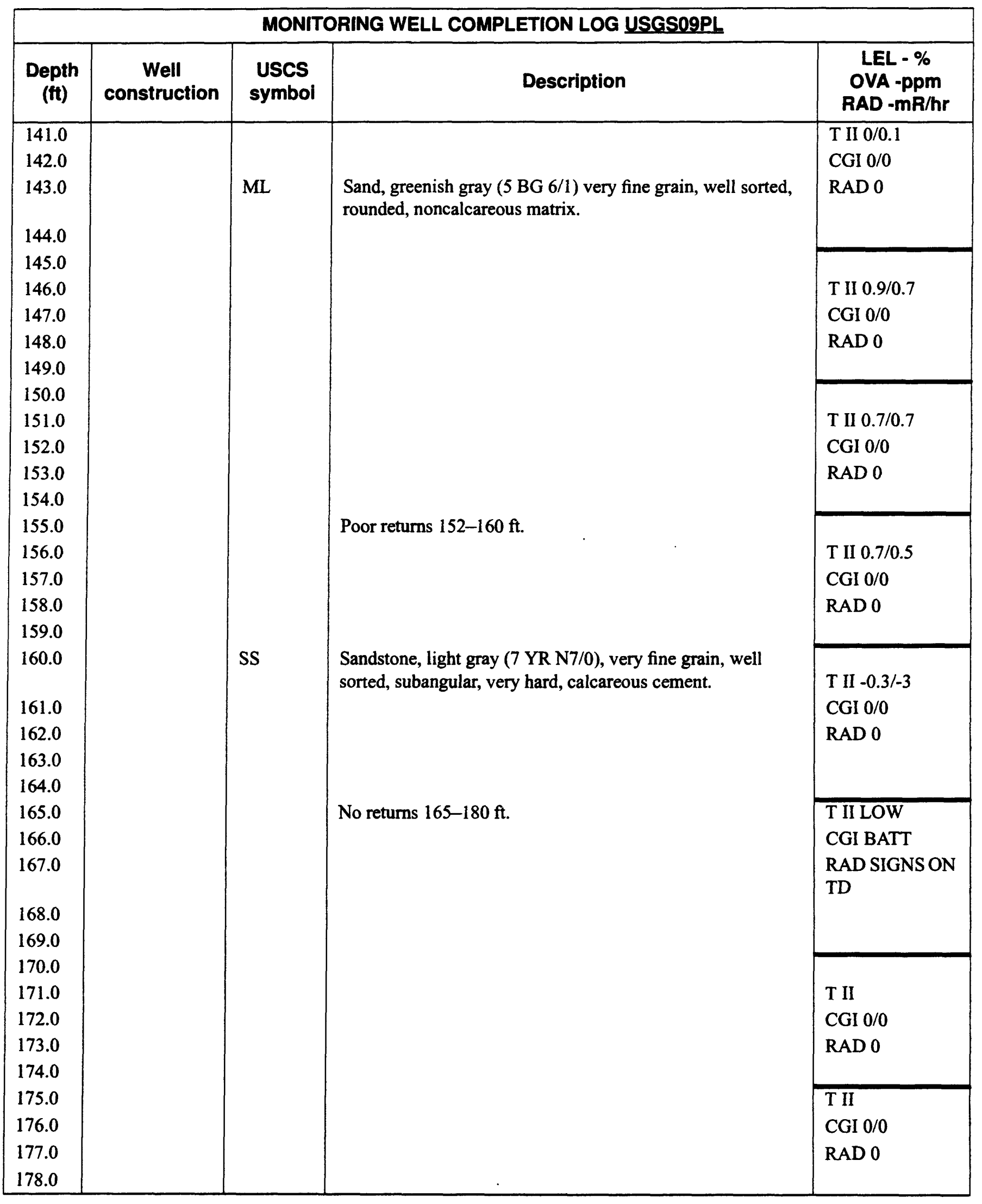




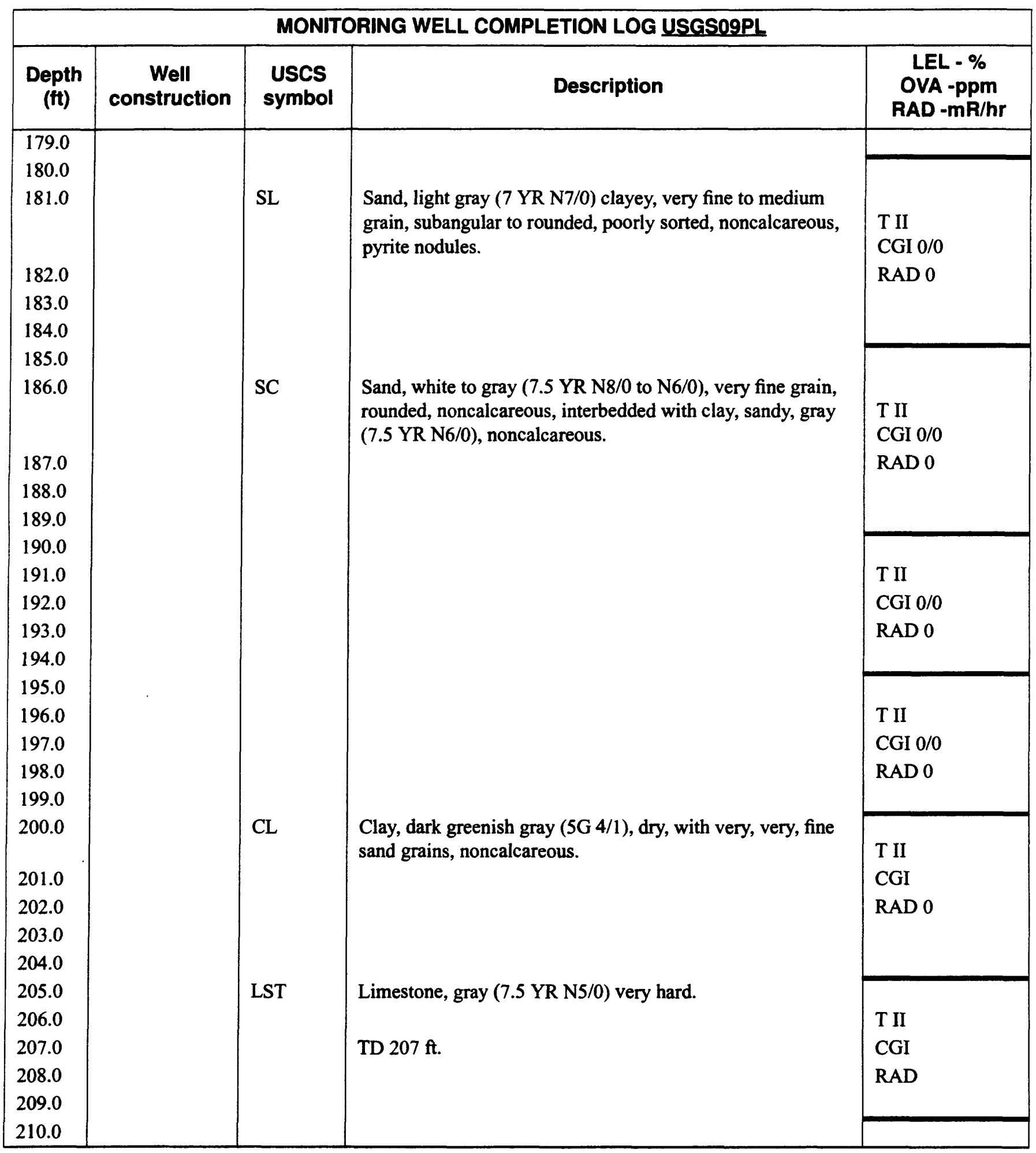




\section{MONITORING WELL COMPLETION LOG}

Driller: U.S. Geological Survey

Method: Mud rotary

Well no. USGS09PM

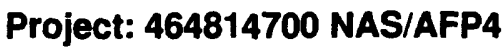

Hole no.: P2-M

\begin{tabular}{|c|c|c|c|}
\hline \multicolumn{4}{|c|}{ Location: East of Texas Army National Guard Armory } \\
\hline Northing: & 6967336.210 & \multirow{7}{*}{$\begin{array}{l}\text { Easting: } \\
\text { Lat/Long: } \\
\text { How determined: } \\
\text { Well depth (ft): } \\
\text { MP description: } \\
\text { Slot size: } \\
\text { Reaming bit size (in.) }\end{array}$} & \multirow{3}{*}{$\begin{array}{l}228678.015 \\
3246380972718 \\
\text { Survey }\end{array}$} \\
\hline Ground elevation ( $\mathrm{ft} \mathrm{msl}$ ): & 631.82 & & \\
\hline Hole depth (ft): & 117 & & \\
\hline MP height (ft): & 631.75 & & 117 \\
\hline Surface bit size (in.): & $97 / 8 \mathrm{OD}$ & & Top of 2-in. riser \\
\hline Below surface (in.): & $57 / 8 \mathrm{OD}$ & & 0.020 \\
\hline Coring bit size (in.): & & & \\
\hline
\end{tabular}

\begin{tabular}{|c|c|c|c|c|}
\hline TYPE & $\begin{array}{c}\text { DIA } \\
\text { (in. OD) }\end{array}$ & \multicolumn{3}{|c|}{$\begin{array}{l}\text { INTERVAL } \\
\text { (ft) }\end{array}$} \\
\hline Outer casing: PVC flush joint Tri-Lok & & & to & \\
\hline Blank casing: PVC flush joint Tri-Lok & 6.0 & 0 & to & 7 \\
\hline Blank casing: PVC flush joint Tri-Lok & 2.0 & 0 & to & 116.5 \\
\hline Screen: PVC slotted Tri-Lok, 0.020 & 2.0 & 96.5 & to & 116.5 \\
\hline End cap: PVC flush joint Tri-Lok & 2.0 & 116.5 & to & 117 \\
\hline Surface seal: Pakmix concrete & 0.0 & 0 & to & 3 \\
\hline Upper seal: cement grout $w / 4-8 \%$ bentonite & 0.0 & & to & N/A \\
\hline Lower seal: volclay grout & 0.0 & 3 & to & 82 \\
\hline Secondary sand pack: washed silica sand - 30-70 & 0.0 & 82 & to & 90 \\
\hline Primary sand pack: washed silica sand - 10-20 & 0.0 & 90 & to & 117 \\
\hline Date drilled: $1 / 25 / 94$ to $1 / 27 / 94$ & & & & \\
\hline
\end{tabular}

Depth to water $58.421 / 27 / 94$ 


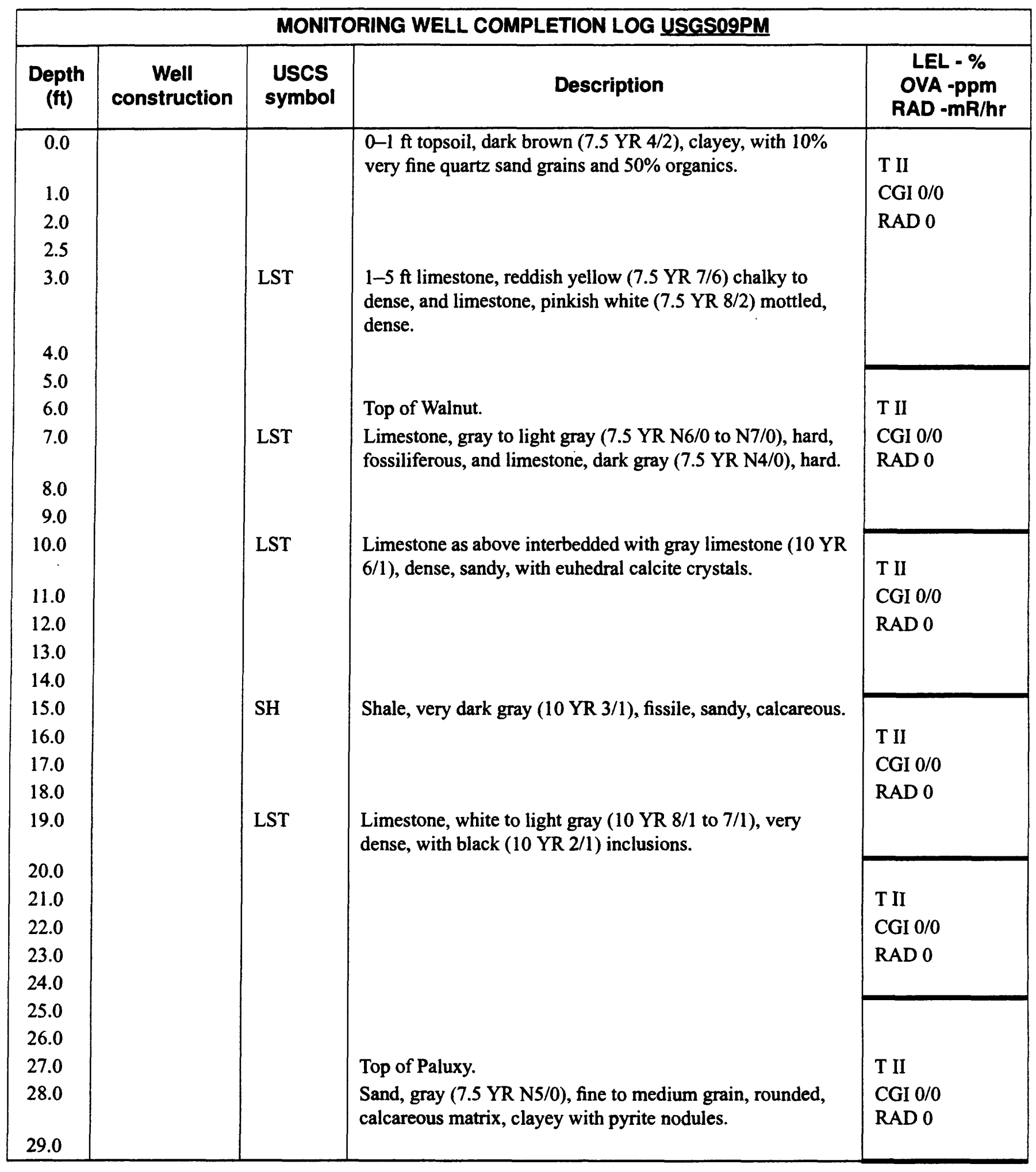




\begin{tabular}{|c|c|c|c|c|}
\hline \multicolumn{5}{|c|}{ MONITORING WELL COMPLETION LOG USGS09PM } \\
\hline $\begin{array}{l}\text { Depth } \\
\text { (ft) }\end{array}$ & $\begin{array}{c}\text { Well } \\
\text { construction }\end{array}$ & $\begin{array}{l}\text { USCS } \\
\text { symbol }\end{array}$ & Description & $\begin{array}{l}\text { LEL - \% } \\
\text { OVA -ppm } \\
\text { RAD - mR/hr }\end{array}$ \\
\hline 30.0 & & \multirow{5}{*}{ SS } & \multirow{5}{*}{$\begin{array}{l}\text { Sandstone, light gray ( } 7.5 \text { YR N7/0), fine to medium grain, } \\
\text { subrounded, calcareous cement; pyrite and coal. }\end{array}$} & \\
\hline 31.0 & & & & $\begin{array}{l}\text { T II } \\
\text { CGI } 0 / 0\end{array}$ \\
\hline 32.0 & & & & RAD 0 \\
\hline 33.0 & & & & \\
\hline 34.0 & & & & \\
\hline 35.0 & & \multirow[t]{5}{*}{ SC } & \multirow[t]{5}{*}{$\begin{array}{l}\text { Clayey sand, light gray ( } 7.5 \text { YR N7/0), very fine grain, } \\
\text { noncalcareous matrix; contains euhedral pyrite crystals. }\end{array}$} & T II \\
\hline 36.0 & & & & CGI $0 / 0$ \\
\hline 37.0 & & & & RAD 0 \\
\hline 38.0 & & & & \\
\hline 39.0 & & & & \\
\hline 40.0 & & \multirow[t]{10}{*}{ SC } & \multirow[t]{10}{*}{$\begin{array}{l}\text { Sand, gray (5 YR 6/1), fine grain, well sorted rounded } \\
\text { interbedded with reddish yellow (5 YR } 6 / 0) \text { and weak red } \\
(7.5 \text { YR 4/6), clayey noncalcareous sand. }\end{array}$} & T II \\
\hline 41.0 & & & & CGI $0 / 0$ \\
\hline 42.0 & & & & RAD 0 \\
\hline 43.0 & & & & \\
\hline 44.0 & & & & \\
\hline 45.0 & & & & \\
\hline 46.0 & & & & \\
\hline 47.0 & & & & CGI $0 / 0$ \\
\hline 48.0 & & & & RAD 0 \\
\hline 49.0 & & & & \\
\hline 50.0 & & \multirow[t]{5}{*}{ SC } & \multirow[t]{5}{*}{$\begin{array}{l}\text { Sand, clayey, light gray ( } 7.5 \text { YR N7/0), very fine grain, } \\
\text { subrounded, noncalcareous. }\end{array}$} & T II \\
\hline 51.0 & & & & CGI $0 / 0$ \\
\hline 52.0 & & & & RAD 0 \\
\hline 53.0 & & & & \\
\hline 54.0 & & & & \\
\hline 55.0 & & \multirow[t]{7}{*}{ SC } & \multirow[t]{3}{*}{$\begin{array}{l}\text { Sand, clayey, light greenish gray ( } 5 \mathrm{G} 7 / 1) \text {, very fine grain, } \\
\text { well sorted subrounded, noncalcareous; contains pyrite } \\
\text { nodules. }\end{array}$} & T II $0.8 / 1.0$ \\
\hline 56.0 & & & & CGI $0 / 0$ \\
\hline 57.0 & & & & RAD 0 \\
\hline 57.5 & & & \multirow[t]{4}{*}{$\begin{array}{l}\text { Note: Very hard drilling } 57.5-57.9 \mathrm{ft} \text {; recovered few pieces } \\
\text { of: sandstone, pinkish gray }(7.5 \mathrm{YR} 7 / 2) \text {, very hard, } \\
\text { calcareous cement, very fine grained. }\end{array}$} & \\
\hline 57.9 & & & & \\
\hline 58.0 & & & & \\
\hline 59.0 & & & & \\
\hline
\end{tabular}




\begin{tabular}{|c|c|c|c|c|}
\hline \multicolumn{5}{|c|}{ MONITORING WELL COMPLETION LOG USGS09PM } \\
\hline $\begin{array}{c}\text { Depth } \\
\text { (ft) }\end{array}$ & $\begin{array}{c}\text { Well } \\
\text { construction }\end{array}$ & $\begin{array}{l}\text { USCS } \\
\text { symbol }\end{array}$ & Description & $\begin{array}{l}\text { LEL }-\% \\
\text { OVA -ppm } \\
\text { RAD - mR/hr }\end{array}$ \\
\hline $\begin{array}{l}61.0 \\
62.0 \\
63.0 \\
64.0\end{array}$ & & SC & $\begin{array}{l}\text { Sand, clayey, weak red ( } 10 \text { YR } 5 / 2 \text { ), interbedded with dark } \\
\text { red ( } 10 \text { YR } 3 / 6) \text {, clayey sand, fine to medium grain, } \\
\text { subrounded, noncalcareous. }\end{array}$ & $\begin{array}{l}\text { T II }-0.2 /- \text {. } \\
\text { CGI } 0 / 0 \\
\text { RAD } 0\end{array}$ \\
\hline $\begin{array}{l}65.0 \\
66.0 \\
67.0 \\
68.0 \\
69.0\end{array}$ & & & 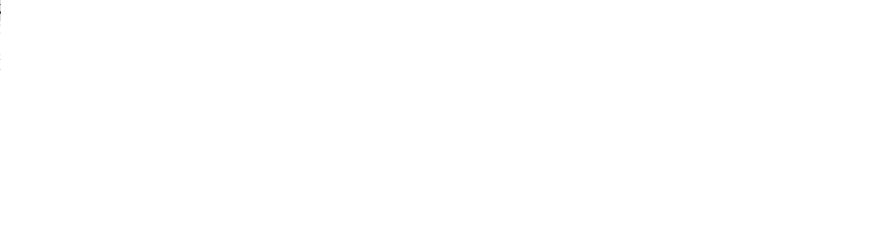 & $\begin{array}{l}\text { T II }-0.6 /-5 \\
\text { CGI } 0 / 0 \\
\text { RAD } 0\end{array}$ \\
\hline 70.0 & & & & \\
\hline $\begin{array}{l}72.0 \\
73.0 \\
74.0\end{array}$ & & CL & $\begin{array}{l}\text { As above interbedded with sand, clayey, light gray ( } 7.5 \text { YR } \\
\text { N7/0), noncalcareous, fine grain, well sorted, rounded; } 50 \% \\
\text { pyrite. }\end{array}$ & $\begin{array}{l}\text { T II }-0.8 /- \\
\text { CGI } 0 / 0 \\
\text { RAD } 0\end{array}$ \\
\hline $\begin{array}{l}75.0 \\
76.0 \\
77.0 \\
78.0 \\
79.0\end{array}$ & & & & $\begin{array}{l}\text { T II }-0.8 /-. \\
\text { CGI } 0 / 0 \\
\text { RAD } 0\end{array}$ \\
\hline $\begin{array}{l}80.0 \\
81.0 \\
82.0 \\
83.0 \\
84.0\end{array}$ & & $\mathrm{SC}$ & 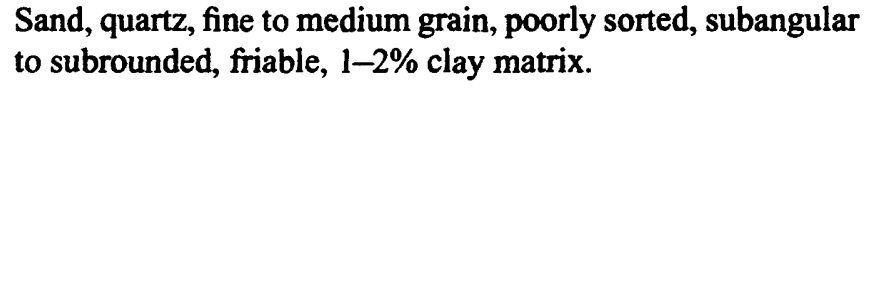 & $\begin{array}{l}\text { T II }-1.7 / \\
\text { CGI } 0 / 0 \\
\text { RAD } 0\end{array}$ \\
\hline $\begin{array}{l}85.0 \\
86.0 \\
87.0 \\
88.0 \\
89.0\end{array}$ & & & & $\begin{array}{l}\text { T II }-1.7 /-1 \\
\text { CGI } 0 / 0 \\
\text { RAD } 0\end{array}$ \\
\hline $\begin{array}{l}92.0 \\
93.0 \\
94.0\end{array}$ & & SW & $\begin{array}{l}\text { Sand, white (10 YR } 8 / 1) \text {, medium grain subangular, well } \\
\text { sorted, interbedded with nodular pyrite. }\end{array}$ & $\begin{array}{l}\text { T II }-1.8 /-1 \\
\text { CGI } 0 / 0 \\
\text { RAD } 0\end{array}$ \\
\hline
\end{tabular}




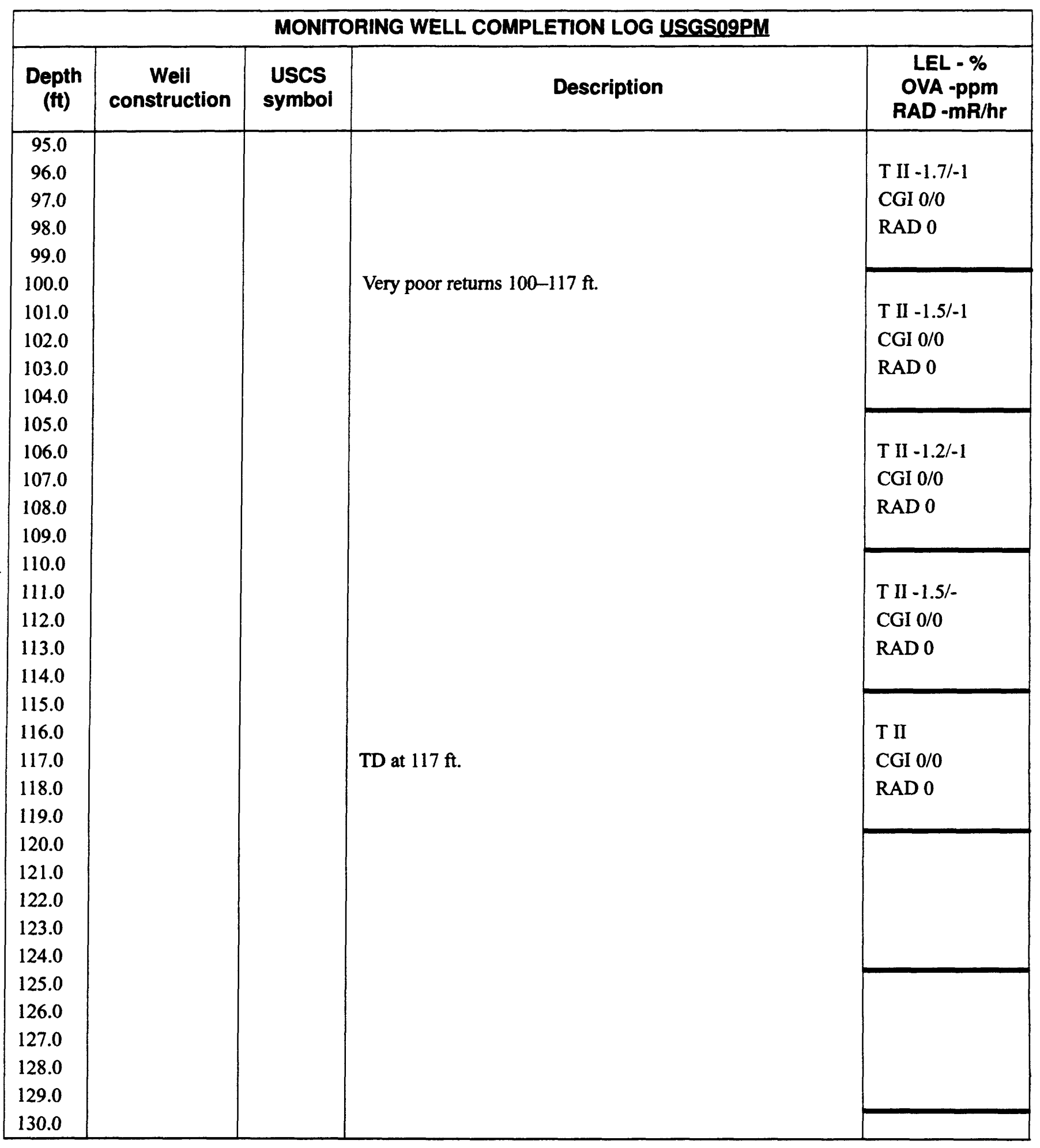




\section{MONITORING WELL COMPLETION LOG}

Drilier: U.S. Geoiogical Survey

Method: Air rotary

Well no. USGSOgPU

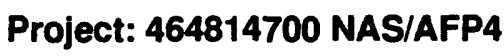

Hoie no.: P2-U

\begin{tabular}{|c|c|c|c|}
\hline \multicolumn{4}{|c|}{ Location: East of Texas Army National Guard Armory } \\
\hline Northing: & 6967337.726 & Easting: & 2289668.015 \\
\hline Ground elevation ( $\mathrm{ft} \mathrm{msl}$ ): & 632.08 & Lat/Long: & 3246380972718 \\
\hline Hole depth (ft): & 78.0 & How determined: & Survey \\
\hline MP height (ft): & 631.81 & Well depth (ft): & 78 \\
\hline Surface bit size (in.): & $97 / 8 \mathrm{OD}$ & MP description: & Top of 2-in. PVC riser \\
\hline Below surface (in.): & $57 / 8 \mathrm{OD}$ & Slot size: & 0.020 \\
\hline Coring bit size (in.): & & Reaming bit size (in.): & \\
\hline
\end{tabular}

\begin{tabular}{|c|c|c|c|c|}
\hline TYPE & $\begin{array}{c}\text { DIA } \\
\text { (in. OD) }\end{array}$ & \multicolumn{3}{|c|}{$\begin{array}{l}\text { INTERVAL } \\
\text { (ft) }\end{array}$} \\
\hline Outer casing: PVC flush joint Tri-Lok & & & to & \\
\hline Blank casing: PVC flush joint Tri-Lok & 6.0 & 0 & to & 7 \\
\hline Blank casing: PVC flush joint Tri-Lok & 2.0 & $\overline{0}$ & to & 57.5 \\
\hline Screen: PVC slotted Tri-Lok, 0.020 & 2.0 & 57.5 & to & $\overline{77.5}$ \\
\hline End cap: PVC flush joint Tri-Lok & 2.0 & 77.5 & to & 78 \\
\hline Surface seal: Pakmix concrete & 0.0 & 0 & to & 3 \\
\hline Upper seal: cement grout w/4 $8 \%$ bentonite & 0.0 & & to & N/A \\
\hline Lower seal: volclay grout & 0.0 & 3 & to & 36.5 \\
\hline Secondary sand pack: washed silica sand $-30-70$ & 0.0 & 36.5 & to & $\overline{43}$ \\
\hline Primary sand pack: washed silica sand $-10-20$ & 0.0 & 43 & to & 78 \\
\hline Date drilled: $1 / 25 / 94$ to $1 / 28 / 94$ & Log & 10y: & I. $\mathrm{Ri}$ & \\
\hline
\end{tabular}

Depth to water $45.071 / 28 / 94$ 


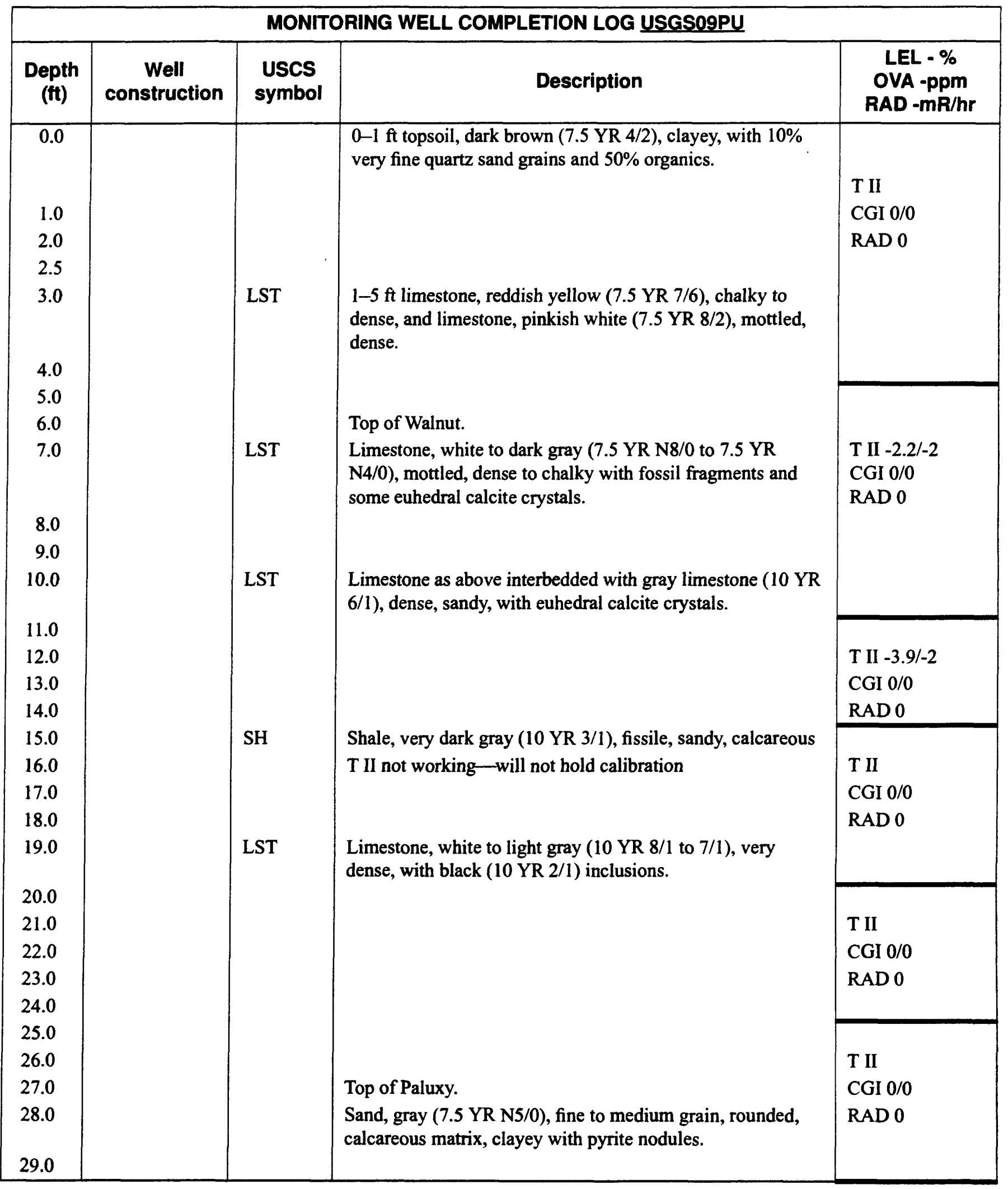




\begin{tabular}{|c|c|c|c|c|}
\hline \multicolumn{5}{|c|}{ MONITORING WELL COMPLETION LOG USGSO9PU } \\
\hline $\begin{array}{l}\text { Depth } \\
\text { (ft) }\end{array}$ & $\begin{array}{l}\text { Well } \\
\text { construction }\end{array}$ & $\begin{array}{l}\text { USCS } \\
\text { symbol }\end{array}$ & Description & $\begin{array}{l}\text { LEL }-\% \\
\text { OVA -ppm } \\
\text { RAD - mR/hr }\end{array}$ \\
\hline 30.0 & & \multirow{5}{*}{ SS } & \multirow{5}{*}{$\begin{array}{l}\text { Sandstone, light gray ( } 7.5 \text { YR N } 7 / 0) \text {, fine to medium grain, } \\
\text { subrounded, calcareous cement; pyrite and coal. }\end{array}$} & \\
\hline 31.0 & & & & $\begin{array}{l}\text { T II } \\
\text { CGI } 0 / 0\end{array}$ \\
\hline 32.0 & & & & RAD 0 \\
\hline 33.0 & & & & \\
\hline 34.0 & & & & \\
\hline 35.0 & & \multirow[t]{5}{*}{ SC } & \multirow[t]{5}{*}{$\begin{array}{l}\text { Clayey sand, light gray ( } 7.5 \text { YR N7/0), very fine grain, } \\
\text { noncalcareous matrix; contains euhedral pyrite crystals. }\end{array}$} & T II \\
\hline 36.0 & & & & CGI $0 / 0$ \\
\hline 37.0 & & & & RAD 0 \\
\hline 38.0 & & & & \\
\hline 39.0 & & & & \\
\hline 40.0 & & \multirow[t]{10}{*}{ SC } & \multirow[t]{10}{*}{$\begin{array}{l}\text { Sand, gray ( } 5 \text { YR } 6 / 1) \text {, fine grain, well sorted rounded } \\
\text { interbedded with reddish yellow ( } 5 \text { YR } 6 / 0) \text { and weak red } \\
\text { ( } 7.5 \text { YR 4/6) clayey noncalcareous sand. }\end{array}$} & T II \\
\hline 41.0 & & & & CGI $0 / 0$ \\
\hline 42.0 & & & & RAD 0 \\
\hline 43.0 & & & & \\
\hline 44.0 & & & & \\
\hline 45.0 & & & & \\
\hline 46.0 & & & & \\
\hline 47.0 & & & & CGI $0 / 0$ \\
\hline 48.0 & & & & RAD 0 \\
\hline 49.0 & & & & \\
\hline 50.0 & & \multirow[t]{5}{*}{ SC } & \multirow[t]{5}{*}{$\begin{array}{l}\text { Sand, clayey, light gray ( } 7.5 \text { YR N7/0), very fine grain, } \\
\text { subrounded, noncalcareous }\end{array}$} & \\
\hline 51.0 & & & & \\
\hline 52.0 & & & & CGI $0 / 0$ \\
\hline 53.0 & & & & RAD 0 \\
\hline 54.0 & & & & \\
\hline 55.0 & & \multirow[t]{7}{*}{ SC } & \multirow[t]{3}{*}{$\begin{array}{l}\text { Sand, clayey, light greenish gray ( } 5 \text { G } 7 / 1) \text {, very fine grain, } \\
\text { well sorted subrounded, noncalcareous; contains pyrite } \\
\text { nodules. }\end{array}$} & T II $0.8 / 1.0$ \\
\hline 56.0 & & & & CGI $0 / 0$ \\
\hline 57.0 & & & & RAD 0 \\
\hline 57.5 & & & $\begin{array}{l}\text { Note: Very hard drilling } 57.5 \text { to } 57.9 \mathrm{ft} \text {; recovered few pieces } \\
\text { of: sandstone, pinkish gray ( } 7.5 \text { YR } 7 / 2) \text {, very hard, } \\
\text { calcareous cement, very fine grained. }\end{array}$ & \\
\hline 57.9 & & & & \\
\hline 58.0 & & & & \\
\hline 59.0 & & & & \\
\hline
\end{tabular}




\begin{tabular}{|c|c|c|c|c|}
\hline \multicolumn{5}{|c|}{ MONITORING WELL COMPLETION LOG USGSO9PU } \\
\hline $\begin{array}{l}\text { Depth } \\
\text { (ft) }\end{array}$ & $\begin{array}{c}\text { Well } \\
\text { construction }\end{array}$ & $\begin{array}{l}\text { USCS } \\
\text { symbol }\end{array}$ & Description & $\begin{array}{l}\text { LEL - \% } \\
\text { OVA -ppm } \\
\text { RAD - mR/hr }\end{array}$ \\
\hline $\begin{array}{l}61.0 \\
62.0 \\
63.0 \\
64.0\end{array}$ & & $\mathrm{SC}$ & $\begin{array}{l}\text { Sand, clayey, weak red (10 YR 5/2), interbedded with dark } \\
\text { red (10 YR } 3 / 6 \text { ) clayey sand, fine to medium grain, } \\
\text { subrounded, noncalcareous. }\end{array}$ & $\begin{array}{l}\text { T II }-0.2 /-. \\
\text { CGI } 0 / 0 \\
\text { RAD } 0\end{array}$ \\
\hline $\begin{array}{l}65.0 \\
66.0 \\
67.0 \\
68.0 \\
69.0\end{array}$ & & & 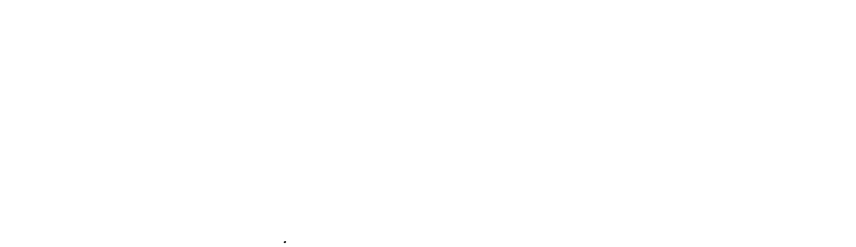 & $\begin{array}{l}\text { T II }-0.6 /-5 \\
\text { CGI } 0 / 0 \\
\text { RAD } 0\end{array}$ \\
\hline 70.0 & & & & \\
\hline $\begin{array}{l}71.0 \\
72.0 \\
73.0 \\
74.0\end{array}$ & & CL & $\begin{array}{l}\text { As above, interbedded with sand, clayey, light gray ( } 7.5 \mathrm{YR} \\
\mathrm{N} 7 / 0 \text { ), noncalcareous, fine grain, well sorted, rounded; } 50 \% \\
\text { pyrite. }\end{array}$ & $\begin{array}{l}\text { T II }-0.8 /- \\
\text { CGI } 0 / 0 \\
\text { RAD } 0\end{array}$ \\
\hline $\begin{array}{l}75.0 \\
76.0 \\
77.0 \\
78.0 \\
79.0\end{array}$ & & & & $\begin{array}{l}\text { T II }-0.8 /- \\
\text { CGI } 0 / 0 \\
\text { RAD } 0\end{array}$ \\
\hline
\end{tabular}




\section{APPENDIX B. NATURAL GAMMA RAY LOGS}




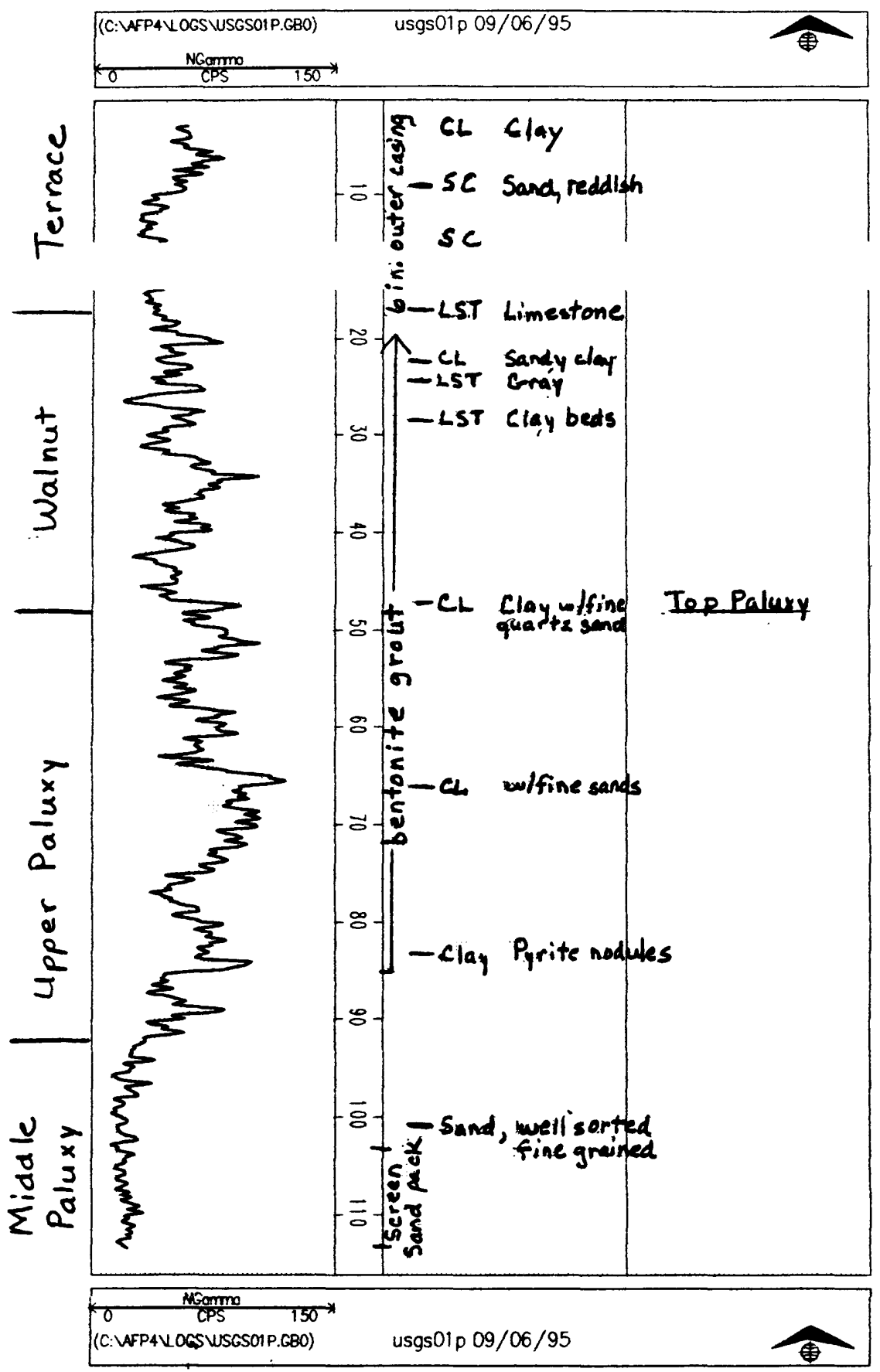




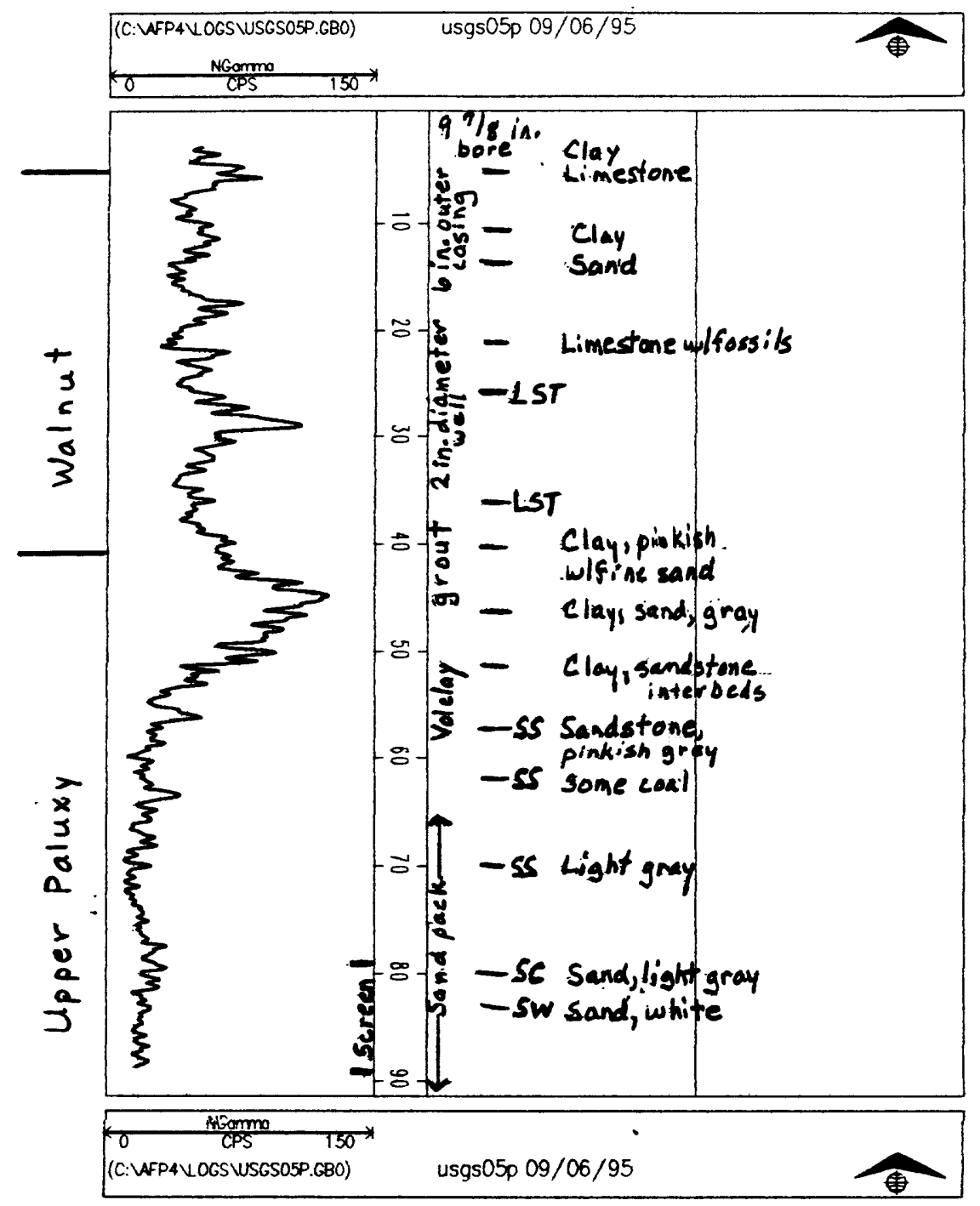




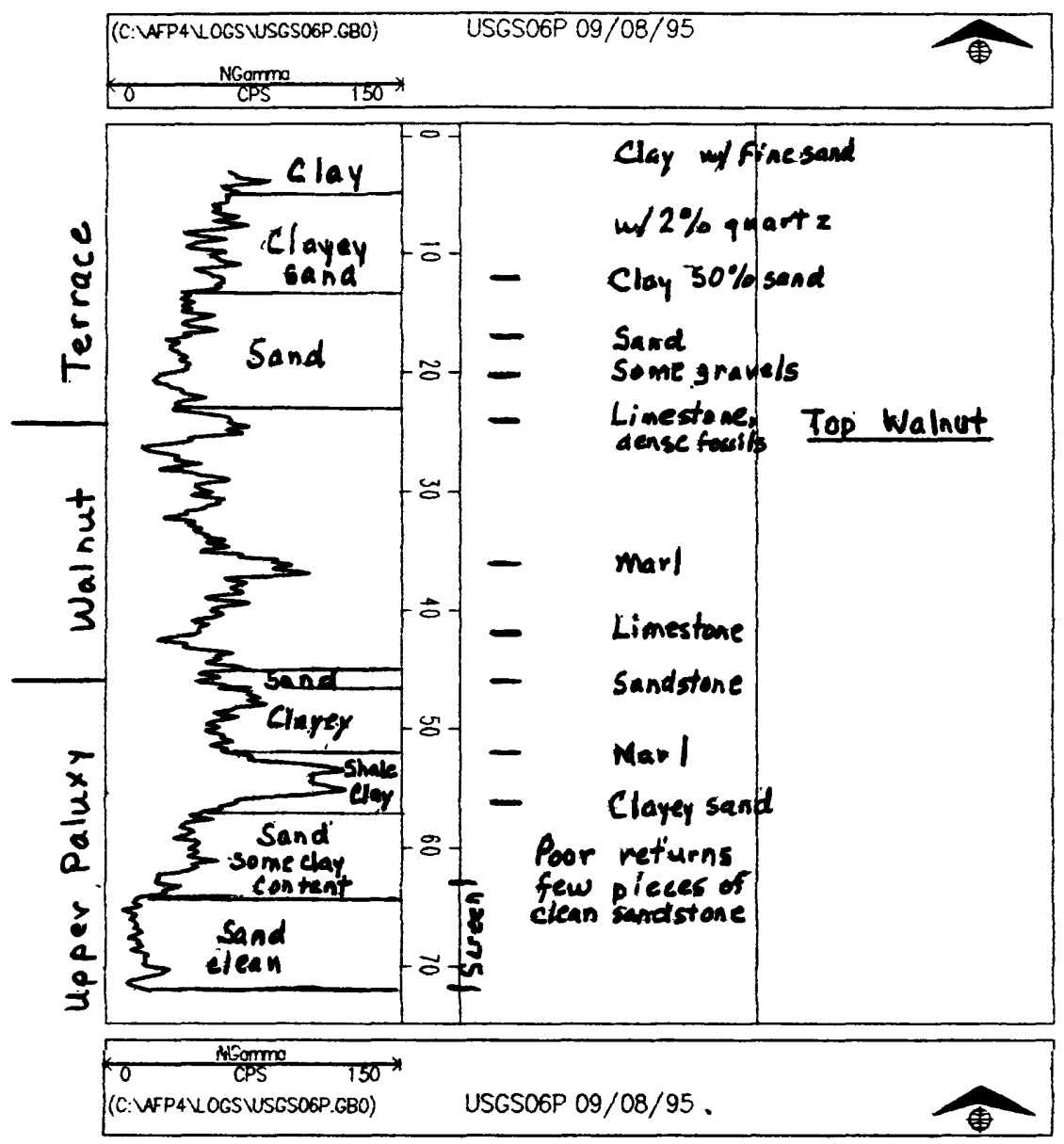




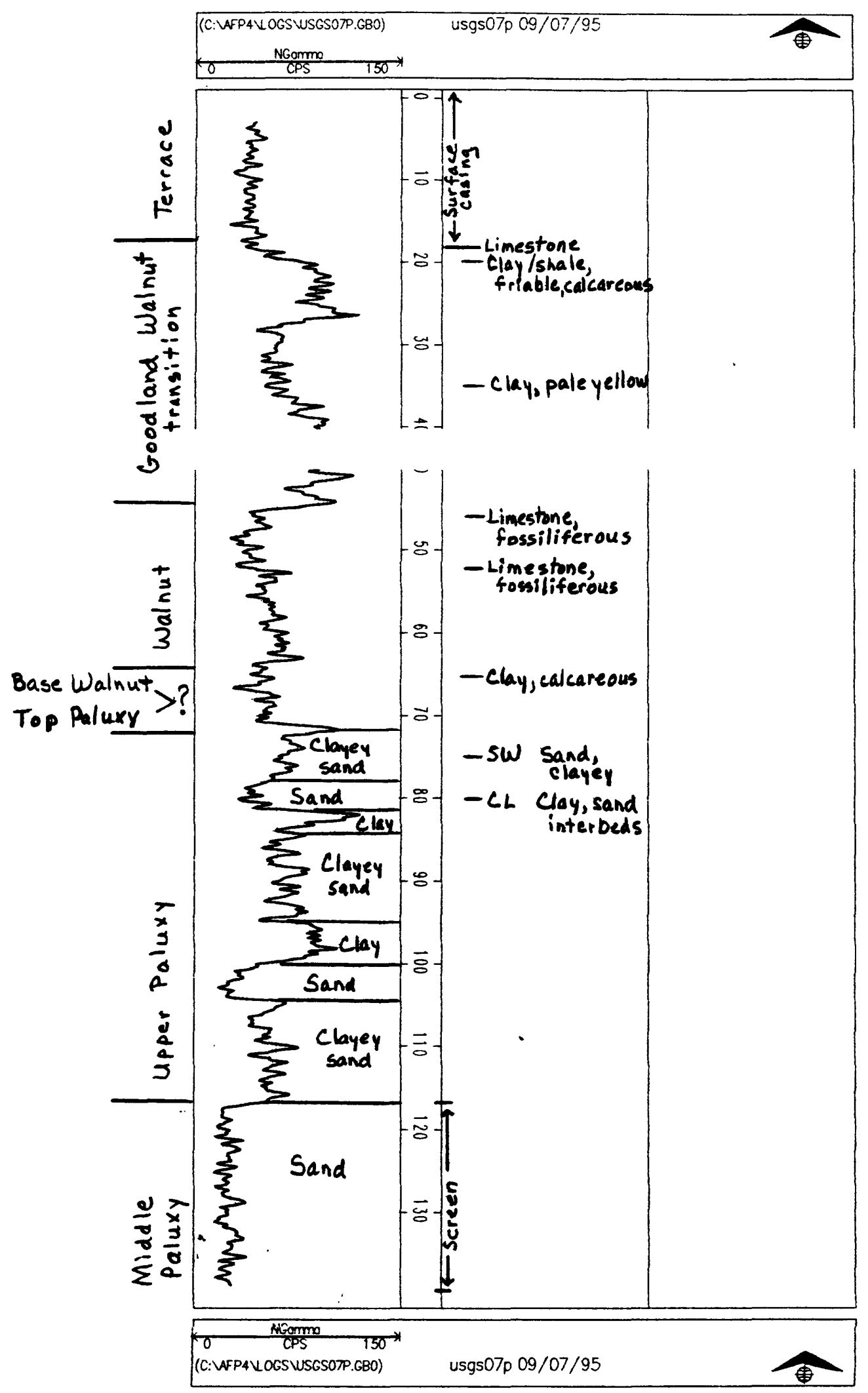




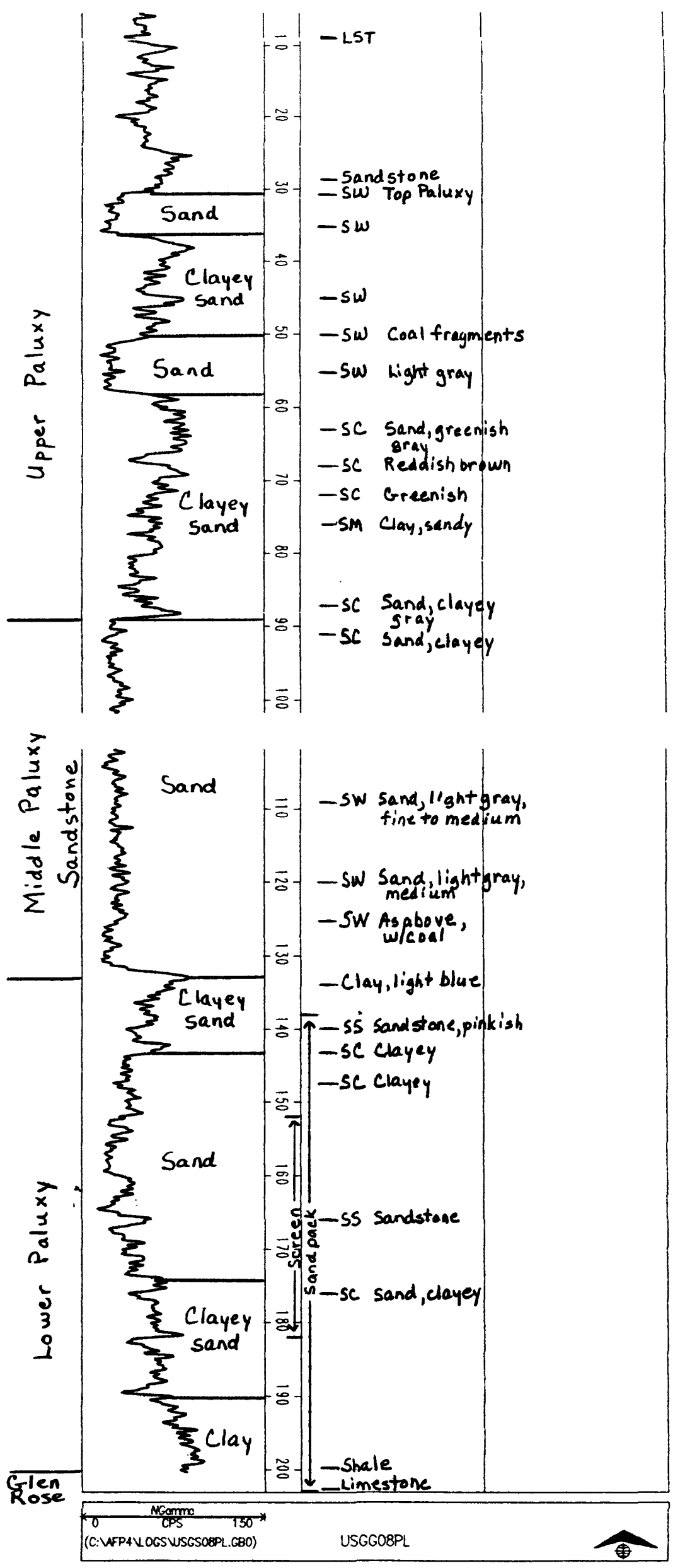




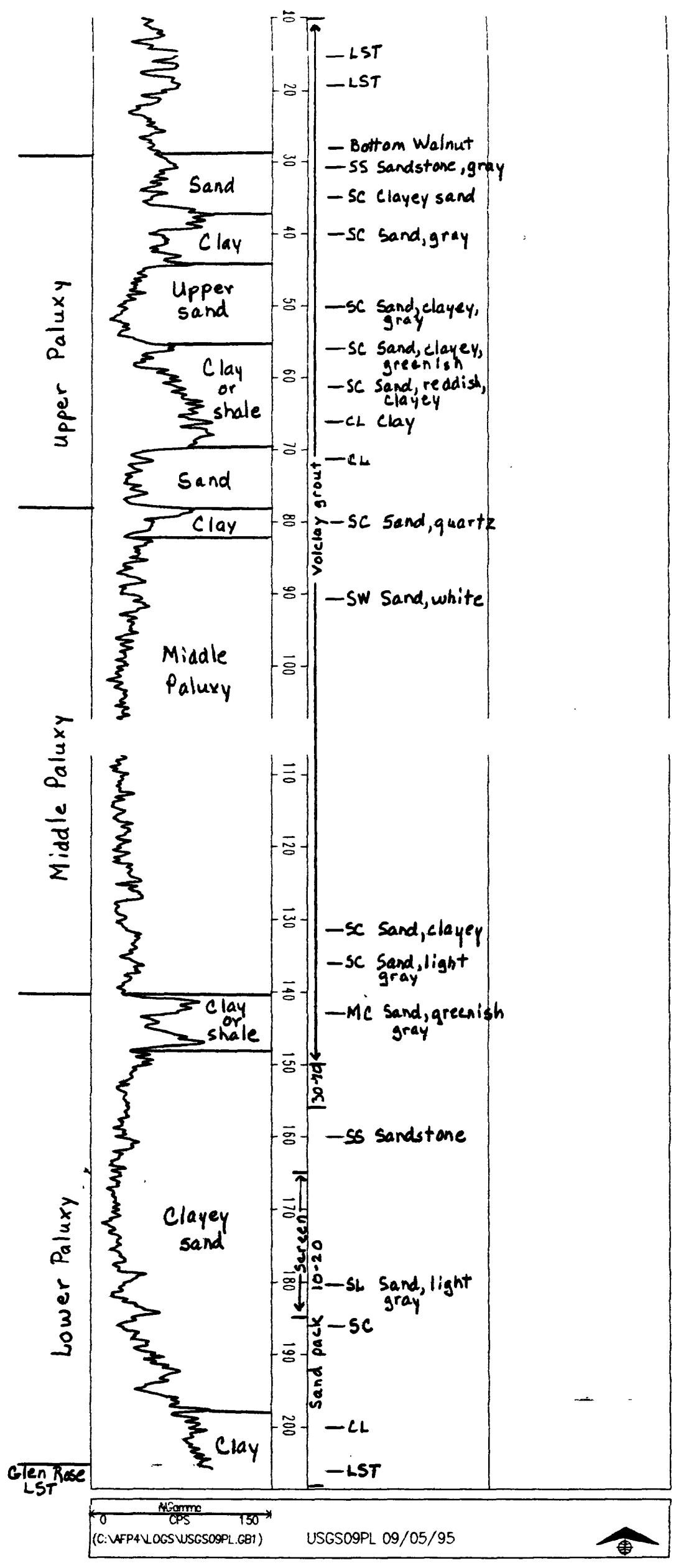



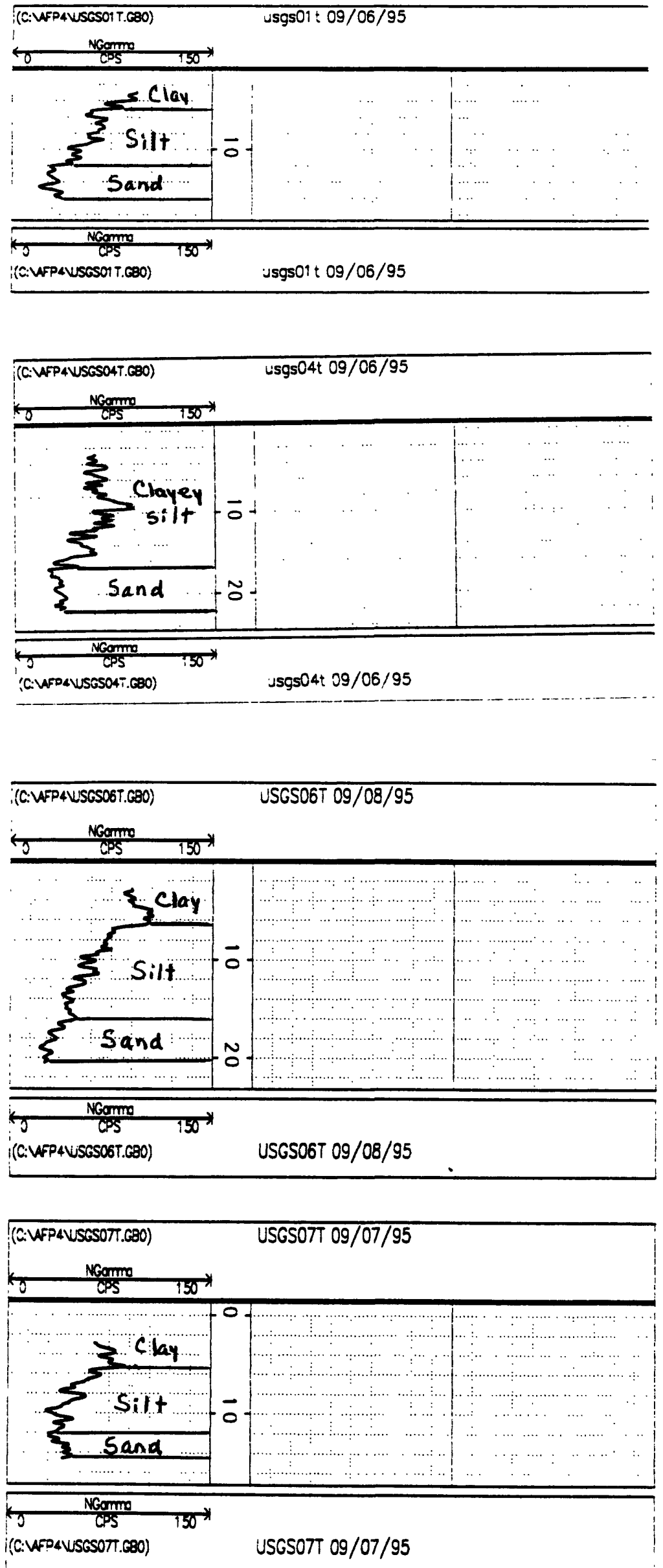